DOE/BC/14989-10

Distribution Category UC-122

\title{
Application of Integrated Reservoir Management
} and Reservoir Characterization to Optimize Infill Drilling

Annual Report for Period

June 13, 1994 through June 12, 1995

By

P.K. Pande, Fina Oil and Chemical Company

Center for Energy and Economic Diversification

David K. Davies and Associates

Mobil Exploration and Producing U.S., Inc.

Schlumberger Well Services

Texas A\&M University

University of Tulsa

November 1996

Work Performed Under Contract No. DE-FC22-94BC14989

Prepared for

U.S. Department of Energy

Assistant Secretary for Fossil Energy

Rhonda Lindsey, Project Manager

Bartlesville Project Office

P.O. Box 1398

Bartlesville, OK 74005

Prepared by

Fina Oil and Chemical Company

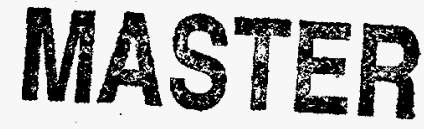

DISTRIBUTION OF THIS DOCUMETT IS UNAHM HK 


\section{DISCLAIMER}

Portions of this document may be illegible in electronic image products. Images are produced from the best available original document. 


\section{DISCLAIMER}

This report was prepared as an account of work sponsored by an agency of the United States Government. Neither the United States Government nor any agency thereof, nor any of their employees, makes any warranty, express or implied, or assumes any legal liability or responsibility for the accuracy, completeness, or usefulness of any information, apparatus, product, or process disclosed, or represents that its use would not infringe privately owned rights. Reference herein to any specific commercial product, process, or service by trade name, trademark, manufacturer, or otherwise does not necessarily constitute or imply its endorsement, recommendation, or favoring by the United States Government or any agency thereof. The views and opinions of authors expressed herein do not necessarily state or reflect those of the United States Government or any agency thereof. 


\section{APPLICATION OF INTEGRATED RESERVOIR MANAGEMENT AND RESERVOIR CHARACTERIZATION TO OPTIMIZE INFILL DRILLING}

\section{Table Of Contents}

Abstract Page 1

Executive Summary Page 2

Introduction Page 4

Historical Background Page 4

Development and Production History Page 4

Lterature Review Page 5

Discussion Page 7

Geological/Petrophysical Study Page 7

Core Analysis Page 7

Formulation of Geologic Model Page 8

Formulation of Rock-Log ModelPage 12

Flow Unit Identification and Reservoir Layering Page 13

Continuity Analysis of Reservoir Pay Page 15

Cross-Borehole Tomography Page 15

Theory and Methodology Page 15

Results Page 16

Operational Considerations Page 18

Cross-Borehole Tomography Status Page 18

Reservoir Performance Page 19

Oil Production Data Analysis Using Decline Type Curves Page 19

Waterflood Performance Analysis Page 23

Reservoir Surveillance Page 25

Water Quality Program Page 26

Pressure Transient Data Acquisition and Analysis Page 27 
Step-Rate Testing

Page 31

Optimization of Completion/Stimulation Procedures Page 31

Coiled-Tubing Workovers Page 32

Cased-Hole Logging Program Page 33

Future Data Acquisition Page 33

Reservoir Management Page 34

Well Deepening Candidates Page 34

Deepening Methodology Page 34

Ranking of Wells Page 35

Strategy Page 35

Geostatistical Simulation Page 36

Methodology Page 36

Conditional Simulation Techniques Page 37

Approach at North Robertson Page 38

Reservoir Simulation Page 38

Methodology Page 39

Selection of Modeling Areas Page 40

Model Initialization Page 41

History Match Criteria Page 42

Conclusions Page 42

Nomenclature Page 44

References Page 45

Tables Page 48

Figures Page 58 


\section{Tables}

Table 1 Reservoir and Fluid Property Data for the North Robertson (Clearfork) Unit

Table 2 Pore Types Identified From Core Thin-sections, XRD, and SEM Analysis

Table 3 Rock Types Defined for the Clearfork and Glorieta Formations

Table 4 Quantitative Analysis of Mercury-Air Capillary Pressure Data

Table 5

Table 6

Table 7 Material Balance Decline Type Curve Results

Table 8

Table 9

Table 10

Bottomhole Pressure Data for Reservoir Simulation History Matching

North Robertson Unit Deepenings - Producer Wells

North Robertson Unit Deepenings - Injector Wells

Results of PVT Analysis on 1991 Surface Fluid Samples (Upper \& Lower Clearfork)

Results of PVT Analysis on Original Bottomhole Fluid Samples (Upper \& Lower Clearfork)

\section{Figures}

Figure 1

Figure 2

Figure 3

Figure 4

Figure 5

Figure 6

Figure 7

Figure 8

Figure 9

Figure 10

Figure 11

Figure 12

Figure 13

Figure 14

Figure 15

Figure 16

Figure 17

Figure 18

Figure 19

Figure 20

Figure 21

Figure 22

Figure 23

Figure 24

Figure 25

Figure 26
Stratigraphic Units of the Central Basin Platform Area of the Permian Basin Region Clearfork Waterflood Projects in Permian Basin

Production and Injection History for the North Robertson (Clearfork) Unit

Location of Cored Wells Within the North Robertson (Clearfork) Unit

Depositional Environments - Lower Middle and Lower Clearfork

Depositional Environments - Upper Middle Clearfork, Upper Clearfork, and Glorieta

Relative Volume Proportions of Pore Types (A-G) in Each Rock Type (1-8)

Mercury/Air Capillary Pressure Curves - Rock Type 1

Water/Oil Relative Permeability Curves - Rock Type 1

Porosity/Permeability Crossplot for All Rock Types

Porosity/Permeability Crossplot for Rock Type 1

Differentiating "Pay" from "Non-Pay" Reservoir Rock Types

Structure Map - Top of Lower Clearfork Section at NRU

Structure Map - Top of Tubb Section at NRU

Structure Map - Top of Upper Clearfork Section at NRU

Structure Map - Top of Glorieta Section at NRU

Results of Pay Continuity Study From 40-Acre Well Data-NRU Sections 5, 325, 329

Schematic Illustration of Tomographic Data Acquisition

Ray Paths for NRU 403/207 Tomography Survey

Processing Flow Chart for Connectivity Mapping

NRU 403/207 Connectivity Map with Gamma Ray and Velocity Logs

Traveltime Tomogram from 2-D Inversion with Bin Size of 40 by 13.12 Feet

Fetkovich/McCray Decline Type Curves for an Unfractured Well

Semilog Production Plot for NRU Well 3510 (Clearfork)

Log-Log Production Plot for NRU Well 3510 (Clearfork)

Rate Functions for NRU Well 3510 (Clearfork) 
Figure 27 Match of Production Data for NRU Well 3510 - Clearfork (Radial Flow Type Curve)

Figure 28 Movable Oil Estimation from Rate History

Figure 29 Map of Contacted Original Oil-In-Place

Figure 30 Map of 40-Acre Well Flow Capacity

Figure 31 Map of Primary Estimated Ultimate Recovery

Figure 32 Map of 20-Acre Well Flow Capacity

Figure 33 Map of Secondary Estimated Ultimate Recovery

Figure 34 Match of Primary Production Data for NRU (All Wells) - Clearfork (Radial Flow Type Curve)

Figure 35 NRU Estimated Total Movable Oil from Rate History

Figure 36 NRU EUR Ratio By Section

Figure 37 NRU Daily Injection and Production as a Function of Cumulative Water Injected

Figure 38 Waterflood Performance Diagnostic Plot

Figure 39 Example of Hall Plot

Figure 40 Hall Plot Field Example

Figure 41 Hall Plot For NRU 301

Figure 42 NRU Well 1008 Pressure Buildup Analysis Using Pressure Derivative and Integral Derivative

Figure 43 NRU Well 3510 Pressure Buildup Analysis Using Pressure Derivative and Integral Derivative

Figure 44 NRU Well 301 Pressure Falloff Analysis Using Pressure Derivative and Integral Derivative

Figure 45 NRU Well 3510 Pressure Falloff Analysis Using Pressure Derivative and Integral Derivative

Figure 46 Cartesian Plot of $p_{w s}$ Versus Shut-in Time for NRU Well 301 Pressure Falloff Test

Figure 47 Comparison of Average Parting Pressures from Step-Rate Tests (1988-1993)

Figure $48 \quad S_{\mathbf{w}}$ Monitoring Using Thermal Decay Time Logs (Lower Clearfork)

Figure 49

Figure 50

Deepening and Associated Recompletion Candidates Map - North Robertson Unit Map of Tentative Partial-Unit Model Areas for Reservoir Simulation 


\title{
APPLICATION OF INTEGRATED RESERVOIR MANAGEMENT AND RESERVOIR CHARACTERIZATION TO OPTIMIZE INFILL DRILLING AT THE NORTH ROBERTSON (CLEARFORK) UNIT, GAINES CO., TX
}

\author{
ANNUAL REPORT
}

June 13, 1994 to June 12, 1995

\section{ABSTRACT}

This project has used a multi-disciplinary approach employing geology, geophysics, and engineering to conduct advanced reservoir characterization and management activities to design and implement an optimized infill drilling program at the North Robertson (Clearfork) Unit in Gaines County, Texas. The activities during the first Budget Period have consisted of developing an integrated reservoir description from geological, engineering, and geostatistical studies, and using this description for reservoir flow simulation. Specific reservoir management activities are being identified and tested. The geologically targeted infill drilling program will be implemented using the results of this work.

A significant contribution of this project is to demonstrate the use of cost-effective reservoir characterization and management tools that will be helpful to both independent and major operators for the optimal development of heterogeneous, low permeability shallow-shelf carbonate (SSC) reservoirs. The techniques that are outlined for the formulation of an integrated reservoir description apply to all oil and gas reservoirs, but are specifically tailored for use in the heterogeneous, low permeability carbonate reservoirs of West Texas.

New and emerging technologies such as cross-borehole tomography, geostatistical modeling, and rigorous decline type curve analysis can be used to quantify reservoir quality and the degree of interwell communication. These results can be used to develop a 3-D simulation model for prediction of infill locations. The application of reservoir surveillance techniques to identify additional reservoir "pay" zones, and to monitor pressure and preferential fluid movement in the reservoir will be demonstrated. These techniques include: long-term production and injection data analysis, pressure transient analysis, and advanced open and cased hole well log analysis.

This project will focus on developing cost-effective reservoir characterization techniques for the shallow-shelf carbonate reservoirs of the Permian Basin of West Texas, specifically the Clearfork dolomite. Examples of these technologies include:

- Formulation of a "rock-log" model to identify the highest quality pay intervals using available open-hole well log data for the extrapolation of core properties from a limited number of wells.

- Calculation of total and movable fluid volumes and estimation of formation flow characteristics using a rigorous decline type curve method for the analysis of readily available oil production 
and water injection data.

- Low-cost acquisition and analysis of pressure falloff data from injection wells and pressure buildup data from producing wells using both downhole and surface pressure gauges.

- Development of spatial relationships for reservoir variables of interest $(\phi, k$, and rock type) at unsampled (interwell) locations across the Unit using geostatistical techniques.

- Performing 3-D reservoir simulation for history matching, infill drilling development forecasting, and validation.

\section{EXECUTIVE SUMMARY}

In this project, we are demonstrating that infill drilling of wells on a uniform spacing, without regard to reservoir performance and characterization, must become a process of the past. Such efforts do not optimize reservoir development as they fail to account for the complex nature of reservoir heterogeneities present in many low permeability reservoirs, and carbonate reservoirs in particular. The North Robertson Unit lies along the northern edge of the Central Basin Platform of the Permian Basin, in Gaines County, Texas. The unitized interval includes both the Glorieta and Clearfork Formations, which are Permian Age, Leonardian Series carbonates (Fig. 1), consisting primarily of dolostone with varying amounts of anhydrite, siltstone, and limestone. These carbonate reservoirs are typically characterized by:

- Large, discontinuous pay intervals

- Vertical and lateral changes in reservoir properties

- High residual oil saturation

- Low recovery efficiency

The operational problems we encounter in these types of reservoirs include:

- Poor or inadequate completions and stimulations

- Early water breakthrough

- Poor reservoir sweep efficiency in contacting oil throughout the reservoir as well as in the nearwell regions

- Channeling of injected fluids due to preferential fracturing caused by excessive injection rates

- Limited data availability and poor data quality

Conclusions and observations which can be drawn from the project to date are:

Geological Reservoir Characterization, Importance of Core: The elements of a successful characterization include: 1) development of a competent depositional environment model and a sequence stratigraphic model; 2 ) rock type constrained core-measured porosity versus permeability 
relationships; 3) sufficient modern wireline log data; and, 4) adequate historical production data. It is important to emphasize that availability of core data and core descriptions are the key to calibrating the wireline log data, thereby allowing one to generate and then test a "rock-log" model. The model can be used to calculate permeability values from wireline log calculated porosities in areas of the reservoir with insufficient core measured permeability values.

Relative Permeability Measurements \& Special Core Analysis (SCAL): Due to the importance of special core data for reservoir flow simulation, the acquisition of additional data during the infill drilling process is of paramount importance. These data are required for reservoir description as well as for predicting the future performance of an infill drilling program. Core imaging technologies are being utilized so that the section of core upon which costly SCAL tests are to be performed can be appropriately screened. To ensure that quality data are obtained, a quality control program will be an integral part of the SCAL program.

Cross-Borehole Tomography: Due to the problems associated with the utilization of older boreholes for recording interwell surveys, the level of heterogeneity in the Glorieta/Clearfork section, and low benefit-cost ratio for this particular Unit, it was determined that the use of crossborehole tomography as a reservoir characterization tool is not a cost-effective technology at NRU. Improvements currently being made to new downhole tools may offer future opportunities to obtain data of sufficient resolution for integrated reservoir description in heterogeneous formations such as the Glorieta and Clearfork.

Material Balance Decline Type Curve Techniques: This approach gives excellent estimates of contacted reservoir volumes (total and movable), and reasonable estimates of formation flow characteristics. Using this method to analyze and interpret long-term production and injection data is relatively straightforward and can provide about the same information as that derived from conventional pressure transient analysis, without the associated cost of data acquisition, or loss of production and injection. The results will be used together with the geological analyses to identify 10 -acre infill locations, and to calibrate the reservoir simulation models with respect to contacted oil-in-place.

Reservoir Surveillance: Surface pressure acquisition during pressure falloff tests yields data of sufficient quality for interpretation, even when low precision pressure gauges are utilized. This is an efficient and cost-effective waterflood surveillance tool. Pressure buildup surveys have been combined with the results of the pressure falloffs, and the cased-hole logging program to build a "baseline" data set for future reservoir surveillance programs. During the Field Demonstration phase of the project, pressure transient tests will be performed over specific completion intervals in an attempt to identify the relative contribution of each zone within the Glorieta/Clearfork section. Oil fingerprinting (analysis of oil compositions) will also be used in an effort to determine specific zonal contributions.

New Well Completions: The results of the previous hydraulic fracture treatments on producing wells at the NRU have been relatively poor, resulting in short, low conductivity fractures. New completion and stimulation designs will be implemented to improve completion efficiency and optimize the hydraulic fracturing procedures. New injection wells will be completed and 
stimulated differently than producing wells in order to by-pass high permeability zones that may become "thief" zones. We will also experiment with chemically altering near-well wettability characteristics in order to improve production and injection efficiency.

Water Quality Monitoring: Injection water quality is one of the critical components in the implementation of a successful waterflood. Surveillance programs set up to continuously monitor injection water quality should be an essential part of all operators' waterflood programs.

Geostatistics: Geostatistics appears to be a valuable tool for developing a reservoir description which is consistent with the underlying geology, petrophysical data, and oil-in-place calculations based on material balance techniques. We have been able to generate detailed reservoir descriptions which can be qualitatively evaluated in order to understand the relative continuity of point data (well logs) across the reservoir. It should be noted that the development of a geostatistical reservoir description is both time and computationally intensive, and this must be considered when assessing the cost/benefit relationship for a geostatistically based approach.

Reservoir Flow Simulation: We will use both conventional and geostatistical 3-D reservoir simulation models for history matching, defining infill drilling locations, and developing production forecasts for the geologically targeted infill areas. Conventional reservoir description methods for flow simulation have limitations as the true heterogeneity present in many SSC reservoirs will not be captured. This "layer cake" treatment of the reservoir may result in future projections which show reserves acceleration rather than the additional recovery of bypassed incremental reserves. It is important to understand the limitations of conventional simulation when analyzing the results of this approach, however, it should also be noted that conventional simulation can be accomplished in a more time efficient manner, which is a major concern for most operators. By comparing the results of the two simulation approaches we can better quantify the uncertainties in predicting future performance, and by comparing these results, we can target infill well locations with more certainty.

\section{INTRODUCTION}

\section{HISTORICAL BACKGROUND}

The North Robertson (Clearfork) Unit (NRU) is located in Gaines County, Texas on the northern edge of the Central Basin Platform of the Permian Basin (Fig. 2). The producing horizons are the Glorieta and Clearfork Formations (referred to as the Upper and Lower Clearfork). The hydrocarbon bearing interval extends from the base of the Glorieta to the base of the Lower Clearfork, between the correlative depths of approximately 6,150 to 7,250 feet. The NRU project area of 5,633 acres contained a total of 254 wells as of January, 1995. This includes 144 active producing wells, 109 active injection wells and 1 water supply well.

\section{DEVELOPMENT AND PRODUCTION HISTORY}

Production from the North Robertson field area began in the early 1950s with 40 -acre primary well development. This 40 -acre primary development resulted in 141 producing wells. The NRU was 
formed effective March, 1987 for the purpose of implementing waterflood and infill drilling operations to reduce nominal well spacing from 40 acres to 20 acres. At the time of unitization, oil production from the Unit area was approximately $670 \mathrm{STBO} / \mathrm{D}$, with a GOR of $1,550 \mathrm{scf} / \mathrm{STB}$, and water production of $500 \mathrm{BW} / \mathrm{D}$. Secondary recovery operations were initiated after unitization and in conjunction with infill drilling. Most of the 20-acre infill drilling was completed between unitization and the end of 1991 . The relevant fluid, formation, and production data are shown in Table 1. The cumulative produced and injected fluid volumes are summarized below. Fig. 3 shows the production and injection history of the Unit from development in 1956 through February, 1995.

$\begin{array}{cccc} & \begin{array}{c}\text { Oil Produced } \\ \text { (MMSTB) }\end{array} & \text { Water Produced } & \text { Water Injected } \\ \text { As of } 1987 & 17.5 & \text { (MMBW) } & \text { (MMBW) } \\ 1987-1995 & 7.8 & 8.2 & 0.0 \\ & & 21.9 & 54.1\end{array}$

At the time of unitization, the estimated ultimate recovery (EUR) for primary production was 20.5 MMSTBO, and the secondary to primary recovery ratio was estimated to be approximately $1: 1$. The current waterflood utilizes an east-west line drive pattern with 20 -acre nominal well spacing. Current Unit production rates are approximately 3,000 STBO/D, 1,400 MCF/D, and 11,000 BW/D. Water injection volumes are approximately $20,000 \mathrm{BWI} / \mathrm{D}$, with injection water comprised of produced water, and fresh water from the Ogallala aquifer obtained from a water supply well within the Unit.

\section{LITERATURE REVIEW}

There are many complicated factors that will affect the successful implementation of infill drilling programs in heterogeneous, low permeability carbonate reservoirs such as the Clearfork/Glorieta of West Texas. Before this project started, an extensive literature review was conducted to gain a better understanding of the producibility problems at the North Robertson Unit (NRU). Fortunately, these reservoirs have a long producing history and there is a large quantity of useful data available from case studies for primary, secondary, and tertiary operations in the Clearfork and other analogous reservoirs.

In a 1974 case study concerning waterflooding operations at the Denver (San Andres) Unit, Ghauri, et $a l^{1}$ gave valuable insights concerning reservoir discontinuity, injector-to-producer conformance, and the effect of reservoir quality on reservoir sweep efficiency.

Poor reservoir rock quality and the existence of discontinuous pay between injection and producing wells resulted in a recommendation to reduce nominal well spacing from 40 acres to 20 acres. An outcrop study on the San Andres was performed to verify reservoir discontinuity. Injection wells were completed and stimulated preferentially in an effort to flood only the continuous layers of the reservoir. The original peripheral injection design was converted to inverted nine-spot patterns in an effort to decrease the amount of water channeling and early water breakthrough via the most permeable members.

In 1976, Stiles ${ }^{2}$ summarized the difficulties encountered in waterflooding operations at the Fullerton (Clearfork) Unit. The author noted that increasing the injection rate would never result in an equal response at the producing wells. The concept of "pseudo fill-up" was introduced to explain that 
although reservoir fill-up may occur in the most permeable or continuous layers of the reservoir, a large gas saturation still exists in the poorer quality reservoir rock. For this reason, the theoretical maximum producing rate would never be achieved without contacting the discontinuous areas through infill drilling.

A statistical study was performed to quantify reservoir continuity as a function of interwell distance on the basis of continuous and discontinuous reservoir layers. Stiles maintained that injection pressures above the parting pressure of the formation were required in order to maintain acceptable injection rates in the reservoir.

In a 1978 review of West Texas carbonate reservoir waterflooding operations, George and Stiles ${ }^{3}$ outlined their recommendations for optimizing waterflood operations in the Means (San Andres), Fullerton (Clearfork), and Robertson (Clearfork) Units. These authors stressed the importance of infill drilling and pattern modification to overcome pay rock stratification, and the need for continuous interaction between geologists and engineers in order to produce a program of optimal reservoir development and depletion.

A "rock-log" model was formulated for the Robertson (Clearfork) using a limited amount of core data and old gamma ray/neutron logs that were available field-wide. Original oil-in-place (OOIP) was calculated using both volumetric and material balance methods. The authors pointed out that the ratio of material balance OOIP to volumetric OOIP should yield a qualitative measure of reservoir continuity since the material balance calculation only considers intervals that are continuous or effectively completed, while the volumetric calculation allows consideration of all "pay" quality reservoir rock.

George and Stiles provided a method to identify "floodable" pay, which was differentiated from continuous pay on the basis of the most probable geometry of a continuous layer between an injection and producing well. Obviously, the amount of floodable pay in the reservoir was always slightly less than the amount of continuous pay, and both could be optimized through infill drilling. The authors concluded that floodable pay must be continuous between injection and producing wells, must be injection supported, and should be effectively completed at the producing well.

In a 1980 summary of work completed at the Denver (San Andres) Unit, Ghauri ${ }^{4}$ outlined the importance of integrated geologic and engineering studies in the development of the Wasson (San Andres) field from primary through tertiary depletion. The author gave great detail in describing the processes that were utilized to increase sweep efficiency, optimize completion and stimulation procedures, and improve well conformance. The design and installation of automated artificial lift systems were also highlighted.

Barber, et $a l^{5}$ provided a case study in 1983 describing infill drilling results in nine carbonate and clastic reservoirs in Texas, Oklahoma, and Illinois. This work resulted in an extremely important observation regarding the effect of reduced well spacing on pay continuity. Using data for 20-acre wells in the Means (San Andres) Unit, a 4 percent increase in pay continuity was expected when nominal spacing was reduced to 10 acres. However, after pay continuity was recalculated on the basis of 10 -acre well data, it was found that the actual pay continuity increase was 14 percent. The authors noted that past 
observations regarding additional recovery from infill wells made prior to drilling were probably extremely pessimistic.

In 1987, Barbe and Schnoebelen ${ }^{6}$ summarized the results of an aggressive infill drilling program in the Robertson (Clearfork) Unit. The authors found that obstacles associated with poor reservoir continuity in heterogeneous, low permeability carbonate reservoirs would likely only be overcome through infill drilling on a reduced nominal well spacing.

In addition, reservoir performance data analysis and pressure transient test results indicated a roughly east-west directional permeability or fracture orientation. Pay continuity was quantified using geological, reservoir performance, and pressure transient data, and all three methods gave similar results. Wireline formation test results showed that individual layers had widely different formation pressures, indicating a lack of vertical continuity within the Clearfork.

A further conclusion was made regarding the best locations for the infill wells. Barbe and Schnoebelen found that the best 10 -acre and 20 -acre producers were in the same areas as the best 40 -acre producers, which indicates that the identification of areas of high quality reservoir rock is perhaps more important than finding the areas of poor reservoir continuity when deciding on infill well locations.

The literature summarized above explains the concepts behind the initiation of successful waterflood and infill drilling programs for heterogeneous, low permeability carbonate reservoirs.

\section{DISCUSSION}

\section{GEOLOGICAL/PETROPHYSICAL STUDY}

\section{Work Performed}

- Core analysis

- Formulation of Geologic Model

- Formulation of Rock-Log Model

- Flow Unit Identification And Reservoir Layering

- Continuity Analysis Of Reservoir Pay

\section{Core Analysis}

A geologic model ${ }^{7}$ was constructed on the basis of both macroscopic (visual) and microscopic (petrographic thin section and scanning electron microscope) data obtained from the analysis of available whole core from a limited number of wells throughout the Unit (Fig. 4). The development of the geologic model included the study of the depositional setting and variability, depositional environments, diagenetic effects, lithological variations, effects of pore system geometry, physical properties, and natural fractures. 
Due to the lack of conventional core (a common problem in older reservoirs), there was a need to develop a unit-wide geological/petrophysical model so that individual rock types could be identified on the basis of well log responses in areas where core was not available. The rock-log model ${ }^{7}$ that was developed is based on the petrophysical and lithological study of 4,600 feet of whole core from eight wells in the NRU. This work involved detailed sedimentologic observations of the whole core, thinsection analyses, $\mathrm{x}$-ray diffraction (XRD), special core analysis (SCAL), and pore geometry investigations using scanning electron microscope (SEM) image analysis. The relationships between pore volumes and pore throats have been quantified by direct measurements of pore casts.

Quantitative rock type porosity-permeability relationships were established in order to identify the most attractive pay intervals. The distribution of pay rock types in individual wells has been calculated and is being used to generate interwell reservoir quality maps using geostatistical methods. These results are then utilized to describe the reservoir for 3-D flow simulation.

\section{Formulation of Geologic Model}

\section{Depositional Environments}

The interpretations for depositional environments have been derived primarily from qualitative descriptions and thin-section studies of the whole core samples. The depositional environments for the Clearfork and Glorieta formations are as follows:

- Highstand Lithofacies Tracts

- supratidal and subaerial deposits

- intertidal and channelized tidal flats

- open and restricted lagoons

- grainstone shoals

- subtidal

- open shelf

- Transgressive Lithofacies Tracts

- shelfal and patch reef

- Low Stand Lithofacies Tracts

- inland sabkha

\section{Lower Clearfork}

In general, the Lower Clearfork (Fig. 5), which is defined as the portion of the Clearfork directly overlain by the Tubb (transgressive marine shaly dolostone interval), was deposited in open marineshelfal conditions and is dominated by grainstones that are thought to have developed in shallow water shoaling environments. The shoaling areas may have coalesced and interfingered with one another resulting in more or less continuous belts (current- and/or wave-dominated) of grainstone deposits (primarily fusulinid or peloidal) which comprise a dolograinstone reservoir facies with some preservation of primary porosity. 
A study of historical production data using contour maps of reservoir performance suggests that these outer shelf grainstone reservoirs appear to be in communication with one another and the amount of compartmentalization and heterogeneity may not be as pronounced as in the Middle and Upper Clearfork (which overly the Tubb marker). This concept may also be attributed, in part, to more widespread and uniform conditions of deposition with less cyclicity (fewer changes in sea level and/or water depth).

\section{Middle/Upper Clearfork and Glorieta}

The remainder of the Clearfork and the Glorieta sequences (Fig. 6) are typified by highstand lithofacies characterized by highly cyclic depositional environments consisting of inner shelfal subtidal flats, restricted and open lagoons, and tidal flats which are frequently channelized, intertidal or supratidal sabkha flats.

The lower portion of the Middle Clearfork, which immediately overlies the Tubb Marker, is characterized by a transgressive lithofacies tract (approximately 150 to 250 feet thick). Within this interval there is some evidence of possible patch reef development represented by the existence of nonporous, mottled boundstones that contain sponge, algae, coral, and bryozoan fragments.

The analysis of historical well performance data suggests that the dolostone reservoir rocks that characterize these depositional environments have generally poorer reservoir parameters. Porosity and permeability are reduced as these transgressive tract dolostones tend to be silty and argillaceous and are frequently anhydritic. Cyclicity has resulted in a high degree of compartmentalization and heterogeneity and variations in petrophysical properties reflect the presence of numerous crossflow barriers which are indicative of reservoir compartmentalization.

Pay quality reservoir rocks, where present, are once again represented by grainstones and wackestones (ooidal and/or skeletal) that were deposited as a result of shoaling depositional environments. Oomoldic and biomoldic porosity may be well developed, however, interconnectivity is usually poor, resulting in low quality reservoir rock.

\section{Diagenesis}

Moldic porosity has been attributed to skeletal and grain dissolution by post-depositional leaching. This has taken place during periods of subaerial exposure. Dolomite crystals have also been leached resulting in the development of intercrystalline porosity. Periods of leaching and dissolution are probably related to sea level fluctuations and predate diagenetic dolomitization.

The dolomitization may be explained by neomorphozation of syndepositional aragonite (highmagnesium calcite) cement which lined fenestral pores. The fenestral fabric is representative of supratidal and intertidal facies. The calcite cement was subsequently dolomitized. 


\section{Pore Geometry}

Reservoir quality and continuity are dominated by variations in pore geometry. ${ }^{8}$ Reservoir rocks having equal values of total porosity may have significantly different permeability, relative permeability, and irreducible fluid saturation characteristics. These discrepancies are a result of changes in pore structure caused by variations in pore type, size, and throat size. ${ }^{9}$ Extreme variation in pore geometry is characteristic of heterogeneous, low permeability carbonate formations such as the Clearfork/Glorieta sequence.

Pore types were quantitatively defined ${ }^{7}$ for the available core using pore cast studies and scanning electron microscope (SEM) image analysis on the basis of:

- Pore body size and shape measurement

- Pore size

- Pore shape factor $=\left[\left(\right.\right.$ pore perimeter $\left.{ }^{2}\right) /\left(4 \pi^{*}\right.$ pore area $\left.)\right]$

- Length to width ratio

- Pore throat measurement

- Coordination number $=[\#$ pore throats/pore $]$

- Aspect ratio $=$ [pore size/pore throat size]

- Matrix/pore arrangement and interconnection in two and three dimensions

Pore geometries are classified by shape as triangular, irregular, polyhedral and tetrahedral. ${ }^{7}$ Primary interparticle porosity has triangular pores, and the vuggy porosity is described as being irregular (and sometimes elongated). The triangular pores are generally well interconnected and are typical of the grainstone reservoir facies. The irregular pores are typical of dissolution porosity and although porosity values may be high relative to triangular pores, interconnectivity is usually relatively poor resulting in lower reservoir rock quality.

On the basis of these analyses, seven unique pore types were identified for use in rock typing. Their characteristics are summarized in Table 2.

\section{Rock Type Definition}

A total of eight rock types have been identified of which four have reservoir potential (one being limestone and water bearing). Rock types have been identified on the basis of volume proportions of pore types and unique lithological characteristics. The relative volume proportions of each of the seven pore types in each rock type are shown in Fig. 7. Average core values for porosity, permeability, and estimated recovery efficiency are presented for each of the eight rock types in Table 3. Recovery efficiency was estimated using methods outlined by Wardlaw and Cassan ${ }^{10}$ on the basis of the pore arrangement, coordination number, and aspect ratio. Low aspect ratios and high coordination numbers typically result in good reservoir sweep efficiency.

Rock types 1 and 2 make up the primary reservoir "pay" intervals at the NRU. These rock types consist 
of coarsely crystalline dolostones that differ in terms of their pore size and geometries. These rocks generally correspond to subtidal sandflats, grainstone shoals, and open shelf depositional environments. Rock type 3 is productive in certain areas of the Unit, and consists primarily of finely crystalline dolostones that have different pore geometries and usually correspond to supratidal, tidal flat, and restricted lagoon depositional environments. Rock type 5 is limestone and water-bearing.

The highest quality reservoir rocks are typically associated with rock type 1 , which consists primarily of grainstones. Coordination numbers and aspect ratios are less favorable than for the other reservoir quality rock types $(2,3$, and 5$)$, however, the interconnectibility is much more favorable, resulting in good fluid flow potential. The less favorable reservoir rock types have generally low coordination numbers (fewer pore throats connecting pores) and high aspect ratios (small pore throats connecting pores) reflecting relatively poor fluid flow potential.

The non-reservoir rock types (rock types 6,7 , and 8 ) are essentially impermeable and can be considered to be vertical flow barriers. The presence of these rock types is a significant factor in the level of reservoir heterogeneity and compartmentalization. Knowledge of the distribution of these non-reservoir rock types is essential to the successful implementation and operation of secondary and tertiary recovery programs.

Irregular porosity development and the abundance of small pore throats within the Glorieta/Clearfork interval result in poor reservoir continuity, directional permeability and fracture trends, as well as poor sweep efficiency during waterflooding operations. These same characteristics suggest that infill drilling on a reduced spacing and a vigilant reservoir surveillance program are required.

\section{$\underline{\text { Special Core Analysis }}$}

Representative rock-fluid interaction data are required to accurately model reservoir flow conditions and define reservoir rock types. The available capillary pressure and relative permeability data sets will be augmented with additional data from proposed infill wells during Budget Period II. The initial analyses have helped identify which rock types will be important with regard to reservoir producing mechanisms, as well as the rock types that will act as barriers to fluid flow. This data will be used as initial input data for reservoir simulation, as well as being a guide for future data acquisition.

\section{Capillary Pressure Measurements}

A total of twenty-four core plugs from two wells (NRU 207 and 3522) were used to generate mercuryair capillary pressure curves. These data clearly show significant differences in the displacement characteristics of the reservoir rock types. Although these data are from wells in areas of the Unit with the highest degree of reservoir continuity, we can make some qualitative interpretations regarding reservoir quality and production/injection potential as a function of rock type. The capillary pressure curves for rock type 1 are shown in Fig. 8.

Using the methods presented by Thomeer, ${ }^{11}$ the data have been interpreted as hyperbolic functions in order to estimate composite averages of pore throat radius, minimum entry pressure, and the relative 
amount of ineffective porosity (porosity occupied by mercury at injection pressures exceeding 500 psia) for each rock type. The results are summarized in Table 4, which indicates that rock type 1 is the primary reservoir rock with the largest pore throat radius, the lowest entry pressure, and the least amount of ineffective porosity. Rock types 2 and 5 are moderate quality reservoir rocks, and rock types 3 and 4 appear to have limited reservoir potential due to their smaller pore throat radii and large percentage of ineffective porosity. Rock types 6,7 , and 8 can be characterized as flow barriers in the reservoir.

\section{Relative Permeability Measurements}

The oil/water relative permeability data were taken at various water saturations on twelve core samples from a single well in the Unit (NRU 3522). Relative permeability curves for rock type 1 are shown in Fig. 9. These results also confirm that rock types 1 and 2 are the primary pay rocks in the reservoir. From the limited data available, rock type 1 has a comparatively lower irreducible water saturation, however, the residual oil saturation appears to be extremely high. The planned acquisition and analysis of additional data will give us the opportunity to further study the wettability and relative permeability characteristics of the various rock types.

\section{Formulation of Rock-Log Model}

The objective of the rock-log model work is to facilitate the identification of reservoir flow units. Eight rock types have been identified of which only three can be truly classified as potential oil-producing pay rock. The need for a reservoir model that has field-wide application is essential as only a limited number of wells in the NRU have been cored in the Glorieta/Clearfork Formations.

As a whole, there is no simple, direct relationship between core porosity and core permeability (Fig. 10). However, when the data were segregated by rock types generated from core analysis, the relationship between porosity and permeability became fairly unique, with correlation coefficients between 0.7 and 0.95. Simple linear relations were then utilized to define the permeability on the basis of porosity (Fig. 11).

If reservoir rock types can be defined using core data, then the same porosity-permeability relationship can be applied to wireline log data, and the model can be extended throughout the Unit to all wells with the requisite well $\log$ data.

This rock-log model $^{7}$ requires the following modern wireline logs:

- Gamma ray (GR)

- Photoelectric capture cross-section (PE)

- Compensated neutron (CNL $\phi)$

- Compensated formation density $\left(\rho_{b}\right)$

- Dual Laterolog (LLD and LLS - deep/shallow resistivities) 
- Borehole caliper

Sonic and Microlaterolog data would have been extremely useful in isolating "pay" rock types, however, these well logs were run with insufficient frequency to be used in the model's formulation.

The rock-log model was formulated to take advantage of the large amount of modern well log data (123 wells) that was available due to the completion of a 20 -acre post-unitization infill drilling program between 1987 and 1991. These modern well log suites allow for a more comprehensive evaluation of formation properties than would be possible using older porosity and resistivity well log suites.

The wells drilled prior to unitization do not have the requisite well log suites to apply the model. However, since there is usually an abundance of older wireline log data for many older properties, such as the North Robertson Unit, we note that these well logs would be sufficient to formulate a competent rock-log model if the well $\log$ data are properly interpreted and normalized.

The wireline log data has been corrected for wellbore environment, normalized on the basis of core porosity and the average porosity across the interval of interest (when required), and depth shifted. Rock types 1-4 are differentiated from rock types 5-8 on the basis of apparent matrix density, $\rho_{m a a}$, apparent photoelectric capture cross-section, $U_{\text {maa }}$, gamma ray response, and lithology (Fig. 12). To segregate the four "pay" rock types, Pickett plots of the Dual Laterolog Deep Resistivity Log response versus neutrondensity crossplot dolomite porosity were utilized. Rock types 3 and 4 were segregated on the basis of their Dual Laterolog Shallow Resistivity Log response. We obtained reasonable matches between the lithology of petrophysical rock types 1-4 and the core observed rock types 1-4, however, we hope to improve the correlation with additional core and $\log$ data during Budget Period II.

Foot-by-foot permeability values were estimated from wireline log calculated porosity values utilizing the core-based porosity versus permeability relationships for the applicable rock type. We tested the accuracy of the model by crossplotting calculated permeabilities versus core measured permeabilities. Results were mixed (correlation coefficients between 0.6 and 0.8 ), but we deem the model results acceptable. The model reflects the general trend of permeability values from core (where core measured permeabilities are high, the rock-log model predicts high values of permeability, etc.). The model worked best for rock type 1 , which is the best quality reservoir rock type. Also in a very general sense, the model did a better job of predicting areas of high permeability than it did for areas of low permeability. We will work on improving the model's error rate during Budget Period II by utilizing the additional core data obtained from the Field Demonstration phase of the project.

\section{Flow Unit Identification and Reservoir Layering}

The formulation of a rock-log model has provided us with a mechanism to identify particular flow units, which may consist of one or more rock types, and which may be related to their respective depositional environments. It is worth noting that rock types are usually not unique to a particular depositional environment. Flow units are discontinuous and reflect a high degree of reservoir compartmentalization and heterogeneity both laterally and vertically. 
The methodology used in the determination of flow units involved the following studies:

- Sedimentologic descriptions of 4,600 feet of whole rock cores from eight wells

- Log analysis to correlate markers, porosity, and other features from all wells

- X-ray diffraction of core samples for mineralogy and quantification of clay mineralogy

- Pore geometry analysis by SEM and pore cast studies

- Special core analysis for determination of relative permeability and capillary pressure characteristics for each rock type

- Development of a rock-log model to determine porosity and permeability relationships unique to each rock type

The Glorieta/Clearfork Formations (approximately 1,200 feet gross thickness) have been layered into 19 individual "flow" units. Nearly all of these flow units are bounded by potential crossflow barriers that are representative of a sabkha or supratidal depositional environment (the culmination of a shoaling upward, fifth order cycle ranging from approximately 50 feet to 200 feet in total thickness). These cycles have been identified within the whole cores and in some instances have well log responses that are characteristic of specific rock types.

These units have an origin related to rapid and frequent eustatic (sea level) changes on a carbonate shelf or platform that was essentially featureless or without any significant topography. Therefore, small changes in water level produced highly cyclic sequences. These parasequences are carbonate-dominated with insignificant clastic influences.

Structure maps have been constructed for the top of each stratigraphic unit, and have been observed to stack (Figs. 13-16). Isopachs have also been made for each unit to ascertain where changes in shelfal accommodation for sediments has occurred.

The relative distributions of potential reservoir rock types $(1,2,3$, and 5) and non-reservoir rock types $(4,6,7$, and 8$)$ for each stratigraphic unit is being determined by predictive facies analysis. This involves showing the distribution of a particular reservoir rock as a function of:

- Total thickness of reservoir rock/total thickness of non-reservoir and reservoir rock

- Thickness of a particular reservoir rock type/total thickness of non-reservoir and reservoir rock

- Thickness of a particular reservoir rock type/total thickness of all reservoir rocks

There is correspondence between the sediment accommodation indicated by the respective stratigraphic unit isopachs and the distribution(s) of the productive reservoir rock types. There is also correspondence between the occurrence of the reservoir rock types and the areas of the Unit exhibiting good historical production and interconnectivity as per the reservoir performance maps (in particular, the distribution of reservoir rock type 1 , the most favorable reservoir rock). 
Additionally, based on the rock-log model, $k h$ and $\phi h$ maps have been constructed for each stratigraphic unit. There is an extremely good correspondence between the distribution of the reservoir rock types, porosity and permeability distribution(s) within the interval isopachs, and the reservoir performance maps.

The results of this work are being incorporated within the geostatistical analysis of the reservoir. Areas that have been qualitatively evaluated as very favorable, favorable, and unfavorable for infill drilling are being quantified with the simulation. This process involves assessing the merits of respective areas of the reservoir for infill drilling on the basis of the relative probability of success: i.e., the qualitative geologic evaluation for relative success of infill drilling will be quantified and uneconomic blanket drilling in the less favorable areas of the reservoir will hopefully be eliminated.

\section{Continuity Analysis of Reservoir Pay}

The quantification of pay continuity based on 20 -acre well log data is in progress. Although reservoir continuity will vary for individual wells depending upon the direction in which the correlations are made, this is still an effective tool for the evaluation of pay continuity, as well as locating the best areas for infill drilling.

A study based on 40 -acre well $\log$ data was performed prior to unitization on thirty-nine wells in Sections 5, 325, and 329 using methods introduced by Stiles. ${ }^{2}$ Prior case studies ${ }^{2,5}$ indicate that analysis of the existing 20 -acre, and future 10-acre well data will show that the actual reservoir continuity is less than that predicted from 40 -acre well analysis, and that by reducing well spacing to 10 acres, a much larger volume of the reservoir will be contacted. This 40 -acre continuity data, and the estimated results of 20- and 10-acre well analyses are shown in Fig. 17.

\section{CROSS-BOREHOLE TOMOGRAPHY}

\section{Work Performed}

- Theory and Methodology

- Results

- Operational Considerations

- Cross-Borehole Tomography Status

\section{Theory and Methodology}

The objective of the cross-borehole tomography work is to obtain interwell data concerning the spatial variability of formation properties, reservoir structure, and reservoir heterogeneity. The cross-borehole seismic technique has promise since it provides a mechanism for understanding the physical scale of the interwell vertical and lateral continuity. This geophysical information can be used with geostatistical studies to formulate an integrated reservoir description, and provides an additional method for choosing 
optimum infill drilling locations, as well as a method for monitoring flood fronts during secondary and tertiary recovery operations. ${ }^{12}$

Reservoir analysis utilizing data from cores and well logs is incomplete since it does not include enough information concerning properties between individual wells. Pressure transient testing only considers portions of the reservoir that are in communication with the wellbore, but will not adequately delineate reservoir heterogeneities and flow barriers.

Cross-borehole seismic data is acquired by physically lowering seismic source and receiver arrays down wellbores via electric wireline and recording waves reflected off reservoir interwell facies that possess varying acoustical impedance properties. The use of cross-borehole seismic results in higher resolution images than are possible using surface seismic since the distances over which the acoustic waves must travel are shorter, resulting in less wave attenuation and allowing for the use of a broader range of bandwidths for interpretation. 13

\section{Seismic Travel Time Tomography Approach}

Seismic travel time tomography has been in use for several years. $12-16$ Seismic energy transmitted through the formation is expressed in terms of a source-to-receiver travel time and inverted to a velocity field representation of the formation. In order to have a sufficient number of ray paths for inversion to the velocity field, many combinations of source/receiver pairs are recorded. The recording design is based on reservoir conditions and imaging requirements. A schematic diagram of the tomographic data acquisition operation is shown in Fig. 18. An example showing the number of ray paths from the tomogram recorded between NRU wells 207 and 403 is shown in Fig. 19.

Seismic travel time inversion tomography measures changes in velocity between the wells, for which the relationship of rock properties to velocity is the principle concern. A decrease in velocity is expected with an increase in porosity (higher fluid content).

\section{Results}

\section{Completed Tomography}

A cross-well tomography survey using NRU wells 207 and 403 was completed during July, 1994. This particular area was chosen because a fully cored well was available as a control point for data analysis (NRU 207).

Survey parameters used for the completed survey on NRU 207 (Receiver Array) and NRU 403 (Source) were:

- 80 X 80 survey ( 80 source and 80 receiver positions)

- 800 Hertz, 32 Golay

- Receiver and source spacing of 4 meters (13.1 feet), 1048 feet vertical distance surveyed 
- Interwell spacing of approximately 1040 feet

\section{Processing}

The interwell continuity of the reservoir has been investigated using a "connectivity mapping" process and with travel time tomography for the NRU well $207 / 403$ survey data.

\section{Connectivity Mapping Processing}

Connectivity mapping is an effective imaging technique in mapping the acoustic impedance of interwell formations. The technique is based on the principles of wave guide phenomena. Wave guides are formed in bed layers possessing different acoustic velocities. The principle is similar to that of a focused resistivity tool. As in fluid flow analysis, seismic waves will always follow the path of least resistance.

This processing method utilizes spectral analysis of the specific acoustic wave trains (channels) formed in each frequency domain of interest in order to estimate bed connectivity on the basis of the quality of wave transmission through it. The advantage of this method is that it requires only a small portion of the full tomographic data set for processing.

There are several data analysis steps required for processing as shown on the flow diagram (Fig. 20) and described in Ref. 16. Fig. 21 shows the connectivity map of the NRU 403/207 survey based on these spectral characterizations. The connectivity map displays the interwell acoustic similarity of the beds from the source well to the receiver well. The map shows intervals with good sonic transmission characteristics. This does not mean they are continuous, simply that they have the same acoustic properties throughout the section.

\section{Travel Time Tomography Processing}

Travel times were derived by picking the first clearly identifiable coherent event on each trace in the data set. The travel times, well deviation, and surface location data were used as input to the processing. Fig. 22 shows the travel time tomography result for the survey.

The connectivity map is well correlated with the existing sonic and gamma ray logs. The travel time tomography map is also correlated with the logs but the level of detail with the connectivity map is better. Large-scale interwell heterogeneities can be identified from the map, and are especially apparent in the lower portion of the Middle Clearfork, which would be expected from the geologic interpretation of the interval. The results also indicate that several intervals exhibit high acoustic similarity. This is not surprising, since the results of geologic and reservoir performance work indicate this area of the Unit has relatively high reservoir continuity. It should be noted that due to the diagenetic processes that are common in carbonate reservoirs, the resulting wave guides that form will not always follow depositional boundaries, but may also form along zones in which post-depositional porosity has been created via diagenesis.

Due to the extremely heterogeneous nature of this Clearfork/Glorieta reservoir, the cross-borehole 
seismic results obtained from this survey did not possess sufficient vertical resolution to characterize this reservoir on the scale which is required.

\section{Operational Considerations}

Approximately half the expenditures on the initial survey pertained to pre- and post-survey well preparation costs. The planning required to use producing wells for tomographic surveys is much more straightforward (and economic) than for injection wells. In waterfloods such as the NRU, where the producing wells are pumping wells, flowback is generally not a concern. The preparatory work required for producers typically involves just removing the pump, rods, and tubing. Injection wells generally have to be "killed" with mud or salt water to achieve static wellbore conditions for the survey. Postsurvey restimulation using acid or other chemicals may be required in order to restore injectivity. This stimulation work on the injector adds significantly to post-survey costs.

In the Permian Basin, typically sour gas $\left(\mathrm{H}_{2} \mathrm{~S}\right)$ conditions exist in reservoirs for which tomographic data would be of interest. Operators contemplating surveys should work with the service company to carefully consider the ability of the tools to withstand sour wellbore conditions. The materials used in the tools must be able to survive normal "live" wellbore conditions, in which gas is likely to be present in wellbore fluids.

Receiver arrays are generally more time consuming to move from well to well than the source tool. For this reason, consideration should be given to minimize well-to-well moves of the receiver array whenever possible in multiple well surveys. In addition, consideration should be given to the amount of wellbore "rathole". In order to perform both tomography and reflection profiling work, there needs to be sufficient rathole so that tool strings can be positioned below the zones of interest to generate seismic waves uphole, as well as downhole.

Service companies offering tomographic services are becoming more aware of the need of operators to minimize pre- and post-survey operational costs. Efforts to reduce tool size and minimize the possibility of tool sticking are also in progress. Service companies have also recognized the need to reduce operational downtime of tools. Only if a significant number of surveys are recorded with the prototype tools to ensure reliability and provide benefits to the operator will survey costs be reduced to the point where tomographic services can become a part of standard reservoir characterization and surveillance operations.

\section{Cross-Borehole Tomography Status}

No additional surveys will be conducted at North Robertson. The primary reasons for this are:

\section{Operational Aspects}

Operational difficulties have been outlined above. The sour gas environment at NRU is extremely corrosive to the current tomography tools available and destruction of tools is costly. There are also problems with the integrity of the wells to be used in the surveys due to their age, and there is significant 
potential for permanent wellbore damage.

\section{Poor Cost/Benefit}

The cost of the survey was approximately ten times higher than anticipated due to the problems encountered. This results in a very poor benefit/cost relationship for the technology at the NRU.

\section{Applicability For Reservoir Description}

The technology relies on more than one survey per area to be effective and give confidence to the data for use in integrated reservoir description with geostatistics. It is economically and operationally impossible to support several surveys in each area at present.

\section{RESERVOIR PERFORMANCE}

\section{Work Performed}

- Oil Production Data Analysis Using Decline Type Curves

- Example Analysis (NRU 3510)

- Mapping of Results

- Waterflood Performance Analysis

- Secondary-Primary EUR Ratio

- Injection-Production Ratio

- Jordan Plot

- Hall Plot

- Future Work

\section{Oil Production Data Analysis Using Decline Type Curves}

In order to verify the results of the rock-log modeling, the analysis of long-term production data was performed using a rigorous material balance decline type curve method. ${ }^{17}$ An initial study of both the 40- and 20-acre producers has been completed utilizing the Fetkovich/McCray Type Curve. ${ }^{18-20}$ (Fig. 23). A step-by-step procedure for the use of this technique is given in Ref. 17.

This method yields excellent results for both variable rate and variable bottomhole flowing pressure cases, without regard to the structure of the reservoir (shape and size), or the reservoir drive mechanisms. The use of three different type curve plotting functions (rate, rate integral, and rate integral derivative) allows for the analysis and interpretation of typical "noisy" field production data. In addition, the integral functions provide better type curve matches than could be obtained using existing decline type curve matching techniques and increases confidence in our interpretations. These analysis techniques have been verified by evaluation of a number of simulated and actual field data cases, with outstanding results. 
Results of these analyses include the following:

- In-place fluid volumes:

- Original oil-in-place, $N$

- Movable oil at current conditions, $N_{p, m o v}$

- Reservoir drainage area, $A$

- Reservoir properties:

- Skin factor for near well damage or stimulation, $s$

- Formation flow capacity, $k h$

One benefit of this technique is that analysis can be performed using data that operators acquire as part of normal field operations (e.g., production rates from sales tickets and pressures from permanent surface and/or bottomhole gauges). In most cases, these will be the only data available in any significant quantity, especially for older wells and marginally economic wells, where both the quantity and quality of any types of data are limited. This approach also eliminates the loss of production that occurs when wells are shut in for pressure transient testing, and provides analysis and interpretation of well and field performance at little or no cost to the operator. This technique allows properties to be evaluated quickly and easily, provides an additional method for locating the most productive areas of the reservoir, and allows for the possible identification of any preferential flow paths that may exist.

An example analysis performed on NRU 3510 is shown below. For Clearfork production data analysis, we prefer to report flow capacity, $k h$, instead of permeability due to the fact that accurate values for net pay interval are not available. Average fluid properties were used in the analysis and are shown in Table 1.

\section{Example Analysis: NRU Well No. 3510}

NRU 3510 is located in the northwest area of the Unit, and is in a region of fairly high reservoir quality as defined by the geologic analysis and historical production performance. This well was drilled in 1963, and completed in the Lower, Middle, and Upper Clearfork. The Lower Clearfork was stimulated with 2,000 gallons of acid, and hydraulically fractured down casing with 21,500 gallons of fracturing oil and 60,000 pounds of 20/40 sand. The Middle and Upper Clearfork were stimulated with 2,000 gallons of acid, and fractured down casing with 86,000 gallons of fracturing oil and 180,000 pounds of 20/40 sand.

The well initially tested at 55 STBO/D from the Lower Clearfork and 127 STBO/D from the Middle and Upper Clearfork. It had produced approximately $226 \mathrm{MSTBO}$ as of July 1989, when it was converted to a water injection well. Semilog and $\log -\log$ production plots shown in Figs. 24 and 25 indicate that there was a significant rate fluctuation after a workover/recompletion that occurred in 1968. The data set was reinitialized in time to eliminate this data "spike". At the time of its conversion to injection, there had been no visible response to Unit water injection that began in 1987. 


\section{Type Curve Analysis Results: (Figs. 26 and 27)}

We now consider the type curve matching of the rate, rate integral, and rate integral derivative functions plotted versus material balance time on the Fetkovich/McCray type curve. The three rate functions are force matched on the Arps $b=1$ (harmonic) decline stem as dictated by theory for the use of material balance time, ${ }^{17,20}$ and the appropriate match points are obtained.

To obtain the best type curve match, the data was reinitialized at a time of 2227 days. After reinitialization, we obtained a good match on the depletion stems and a unique match on the $r_{e D}=800$ transient stem. From the log-log production plot (Fig. 25), it is noted that transient flow conditions caused by a well workover had not ended at a time of 2227 days, therefore the transient match should be valid. Using this dimensionless radius and the time and rate match points, values are calculated for inplace oil, drainage area, flow capacity, and skin factor:

$$
\begin{array}{llll}
\text { Matching Parameter: } & r_{e D} & =800 \\
{\left[t_{D d}\right]_{\mathrm{MP}}=1.0} & {\left[t_{b a r}\right]_{\mathrm{MP}}} & =10,000 \text { days } \\
{\left[q_{D d}\right]_{\mathrm{MP}}=1.0} & {[q / \Delta p]_{\mathrm{MP}}} & =0.009 \mathrm{STB} / \mathrm{D} / \mathrm{psi}
\end{array}
$$

Based on the estimated value for total compressibility, the following results are obtained:

$$
\begin{array}{ll}
N c_{t} & =90.0 \mathrm{STB} / \mathrm{psi} \\
N & =3.60 \mathrm{MMSTB} \\
A & =43.1 \mathrm{acres} \\
r_{e} & =773.0 \mathrm{ft} \\
k_{o} h & =12.75 \mathrm{md}-\mathrm{ft} \\
s & =-1.1
\end{array}
$$

A pressure buildup test was performed on well NRU 3510 in 1988, and the permeability to oil was estimated to be $0.43 \mathrm{md}$, with a calculated skin factor of -1.93. For decline type curve analysis, the calculated skin factor was -1.1 , and using the estimated net pay interval for the well (150 feet), the calculated oil permeability was $0.085 \mathrm{md}$. The large difference in the permeabilities is due in large part to the fact that the decline type curve calculation is based on twenty-five years of production history, while the pressure buildup results reflect reservoir pressure behavior near the well over a 250 hour period.

\section{Estimated Ultimate Recovery (EUR): (Fig. 28)}

Since there are no bottomhole flowing pressure data available, the daily oil rate, $q$, is plotted versus cumulative oil production, $N_{p}$, to estimate the movable oil volume. The calculation of movable oil volume using this plot yields acceptable results unless $p_{w f}$ varies significantly. The extrapolation of the 
data trend to the $N_{p}$ axis intercept yields a movable volume at the time when all reservoir energy has been depleted.

Simulated data cases were used to verify that the $q$ versus $N_{p}$ plot yielded similar results to those predicted by more rigorous plots that could be made when bottomhole flowing pressure data were available. This conclusion has also been confirmed for field data cases for which both surface and bottomhole flowing pressure data were available. ${ }^{17}$

The estimate for primary EUR is 270 MSTBO. The results indicate that approximately 44 MSTB of primary movable oil remained in the drainage area of the well when it was converted to water injection. The actual movable oil volume will be slightly less than the volume extrapolated for production to zero oil rate.

Volumetric Analysis Results:

$$
\begin{array}{ll}
N_{p} & =226.0 \mathrm{MSTBO} \\
N_{p, \text { mov }} & =270.0 \mathrm{MSTBO} \text { (primary EUR) } \\
\text { Recovery Factor } & =7.5 \% \text { (primary) }
\end{array}
$$

The results of the type curve match and material balance analysis yield rigorous estimates for original oil-in-place and movable oil, and qualitative estimates for drainage area, flow capacity, and skin factor. The primary recovery factor calculated using the value of OOIP from the type curve match is typical for wells at the NRU.

\section{Mapping of Results}

The results of the individual well decline type curve analyses were used to generate reservoir quality maps of original oil-in-place, as well as $k h$ and estimated ultimate recovery (EUR) for both the original 40-acre (primary), and 20-acre (secondary) producing wells as shown in Figs. 29-33.

These maps verify that the areas of the Unit possessing the best production characteristics are in the northwest (Section 329), south (Section 326), and southeast (Section 5). In addition, there also appears to be an extremely good area to the southwest (Section 327). Each area has higher than average OOIP, $k h$, drainage area, and EUR. These areas were also identified by the geological/petrophysical analysis.

The total original oil-in-place for the individual analyses of all 40-acre primary producing wells was 261.8 MMSTB. An additional analysis performed on total primary Unit production data (Figs. 34 and 35) resulted in a calculated OOIP of 280.0 MMSTB. Previous estimates of OOIP for the Unit have ranged between 200 and 300 MMSTB based primarily on analogy to offsetting properties. It is important to understand that OOIP estimates reflect only the oil which is in "communication" with the wellbores and completions.

The estimated primary EUR was 19.6 MMSTBO from individual well analyses, and 20.0 MMSTBO 
from the total Unit production analysis. The estimated secondary EUR was 13.1 MMSTBO from individual well analyses, and approximately 18.0 MMSTBO from the total Unit production analysis. Previous estimates for primary and secondary EUR for the Unit, also based on analogy to offsetting properties, were both approximately 20.5 MMSTBO (1:1 primary-secondary ratio). Secondary recovery is difficult to estimate accurately at this point in time as many of the producing wells have only recently begun to experience rate declines.

Individual well averages for OOIP, EUR, recovery factor, drainage area, and $k h$ are summarized in Table 5.

\section{Waterflood Performance Analysis}

The NRU was developed using 40-acre five-spot patterns (1:1 injector/producer ratio) for optimum injectivity and pressure support. Sweep efficiency is still low due to the discontinuous nature of the reservoir and propagation of fractures along preferential paths (east-west) between injection wells. Additional tools are required to help delineate the nature of the problem.

There are many simple graphical waterflood performance evaluation techniques that can be applied in order to identify the problems that affect flood efficiency. These diagnostic plots can be made using long-term production and injection data, which are generally available to all operators.

\section{Secondary-Primary EUR Ratio}

By comparing the estimated ultimate recoveries for both primary and secondary production a qualitative assessment of sweep efficiency can be obtained. A bar graph for EUR ratio in each section of the Unit with more than one producing well is shown in Fig. 36, where:

EUR Ratio $=\quad$ Average 20-acre EUR

Average 40-acre EUR

This shows the areas of the Unit which are being most effectively swept via waterflooding, and also indicates that the average secondary-primary recovery ratio will be less than unity in most areas of the Unit as was predicted from decline type curve analysis.

\section{Injection-Production Ratio}

A plot of daily injection rate and daily total fluid production rate versus cumulative water injected is used to estimate the current waterflood efficiency. Figure 37 shows that the injection-to-production ratio has steadily decreased since reservoir fill-up (at approximately $20 \mathrm{MMBW}$ injected). Since unitization, the ratio of total injected to produced fluids is approximately $1.85: 1.0$. The current ratio is about 1.35:1.0, indicating that some of the injected water may still be leaving the Unit, but that recent water quality, remediation, and pattern balancing work have been relatively effective. 


\section{Jordan Plot}

Jordan ${ }^{21}$ provided a straightforward graphical technique for evaluating waterflood performance using cumulative produced and injected fluid volumes. A plot of cumulative total fluid production and cumulative oil production versus cumulative water injected can be used to characterize waterflood efficiency (Fig. 38). The following "rules" can be applied to the plot to evaluate waterflood performance:

- The slope of the total fluids produced line is an indicator of sweep efficiency

- The deviation of the cumulative secondary oil produced line from the total fluids produced line at early time is indicative of early water breakthrough

- The cumulative secondary oil production line asymptotically approaches the eventual value of secondary recovery for current operating conditions

The low slope ( $<45$ degrees) of the total fluids curve indicates that the NRU waterflood has relatively poor sweep efficiency. The deviation of the cumulative oil production line from the cumulative total fluid production line at an extremely low volume of cumulative water injection indicates the Unit had extremely early water breakthrough. This line also appears to be nearing an asymptotic value for secondary EUR that will be lower than that predicted (20.5 MMSTB) prior to unitization, as was noted in the analysis of long-term production data.

While these results indicate early water breakthrough, poor sweep efficiency, and low secondary EUR, it should be noted that they are "better-than-average" for West Texas carbonate waterfloods. Targeted infill drilling, the optimization of completion and stimulation procedures, and increased attention in the areas of reservoir management and surveillance should enhance the current flood efficiency at the NRU.

\section{Hall Plot}

Hall 22 provided a straightforward graphical technique for the analysis of long-term injection well performance data. The Hall coefficient, which is defined as the cumulative total of the product of the average monthly injection pressure and the number of days per month the well is on injection, can be plotted versus cumulative water injected to produce a diagnostic plot for monitoring the behavior of injection wells. This is presently the most utilized tool in decisions regarding water injection well workovers at the NRU.

From a plot borrowed from the work of Thakur ${ }^{23}$ (Fig. 39), it is noted that linear trends which fall above the "normal" line (D) indicate pore plugging and a possible water quality problem. Data plotting below the "normal" line (B and $\mathrm{C}$ ) indicate water channeling or injection at pressures greater than the formation parting pressure. Fig. $\mathbf{4 0}$ shows an example Hall plot of an NRU injection well that became plugged and was subsequently worked over to remove formation scale and wellbore fill.

An example of possible water injection at pressures above the parting pressure of the formation and water channeling is shown in Fig. 41. The Hall plot for NRU 301 shows a decrease in slope that is 
characteristic of these phenomena. Verification is provided in the form of a recent pressure falloff test that indicates the well is in fracture communication with an offset injector (Fig. 46). The well's injection rate has declined drastically, and the injection pressure has gradually increased over the past year as it receives pressure support from the offset injector.

\section{Future Work}

Analysis of waterflood performance using conventional techniques such as the Buckley-Leverett, Stiles, and Dykstra-Parsons methods will be difficult due to the problems associated with obtaining accurate estimates of net pay thickness in the Clearfork/Glorieta. Evaluation of these methods will be made to determine if they can be used effectively in the development of a waterflood model for comparison to 3$\mathrm{D}$ simulation results. The formulation of a conventional waterflood model without performing simulation is important as it may not be economically feasible for smaller, independent operators to purchase a commercial simulation package, or obtain the training required to use it correctly.

In addition, to better identify injection well responses such as those summarized above, type curve techniques need to be developed which are similar to those currently used in production data decline curve analysis and pressure transient analysis. One main goal of this study is to identify useful and economical data analysis methods. Thus, efforts will be made towards developing a method for the analysis of long-term injection data.

\section{RESERVOIR SURVEILLANCE}

\section{Work Performed}

- Definition Of Reservoir Surveillance

- Water Quality Program

- Pressure Transient Data Acquisition And Analysis

- Pressure Buildup Test Results

- Pressure Falloff Test Results

- Step-Rate Testing

- Optimization Of Completion/Stimulation Procedures

- Pay Cutoffs

- Hydraulic Fracture Design

- Coiled-Tubing Workovers

- Cased-Hole Logging Program

- Future Data Acquisition 


\section{Definition of Reservoir Surveillance}

As summarized by Robertson and Kelm, ${ }^{24}$ there are a number of factors to consider when initiating a comprehensive reservoir surveillance program. These include:

- Allowing for a maximum pressure differential to exist between the producing and injecting wells without exceeding the formation parting pressure

- Performing early and continuous pressure buildup tests on the producing wells to detect formation damage and monitor reservoir pressure

- Carrying out a systematic program of cased hole surveys (temperature and fluid tracer) on a regular basis

- Utilizing continuous pressure falloff testing on the injection wells to monitor the growth of vertical fractures due to continuous injection

Additional factors for reservoir surveillance at North Robertson include:

- Continuously monitor injection water quality to increase injection efficiency

- Combine the results of pressure falloff test analyses with the results of waterflood diagnostic plots and regular step-rate testing to improve injection efficiency

- Optimize well conformance by injecting only into zones which are continuous between injectors and producers

- Implement a continuous program of interwell conformance and completion/stimulation optimization to improve sweep efficiency

- Utilize Thermal Decay Time (TDT) logs on a periodic basis to monitor the movement of reservoir fluids in the near-wellbore regions of the producing wells

\section{Water Quality Program}

Injection water quality is one of the critical components in the implementation of a successful waterflood. Unfortunately, the continuous monitoring of water quality is still not considered part of many operators reservoir surveillance plan. This often results in poor waterflood efficiency and numerous operational problems.

The total daily injection rate for the NRU had decreased from 30,000 BWI/D in 1989 to $16,000 \mathrm{BWI} / \mathrm{D}$ in 1992. A cost-effective surveillance program was initiated to identify and resolve potential water quality problems. At the same time, an injection well workover program was implemented to remediate the scaling problems in individual wells.

Due to the fact that both fresh (Ogallala aquifer) and produced water are used for injection at the Unit, both waters had to be tested separately for their plugging and scaling tendencies. In addition, both 
waters were tested together to determine if any compatibility problems existed. The following tests were conducted:

- Physical properties

- total dissolved solids

$-\mathrm{pH}$

- particle size distribution

- Filtration

- suspended solids

- acid solubles

- hydrocarbon solubles

- Dissolved Gases

- oxygen

- carbon dioxide

- hydrogen sulfide

- Bacteria

- anaerobes

- aerobes

- dissolved iron

Although the injection waters were found to be compatible, both the produced and fresh waters were found to have substantial plugging and scaling tendencies. The water handling facilities were redesigned and programs were implemented to 1) prevent the formation of solids, and 2) remove all remaining solids from the system. The entire NRU water quality program is outlined in detail in the work by Nevans, et al. 25

The Unit's daily injection rate subsequently increased to $26,000 \mathrm{BWI} / \mathrm{D}$, and is currently between 20,000 and 22,000 BWI/D. At present, quarterly tests are conducted on individual wells, and field-wide tests are conducted biannually.

\section{Pressure Transient Data Acquisition and Analysis}

At the time of unitization, a wide range of fluid bubble points existed in the reservoir. This differential pressure depletion is indicative of poor pressure continuity and is supported by the bottomhole pressure data collected just prior to unitization and during reservoir fill-up (Table 6). A unit-wide pressure transient data acquisition program was initiated in the last quarter of 1994 to provide further data for simulation history matching, to estimate completion and stimulation efficiency, to identify the best areas of the reservoir with regard to pressure support, and to identify any other major problems related to waterflood sweep efficiency.

The majority of the tests are pressure falloffs on injection wells, so as to minimize the loss of oil production. At present, the plan is to run approximately twenty-five falloff tests, and ten to fifteen 
pressure buildup tests in order to generate a "baseline" data set for future surveillance purposes. At this time, nine recent falloff tests and seventeen buildup tests recorded just after unitization (1988) are available for analysis. We have used both pressure and pressure integral data to perform semilog analysis, and log-log analysis using radial homogeneous and fractured well type curves with wellbore storage effects. The results of these analyses were then used to match simulated results (generated by optimizing permeability, skin factor, wellbore storage coefficient, and fracture half-length) to the pressure and pressure integral data.

\section{Pressure Buildup Test Results}

Pressure buildup data recorded in October and November of 1988 was available for seventeen producing wells. At that time, the wells had received limited pressure support as the water injection program was only initiated in the last half of 1987 . Fifteen of these wells were new 20 -acre producing wells, and two were original 40 -acre producers which were subsequently converted to injection.

These surveys were recorded by measuring the shut-in surface pressure while simultaneously making a fluid column height measurement using an echometer (automated well sounder) device. The overall data quality was not good, however, fifteen of the tests were of sufficient quality to perform complete analyses. The results are summarized below, and example analyses for NRU wells 1008 and 3510 are shown in Figs. 42 and 43. As with the material balance decline type curve analysis, a value for the flow capacity is reported rather than the oil permeability due to the fact that the net pay thickness is an estimated value.

\begin{tabular}{ccccc} 
Well \# & $k_{o} h$, md-ft & Skin Factor & $x_{f}, \mathrm{ft}$ & $p_{w s}, \mathrm{psia}$ \\
\hline 201 & 7.5 & -3.7 & 25.0 & 1033 \\
208 & 28.6 & -4.1 & 36.0 & 719 \\
1008 & 37.0 & -3.1 & 14.2 & 985 \\
4202 & 49.5 & -4.7 & 71.0 & 507 \\
2217 & 44.6 & -3.8 & 27.4 & 1350 \\
2224 & 7.9 & -4.1 & 37.0 & 1074 \\
2225 & 2.7 & -3.6 & 22.0 & 1228 \\
804 & 75.6 & -3.2 & 15.0 & 985 \\
2704 & 14.3 & -3.1 & 14.0 & 1431 \\
2804 & 4.9 & -5.0 & 90.0 & 1292 \\
1506 & 32.8 & +1.0 & 0.0 & 840 \\
3011 & 61.6 & -3.5 & 20.0 & 992 \\
3510 & 65.0 & -1.9 & 0.0 & 384 \\
3517 & 78.6 & -3.8 & 26.0 & 939 \\
3523 & 32.4 & -3.1 & 15.0 & 1199
\end{tabular}

Even though the majority of these wells were newly drilled, completed, and stimulated at the time of the surveys, the hydraulic fracture treatments were for the most part unsuccessful. These jobs were designed to produce fracture half-lengths of 120 feet, however, the calculated average half-length is only 27.5 
feet, and no fractures reached the designed length. The results indicated that two wells (NRU 1506 and 3510) had no propped fracture length at all, and NRU 1506 appears to have near-wellbore damage.

From the analysis of NRU 3510 (Fig. 43), it can be seen that as we surmised from the material balance decline type curve analysis, the quality of the reservoir rock in the near-wellbore region is fairly good, however, the low estimated bottomhole shut-in pressure indicates that this well is most probably in a region of relatively poor reservoir connectivity, as it is more pressure-depleted than the surrounding wells (NRU 3517 and 3523).

Most of these pressure buildups were not recorded for a sufficient length of time to see any boundary or interference effects. One of our major goals for future buildup and falloff tests is to record sufficient data to be able to see these effects, and to better define the reservoir's producing mechanisms. In addition, pressure buildups using downhole shut-ins will be performed to reduce wellbore storage effects and obtain better quality data for interpretation. The cost/benefit of the quality of analyses using surface vs. downhole buildups can then be compared.

\section{Pressure Falloff Test Results}

The pressure falloff data were acquired at surface in an effort to reduce costs and demonstrate that these tests can be recorded at little or no cost to the operator. Results to date have been excellent, and have helped to explain some of the major problems associated with waterflooding a low permeability carbonate reservoir. Pressure data at the producers from buildup tests are being compared with estimates of average reservoir pressure at the injectors from pressure falloffs.

The pressure falloff test is the most popular tool for monitoring waterflood pressure performance. By using surface pressure data acquisition, tests can be performed easily and economically with greater frequency. It has been shown that surface pressure acquisition yields data of sufficient quality for interpretation, even when low precision pressure gauges $\left( \pm 1\right.$ psi) are utilized. ${ }^{26}$

In an effort to identify interference/boundary effects on the injection well falloff tests, an effort has been made to let the tests run as long as possible. This is especially important in identifying the problems that may affect reservoir sweep efficiency. The extremely long falloff times we have witnessed to date indicate that the wells may be receiving a great deal of pressure support from offset injectors. This may also be due to the presence of formation scale plugging or wellbore fill which can be identified from waterflood diagnostic plots. 21,22

Pertinent falloff test data for each of the recently completed surveys are shown below:

\begin{tabular}{ccccc} 
Well \# & $q_{\text {inj }}$, BWI/D & $p_{\text {inj }}$, psig & Water Type & Test Time, days \\
\hline 102 & 138 & 4570 & fresh & 65 \\
295 & 330 & 4530 & fresh & 16 \\
3510 & 260 & 4705 & prod & 38 \\
3511 & 270 & 4580 & fresh & 53
\end{tabular}




$\begin{array}{ccccc}301 & 420 & 4950 & \text { prod } & 29 \\ 401 & 520 & 4740 & \text { prod } & 49 \\ 702 & 270 & 4730 & \text { fresh } & 49 \\ 1591 & 125 & 4730 & \text { fresh } & 59 \\ 3004 & 240 & 4850 & \text { prod } & 46\end{array}$

Individual analyses for NRU injection wells 301 and 3510 are shown in Figs. 44 and 45 . The results of all completed falloff tests are summarized below:

\begin{tabular}{ccccc} 
Well \# & $k_{w} h, \mathrm{md}-\mathrm{ft}$ & Skin Factor & $x_{f}, \mathrm{ft}$. & Est. $p_{w s}$, psia \\
\hline 102 & 32.0 & -5.0 & 89 & 2950 \\
295 & 130.0 & -5.0 & 88 & 3730 \\
3510 & 65.0 & -6.9 & 614 & 3400 \\
3511 & 51.0 & -6.0 & 250 & 3150 \\
301 & 184.0 & -5.9 & 232 & 4200 \\
401 & 188.0 & -5.3 & 126 & 3400 \\
702 & 124.0 & -6.3 & 323 & 4000 \\
1591 & 158.0 & -6.1 & 281 & 4250 \\
3004 & 210.0 & -5.9 & 217 & 4000
\end{tabular}

The shut-in bottomhole pressures were estimated using methods introduced by Hazebroek, et al. ${ }^{27}$ These pressures approach the initial parting pressure of the reservoir (approximately 4250 psia in the Lower Clearfork). The bottomhole injection pressures are all above the initial formation parting pressure.

The type of water injected (fresh or produced) seems to have little affect on the longevity of the tests, however, wells with produced water injection are more likely to have pore plugging and wellbore fill problems. ${ }^{25}$ The falloff time seems to be primarily a function of how much pressure support the wells are receiving from offset injectors and the degree of reservoir continuity.

Comparison of the pressure buildup and falloff tests on NRU 3510 shows how severe this problem may be. The buildup test run after the well had been hydraulically fractured (1987), and prior to conversion to water injection (1989), indicated that the well had no effective fracture length. The well was reperforated and acid-stimulated during conversion, but was not refractured. The falloff results show the well currently has an estimated fracture half-length of 614 feet, which must be the result of continued water injection at excessive bottomhole pressures.

Fractures created by this excessive injection have propagated along the suspected preferential fracture direction in the Clearfork, which is approximately east to west ${ }^{6}$. A falloff test run on NRU 301 shows that direct communication exists with an offset injection well to the west (NRU 2601). A 200 psi injection pressure increase at NRU 2601 caused an almost instantaneous pressure increase at NRU 301, which was on falloff (Fig. 46). The existence of direct communication through the fractures between injectors will drastically reduce the sweep efficiency of the injection operation, and because the 
estimated preferential fracture direction is parallel to the injector/producer rows (Fig. 4), the producing wells will be poorly pressure supported. Unfortunately, this is a common problem in West Texas carbonate waterfloods, for which injection pressures must be kept near or above the parting pressure of the reservoir to maintain injectivity.

By utilizing the results of the reservoir pay identification and continuity analyses, and performing further tests to identify the preferential flow directions in the Unit, lowering bottomhole injection pressures will be attempted to avoid excessive fracture propagation, and increase sweep efficiency. Future producing well fracture treatments will be optimized to preferentially stimulate only the intervals that contribute significantly to production and receive effective pressure support from offset injection wells.

\section{Step-Rate Testing}

The analysis of step-rate data collected between 1988 and 1993 for eighty-five NRU injection wells indicates that the estimated formation parting pressure has been steadily increasing from year to year due to reservoir fill-up (Fig. 47). The results of these tests are used primarily to set surface injection pressure limits for individual injection wells, however, after reservoir fill-up has occurred their utility is limited since the reservoir pore pressure has been increased to the point where it is difficult to accurately estimate the true parting pressure of the formation.

Because bottomhole injection pressures at the NRU are near or above the parting pressure of the reservoir, step rate tests should be used together with Hall diagnostic plots and pressure falloff test analyses, not only to determine the optimum injection pressure for individual wells, but also to identify problems affecting injection well efficiency.

\section{Optimization of Completion/Stimulation Procedures}

\section{Pay Cutoffs}

The NRU was developed using an aggressive 20-acre infill drilling program between the time of unitization (March 1987) and early 1991. During this time period, 116 new 20-acre producing wells were added, and 107 of the 141 original 40-acre producers were converted to water injectors. Prior to implementation of the infill drilling program in 1987, parameters were established to identify the "pay" quality intervals in each well. These parameters included porosity, water saturation, and bulk water volume. Any interval having a combination of porosity greater than 3.6 percent (dolomite matrix) and water saturation less than 65 percent qualified as potential pay rock. These parameters were used with only slight variations throughout the 20 -acre infill program. There may be additional uncontacted pay within the reservoir since these simple pay cutoffs do not identify pay rock on the basis of reservoir rock quality or continuity. In addition, many of the producing wells were not drilled to a sufficient depth to access the entire Lower Clearfork section, which is the main pay. These deepenings are discussed in the Reservoir Management section of the report.

Previous completion techniques opened all intervals without regard to rock quality. By utilizing the integrated reservoir description results, more emphasis can be placed on maintaining conformance between producers and injectors only over intervals of the reservoir which effectively contribute to oil 
production. In addition, efforts will be concentrated on maintaining injection over the intervals that can achieve and maintain high injectivity, instead of randomly injecting fluids into intervals with high porosity that may, or may not be effectively connected. Additional completion and stimulation work can be optimized and costs can be reduced.

\section{Hydraulic Fracture Design}

A major concern with regard to well completion work during each phase of Unit development was the need for a limited-entry type fracture job to ensure that the entire productive section was being treated equally. The gross completion interval extends from the top of the Glorieta to the base of the Lower Clearfork (1200-1500 feet). This interval was completed and stimulated in two or three separate stages, depending on the characteristics of individual wells.

Optimization of the fracture treatment program has been an ongoing process during Unit development. Results of the fracture treatments on the original 40-acre primary producers were poor due to the fact that the bottomhole treating pressure could not be maintained at a sufficiently high level for fracture propagation due to burst limitations on the casing. At the time of unitization, the average fracture job was approximately 1,000 barrels of fluid with 100,000 pounds of sand (1-8 pounds/gallon). Since there are no effective large-scale barriers to fracture propagation, sufficient non-perforated intervals must be maintained to prevent communication between successive completion stages. Over the development history of the Unit, the number of perforations per stage have been reduced in order to maintain a limited-entry type of fracture. During the 20 -acre infill program, the optimum number of perforations per stage was determined to be one perforation for each barrel per minute (BPM) injection rate using a 2-D Perkins/Kern (PKN) fracture model. Fracture jobs have been designed to create fracture halflengths of 120 feet.

As shown from the analysis of pressure buildup data on some of the 20 -acre producing wells drilled in 1987 and 1988, these optimized stimulation treatments also did not create effective pressure sinks at the wellbore. Future fracture jobs must be designed to create vertically contained, fairly short, high conductivity (thick) fractures. Previous production history has shown that regardless of the degree of reservoir continuity, long fractures are not necessary, and are in fact harmful to waterflood sweep efficiency. If completion and stimulation of only the most continuous layers of the reservoir are accomplished, then long hydraulic fractures are not required.

We hope to optimize the hydraulic fracturing treatments to prevent vertical fracture propagation outside the interval of interest and to evenly distribute the injected proppant. Downward fracture propagation is a major concern in the Lower Clearfork at the NRU due to the presence of the water-filled Clearfork Lime at the base of the producing interval. New fracturing techniques will be used to confine vertical propagation and produce higher conductivity fractures, resulting in more efficient removal of fluids from the formation.

\section{Coiled Tubing Workovers}

A workover program has been devised to stimulate all injectors that show significant losses in injectivity over any given six month period. Coiled tubing has proven to be a viable method of operation for 
cleaning out and stimulating injection wells at the NRU. The numerous casing problems encountered when entering wellbores that are now almost forty years old (original 40-acre producing wells) make conventional well workovers extremely risky, as well as cost prohibitive. Leaking packer seats and collapsed casing strings were the major problems encountered. By using coiled tubing, injection packers are left in place, and the exposure of the casing to corrosive stimulation fluids is minimized. The results obtained from coiled tubing treatments have been about equal to those obtained conventionally, and stimulation costs have been reduced by approximately one-third.

\section{Cased Hole Logging Program}

While the cost associated with recording a great number of thermal decay time logs (TDT) may be cost prohibitive for most operators, the periodic utilization of TDT logs is an extremely useful tool for monitoring the preferential fluid movement in the near-wellbore regions of producing wells. Approximately ten to fifteen surveys are being run to get updated fluid saturation values for some of the 20-acre producing wells drilled between 1987 and 1991 to use in the history matching segment of reservoir simulation, and for the possible identification of any bypassed production.

Previous reservoir surveillance in Clearfork waterfloods has not included the use of TDT logs because they did not perform well in the low porosity, low salinity conditions that exist at the NRU. Advances in tool design over the past five years have produced a tool (TDT-P) that works well for both fairly fresh formation water and low porosity formations. If positive results are achieved using this new generation tool, it may become a part of the reservoir surveillance and monitoring program at the NRU. Fig. 48 shows the increase in formation water saturation for NRU 3527 between 1987 and 1995.

The use of ordinary gamma ray logs to identify preferential flow paths will also be considered. Depleted intervals and zones through which reservoir waters have passed are likely to be lined with uranium salts, which can be easily detected using a natural gamma ray tool. This phenomenon was noted on correlation logs recorded prior to the tomographic survey on NRU wells 403 and 207, and may be useful in delineating the reservoir flow units.

\section{Future Data Acquisition}

During the infill drilling phase of this project in Budget Period II, acquisition of as much new data as is economically feasible will be carried out to verify the results of our previous geologic and engineering studies. This includes:

- Production data

- Verification of simulation results

- Additional whole core for analysis

- Verification of geologic model

- Verification of rock-log model

- Special core analysis

- New generation open-hole well logs 
- Use of the fracture identification tools to locate intervals with substantial secondary porosity that may have been previously ignored

- Use of the formation test tool to record pressure data in each of the reservoir flow unit layers

to determine if they are in communication

- Use of borehole imaging tools to confirm the preferential fracture direction in the reservoir

- Pressure transient data acquisition

- Use of all available data to optimize completion/stimulation treatments

\section{RESERVOIR MANAGEMENT}

\section{Work Performed}

- Well Deepening Candidates

- Deepening Methodology

- Ranking of Wells

- Strategy

\section{Well Deepening Candidates}

Twenty-two deepening candidates (10 producers, 12 injectors) have been identified based on geological and engineering reservoir characterization of the North Robertson Unit (see Tables 7-8, and Fig. 49). All these wells also have recompletion potential by adding additional perforations in the Lower Clearfork.

The recommended strategy for field work and methodology used to identify the deepenings is described below. It is the result of an integrated geological and engineering effort on reservoir characterization and reservoir performance analysis of NRU.

Estimates of flow potential for eight of the ten candidate producer well deepenings indicate an estimated production increase of $115-170$ BOPD. On the injection side, injection increases of approximately 800 - 1300 BWIPD can be expected from deepening of nine of the twelve candidate wells. Five wells (two producers and three injectors) were excluded from this projected rate increase since estimates of flow potential were not made (as the wells are outside reasonable confidence intervals for a quantitative estimate).

Work is in progress to identify wells which have recompletion potential only by adding additional perforations in the Lower Clearfork.

\section{Deepening Methodology}

The methodology used to identify deepening candidate wells was as follows: 
- Lower Clearfork Potential: Wells not penetrating the Lower Clearfork (MF4, MF5, and MF6 geologic intervals or flow units) were identified based on the geologic flow unit delineation. The Lower Clearfork represents the best pay at NRU.

- Flow Potential: Flow potentials for the candidate wells were estimated based on kh maps for each of the flow units included in the deepening. No estimate of $k h$ could be made in the case of two producers and three injectors as the wells reside outside a reasonable confidence interval from offset wells for a quantitative $k h$ estimate. However, these five wells without a $k h$ estimate, still represent good deepening candidates based on other criteria such as gross deepening footage, new completion footage, and qualitative performance analysis of the surrounding region.

- Additional Completion Potential: All the wells identified for deepening also have additional pay in the existing well configuration as the bottom of the existing perforations are well above the PBTD of the wells.

\section{Ranking of Wells}

Tables 7-8 show the candidate producers and injectors respectively for deepening. The wells are ranked based on highest to lowest flow potential $(k h)$. Wells with deepening potential of 50 feet or less were excluded from this list.

\section{Wells With No Flow Potential Estimates}

The wells where no estimates of $k h$ could be made are on the bottom of the list and are not ranked. It is expected that these wells (without a $k h$ estimate) would fall in the top $50 \%$ of candidate wells for deepening based on deepening footage and general qualitative understanding of NRU performance.

\section{Operational Considerations}

All of the deepening candidates are original 40-acre wells. Three of the wells have history of casing and hole problems and one well has been temporarily abandoned. These operational considerations are noted on Tables 7-8.

\section{Rate Estimates for Economics}

An estimate of production or injection increase, as a result of the deepening, has been noted in Tables 78 respectively to facilitate economic evaluation. This estimate has been based on considering the average $k h$ for producers and injectors across the Unit and scaling this factor to the estimated deepening $k h$.

\section{Strategy}

The following strategy and approach is being used to implement the field program to address the deepenings, barring no major operational factors arise. The plan is for deepenings to be attempted on 
producers in each of the three areas shown below:

1) Best Flow Potential Deepenings, Tract 36, 37 Strategy: These deepenings represent the top $10 \%$ of candidate wells. A deepening/recompletion on producing well 3603 , is being considered. If successful, this will be followed by a deepening of well 3701 .

2) Tract 35, 38 Flow Potential and Strategy: These deepenings represent the top 50\% of candidate wells. These tracts represent one of the best producing areas at NRU. It has been identified as having good potential for geologically targeted drilling and the first simulation model is being set up in this area. A deepening may be attempted on either producing well 3503 or 3502 . As these wells have a documented history of casing and hole problems, the next best candidate in this area is producer well 3802 .

3) Tract 20 Flow Potential and Strategy: These deepenings are also expected to lie within approximately the top $50 \%$ of candidate wells. No estimates of flow potential for the wells in this area have been made as they lie outside a reasonable confidence interval for a quantitative estimate. On a qualitative basis, the wells are expected to have good results from deepening. The strategy for this area would be to deepen producing well 2001 followed by well 2003. Well 2001 has more potential new completion footage than well 2003.

Pending results from this first set of deepenings, the strategy for the remaining wells can be addressed.

\section{GEOSTATISTICAL SIMULATION}

\section{Work Performed}

- Methodology

- Conditional Simulation Techniques

- Approach At North Robertson Unit

\section{Methodology}

Geostatistics is being utilized in this project to develop spatial relationships of reservoir description variables of interest at unsampled (interwell) locations across the Unit. Geostatistics was originally developed ${ }^{28}$ for applications in mining engineering, and has been used increasingly in reservoir engineering to characterize reservoir properties. ${ }^{29}$

One goal of the geostatistics is to identify the degree of reservoir continuity by weighting input data based on the method of acquisition, quality, and scale. Reservoir properties and heterogeneities can be effectively defined using four scale levels: 29,30 
- Microscopic

- micro scale data

- pore and grain size distributions

- pore throat radius

- rock lithology

- Macroscopic

- core scale data

- permeability

- porosity

- saturation

- wettability

- Megascopic

- simulator grid block scale data

- wireline logs

- seismic data

- Gigascopic

- reservoir scale data

- pressure transient tests

- geologic model

To utilize the different types of data and measure reservoir properties on a common scale (such as a reservoir simulator grid block), the effect of the support volume of each data type must be accounted for. In addition, the volume scales of different types of reservoir heterogeneities must also be described in order to model reservoir performance. Obtaining the most complete reservoir description is possible by utilizing an integrated modeling approach, in which personnel from all disciplines of the geosciences and engineering are involved.

\section{Conditional Simulation Techniques}

Two conditional simulation methods, simulated annealing and genetic algorithm, are being used in this project. The advantages of using conditional simulation techniques over conventional interpolation are as follows:

Sample Distribution Data Honored: Unlike simple interpolation or extrapolation, conditional simulation honors the entire sample data distribution rather than reducing the spread of the data distribution. This is important for retaining extreme values (outliers) in the sample data set, which form a very small part of the overall sample, but which may greatly influence the flow performance of the reservoir. An example would be a small streak of high permeability, which can have significant influence on waterflood performance, and still constitute a very small part of the entire productive interval in terms of the total sample distribution. 
Data Spatial Relationships Honored: The second advantage of the conditional technique is that it honors the spatial relationships developed from the sample data. Many conventional interpolation methods generate smooth distributions which do not satisfy the spatial relationships established using the sample data.

Reservoir Description Uncertainties Quantified: The last advantage of the conditional simulation method is its ability to quantify uncertainties in the reservoir description through multiple, equiprobable images of the reservoir. Conditional simulation allows construction of multiple pictures of the reservoir, all observing the same constraint(s).

\section{Simulated Annealing and Genetic Algorithm Methods}

The simulated annealing and genetic algorithm methods are attractive since they are very robust and flexible and allow incorporation of various scales of data in describing the reservoir properties. This includes geological, petrophysical, geophysical, reservoir performance, and pressure transient data. One disadvantage of the method is that the algorithms are slow and computationally intensive, however, they still run faster than conventional reservoir flow simulators with the same number of gridblocks.

These methods involve the definition of an arbitrary objective function which must be minimized. The more constraints (data types) that are imposed on the objective function, the more computationally intensive these methods become. Computational demands should not be a problem with the availability of high-speed personal computers and workstations. These methods best satisfy our requirements since all available data types may be incorporated to produce the most complete reservoir description possible.

\section{Approach at North Robertson Unit}

The interwell distribution of primary pay, secondary pay, and non-pay rock is being generated from intrawell rock type data using the conditional simulation techniques described above. The geologists review these rock type distributions and determine if they honor the geologic model developed for NRU (qualitative check). After realistic rock type distributions have been achieved, petrophysical parameters (porosity and permeability) will be assigned for each of the pay rock intervals by honoring the point data (cores and well logs), and by honoring reservoir performance, pressure transient, and other available engineering data.

The geostatistical analysis will be extremely useful in identifying the best infill locations within the high quality areas of the reservoir, however, the quality and quantity of data is probably insufficient to assign a relative probability of success to a specific infill well location.

\section{RESERVOIR SIMULATION}

\section{Work Performed}

- Methodology

- Reservoir Performance Criteria 
- Selection Of Modeling Areas

- Model Initialization

- History Match Criteria

\section{Methodology}

An important objective of this project is to perform 3-D reservoir simulation for history matching, infill drilling development forecasting, and validation. The results of conventional deterministic simulation runs will be compared to the results of runs using the geostatistical reservoir description. A black oil, three-phase simulator will be utilized. Objectives of the reservoir simulation include:

- Selection of optimum infill drilling sites within the North Robertson Unit

- Prediction of future reservoir performance

- Validation or comparison of predicted and actual reservoir performance during the Field Demonstration phase of the project

\section{Full-Unit vs. Partial-Unit Models}

The types of models which are being constructed are partial-unit models. The areas for these partial-unit models have been selected based primarily on an understanding of the reservoir performance factors discussed below. In addition, the locations of the partial-unit models have been verified by considering the geologic model and the results of the decline type curve analysis.

A full-unit model will not be constructed due to the large number of wells in the Unit ( 259 wells), and the need to focus on detailed flow simulation in areas with the best potential for infill drilling. A fullunit simulation would result in a cumbersome model with a large number of grid blocks primarily due to the large vertical section in the Glorieta/Clearfork and the large number of layers required to adequately model this vertically heterogeneous reservoir. By using partial unit models, the resulting smaller grid block sizes will allow for more detailed flow simulation in the model areas.

\section{Reservoir Performance Criteria}

Reservoir performance factors have been considered to identify the areas which possess good potential for infill drilling from those with little or no potential for infill drilling. These performance attributes for selecting simulation areas at NRU are:

\section{Potential Desirable Areas for Infill Drilling}

- Areas of high productivity

- High primary and secondary recovery

- Presence of pay rock types (rock types 1 and 2) 
- Good porosity and permeability characteristics

- Areas of poor reservoir continuity

- Good primary recovery but poor secondary recovery

- Poor waterflood pattern balance of water injected to fluids produced

- Current production with high oil cut and relatively low secondary production

- Primary decline much higher than normal primary and secondary decline (indicative of compartmentalization)

\section{Potential Undesirable Areas for Infill Drilling}

- Good pattern balance of water injected to fluids produced

- Flat or increasing oil cut (may be indicative of good waterflood sweep efficiency)

- High ratio of secondary estimated ultimate recovery (EUR) to primary EUR

- Uniform increase in pressure in surrounding areas indicating good reservoir continuity

\section{Selection of Modeling Areas}

A selection or scoring criteria was devised to identify the desirable locations for infill drilling based on the following readily available reservoir performance parameters:

- Cumulative primary to secondary recovery ratio (PSR)

- Cumulative replacement ratio (CRR)

- Water/oil ratio (WOR)

for which the cumulative replacement ratio (CRR) is defined as ratio between the cumulative volume of water injected and the cumulative volume of total produced fluids. Production and injection data were allocated to 5-spot waterflood cells, and the performance parameters were calculated for each cell. Average Unit values for each of the scoring criteria were calculated, and each cell was assigned one scoring point for having a higher than average CPP, PSR, or CRR, and a lower than average WOR.

The results of the selection process are shown in Fig. 50. The areas which are shaded lighter (higher score on 0-4 scale) represent the desirable areas for infill drilling. The darker regions represent areas which may be undesirable for infill drilling. We used the results of this study and all previous analyses to choose the subsequent modeling areas for reservoir flow simulation. For the most part, these desirable areas coincide with those identified by the results of the geological study, rock-typing work, and the reservoir performance maps generated from decline type curve analysis on the 20- and 40-acre producing wells (Figs. 29-33).

The total number of wells in the modeling areas ranges between 20 and 40 wells. Injectors serve as boundary wells for all the simulation areas. This configuration was chosen since it is more practical to allocate injection than production in the boundary wells. Also for allocation purposes, the injection rate 
data are more reliable than the oil production data since water injection commenced more recently and is under the control of a single operator.

Reservoir surveillance activities, consisting primarily of pressure transient tests recorded to monitor reservoir pressure and formation flow characteristics, and TDT logs run to monitor water movement in the reservoir, will be performed in and around the modeling areas to obtain additional information for history matching and development forecasting.

\section{Model Initialization}

Initialization of each simulation model requires phase behavior (PVT) data and rock-fluid interaction parameters. Each of the data types required for initialization are discussed below:

\section{PVT Data for Initialization}

The analysis of available fluid data has conclusively established that the fluid properties of the Upper and Lower Clearfork reservoir fluids are different and need to be treated as two separate PVT regions during simulation to properly represent the phase behavior interactions in the reservoir.

Some of the differences between Upper and Lower Clearfork reservoir fluid are illustrated in Table 9. The data are based on black oil PVT laboratory studies conducted on fluid samples obtained from NRU 3522 and 3013 during 1991.

The feasibility of using the original PVT data from bottomhole samples acquired on offset leases in 1947 (Lower Clearfork) and 1958 (Upper Clearfork) was considered. The utilization of this data (Table 10) was considered by using a phase behavior simulator to match the original and recently acquired (1991) PVT data. The validation results indicate that the "original" data may be used to represent PVT properties since the data were found to be consistent with laboratory fluid tests conducted on the surface recombined samples collected in 1991.

The accurate representation of the initial fluid data, along with the integrated reservoir characterization undertaken, will allow the physical processes occurring in the reservoir to be accurately modeled. By using the original data, the simulator will automatically adjust original properties to fluid properties at any subsequent time in the history match or forecast. The fluid properties for the wide range of depletion and repressurization paths can be properly represented.

\section{Rock-Fluid Interaction Data for Initialization}

Existing special core data which will be used for the simulation are primarily relative permeability data. A total of thirteen steady-state displacements for two cored wells (NRU wells 207 and 3522) have been conducted. The displacements include data from the Upper, Middle, and Lower Clearfork. Additional special core work will be completed when new wells are drilled during the field demonstration phase of the project. 


\section{History Match Criteria}

Allocated production data (oil, water, gas) have been determined to be reliable and will be the primary history match criteria. Pressure data are available for the primary depletion phase of the history match (1956-1987). The initial reservoir pressure is known, and pressures prior to water injection and during reservoir fill-up are available for 45 wells throughout the Unit (Table 6). Additional pressure data will be available from pressure falloff and buildup tests that are currently being recorded.

In the initial simulation and history match it will be assumed that there is no flux across the areas to be modeled since all of the model areas lie in multi-patterned waterflood areas of the Unit. It is possible that this simplifying no-flow boundary assumption is invalid due to suspected interwell fracture communication from pressure falloff test results. This assumption may need to be reconsidered on a case-by-case basis for each of the model areas if it is difficult to obtain a history match and it is determined that the flow boundary assumption has an important mechanistic role in the displacement process.

The results of current and future analyses, specifically, geostatistical and 3-D reservoir simulation, will be summarized in great detail in a subsequent work prior to the field demonstration (infill drilling) phase of the project.

\section{CONCLUSIONS}

As a result of this study we hope to identify useful and cost effective measures for the exploitation of the shallow shelf carbonate reservoirs of the Permian Basin. The techniques that are outlined in this work for the formulation of an integrated reservoir description apply to all oil and gas reservoirs, but are specifically tailored for use in the heterogeneous, low permeability carbonate reservoirs of west Texas.

1. A detailed reservoir characterization can be performed with a minimum of core data, as long as a competent geologic model has been constructed, and there is sufficient wireline log, pressure transient, and historical production data available for analysis.

2. It has been noted in previous works $2,3,5,6$ that as well spacing is reduced, estimates of reservoir continuity will decrease. This results in infill recoveries that are greater than what would be expected, as new portions of the reservoir are accessed. This is especially true of heterogeneous shallow-shelf carbonate reservoirs such as we have at the North Robertson Unit.

3. Due to the problems associated with the utilization of older boreholes for recording interwell surveys, the level of heterogeneity in the Glorieta/Clearfork section, and low benefit-cost ratio for this particular Unit, it was determined that the use of cross-borehole tomography as a reservoir characterization tool is not a cost-effective technology at NRU

4. The material balance decline type curve techniques summarized in this work give excellent estimates of reservoir volumes (total and movable), and reasonable estimates of formation 
flow characteristics. Using this method to analyze and interpret long-term production data is relatively straightforward and can provide the same information as conventional pressure transient analysis, without the associated cost of data acquisition, or loss of production.

5. In order to better identify injection well responses and improve the analysis of long-term injection data, we are developing type curve techniques similar to those currently used for decline type curve analysis of production data and pressure transient analysis.

6. At the NRU, we see the same problems that are associated with the majority of heterogeneous, low permeability carbonate reservoirs--a lack of reservoir continuity, low waterflood sweep efficiency, early water breakthrough, and water channeling.

7. Surface pressure acquisition during pressure falloff tests yields data of sufficient quality for interpretation even when low precision pressure gauges are utilized. This is an efficient and cost-effective waterflood surveillance tool.

8. The preferential fracture direction at the NRU appears to be east-west. Several of the injection wells are in communication via hydraulically induced fractures resulting from long-term injection at pressures well above the fracture pressure of the reservoir. We intend to address this problem during Budget Period II by targeting injection intervals and decreasing injection pressures.

9. Injection water quality monitoring should be a major part of an effective waterflood surveillance plan. The plugging and scaling tendencies associated with most carbonate reservoirs can be greatly remediated with vigilant water quality surveillance.

10. The results of the previous hydraulic fracture treatments at the NRU have been relatively poor, resulting in extremely short, low conductivity fractures. Future frac treatments will focus on treating only the intervals that contribute significantly to production, reducing job volumes, and obtaining the optimum fracture conductivity.

11. Aside from the cross-borehole seismic and geostatistical simulation work, all of the data acquisition and analysis techniques used for this integrated reservoir description are readily and economically available to all operators. As with all oil field operations, we recommend that quality data be taken early and often to ensure more accurate analyses and interpretations. 


\section{NOMENCLATURE}

\section{FIELD VARIABLES}

\section{Formation and Fluid Parameters:}

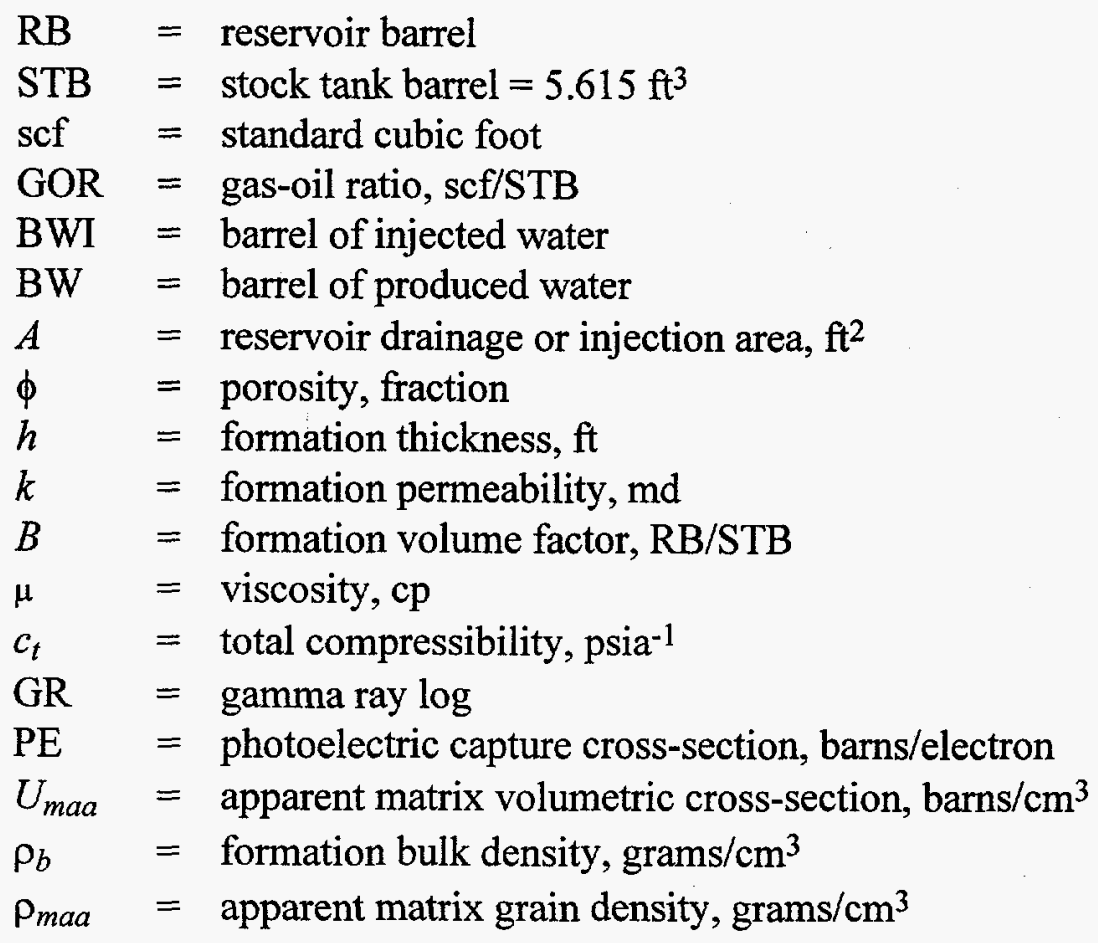

\section{Pressure/Rate/Time Parameters:}

$b=$ Fetkovich $/$ Arps $^{18}$ decline curve exponent

$b_{p s s}=$ constant in the pseudosteady-state equation for liquid flow

$q=$ flow rate, $\mathrm{STB} / \mathrm{D}, \mathrm{BW} / \mathrm{D}$, or BWI/D

$N=$ original oil in place, $\mathrm{STB}$

$N_{p} \quad=$ cumulative oil production, STB

$N_{p, \text { mov }}=$ movable oil, STB

$p \quad=$ pressure, psia

$p_{i} \quad=$ initial reservoir pressure, $\mathrm{psia}$

$p_{w f} \quad=$ flowing bottomhole pressure, psia

$p_{w s}=$ shut-in bottomhole pressure, psia

$\Delta p \quad=\mathrm{p}-p_{w f}$, pressure drop, $\mathrm{psi}$

$r_{e} \quad=$ reservoir drainage radius, $\mathrm{ft}$

$r_{w} \quad=$ wellbore radius, $\mathrm{ft}$

$r_{w a}=r_{w} \exp (-s)$, equivalent wellbore radius, $\mathrm{ft}$

$x_{f} \quad=$ fracture half-length, $\mathrm{ft}$

$t \quad=$ time, days 
$\Delta t \quad=$ shut-in time, hours

$t_{b a r}=N_{p} / q$, material balance time, days (oil production)

\section{DIMENSIONLESS VARIABLES: REAL DOMAIN}

$q_{D d}=$ dimensionless decline rate function as defined by Fetkovich ${ }^{18}$

$q_{D d i}=$ dimensionless decline rate integral as defined by McCray 19

$q_{\text {Ddid }}=$ dimensionless decline rate integral derivative function as defined by McCray 19

$r_{e D}=$ dimensionless drainage radius of reservoir

$s \quad=\quad$ skin factor for near well damage or stimulation

$t_{D d}=$ dimensionless decline time as defined by Fetkovich $^{18}$

$p_{D} \quad=$ dimensionless wellbore pressure function

$p_{D}^{\prime}=$ dimensionless wellbore pressure function derivative

$C_{D f}=$ dimensionless wellbore storage coefficient based on fracture half-length

$C_{f \mathcal{D}}=$ dimensionless fracture conductivity

$t_{L f D}=$ dimensionless time based on the fracture half-length

\section{SPECIAL SUBSCRIPTS:}

$\begin{array}{ll}\text { Dd } & =\text { dimensionless decline variable } \\ \text { MP } & =\text { match point } \\ p s s & =\text { pseudosteady-state } \\ i & =\text { integral or initial } \\ i d & =\text { integral derivative } \\ o & =\text { oil } \\ w & =\text { water } \\ w i & =\text { water injection } \\ a b s & =\text { absolute }\end{array}$

\section{REFERENCES}

1. Ghauri, W.K., et al:: "Changing Concepts in Carbonate Waterflooding - West Texas Denver Unit Project - An Illustrative Example," JPT (June 1974) 595-606.

2. Stiles, L.H.: "Optimizing Waterflood Recovery in a Mature Waterflood, The Fullerton Clearfork Unit," paper SPE 6198 presented at the 1976 SPE Annual Fall Technical Conference and Exhibition, New Orleans, LA, October 3-6.

3. George, C.J. and Stiles, L.H.: "Improved Techniques for Evaluating Carbonate Waterfloods in West Texas," JPT (November 1978) 1547-1554.

4. Ghauri, W.K.: "Production Technology Experience in a Large Carbonate Waterflood, Denver Unit, Wasson San Andres Field," JPT (September 1980) 1493-1502.

5. Barber, A.H., et al:: "Infill Drilling to Increase Reserves - Actual Experience in Nine Fields in Texas, Oklahoma, and Illinois," JPT, (August 1983) 1530-1538. 
6. Barbe, J.A. and Schnoebelen, D.J.: "Quantitative Analysis of Infill Performance: Robertson Clearfork Unit," JPT, (December 1987) 1593-1601.

7. David K. Davies \& Associates, Inc.: Geological-Petrophysical Reservoir Characterization, presented at North Robertson Unit internal meeting, July 13, 1993, Midland, TX.

8. Calhoun, J.C.: "Fundamentals of Reservoir Engineering," University of Oklahoma Press, Norman, (1982).

9. Ehrlich, R. and Davies, D.K.: "Image Analysis of Pore Geometry: Relationship to Reservoir Engineering and Modeling," paper SPE 19054 presented at the 1989 SPE Gas Technology Symposium, Dallas, TX, June 7-9.

10. Wardlaw, N.C. and Cassan, J.P.: "Estimation of Recovery Efficiency by Visual Observation of Pore Systems in Reservoir Rocks," Bulletin Canadian Petroleum Geology, 26 (1978).

11. Thomeer, J.M.: "Introduction of a Pore Geometrical Factor Defined by the Capillary Pressure Curve," JPT, (March 1960), 73-77.

12. Hutt, P.R., et al:: "Applications of Cross-Borehole Seismic Tomography to Monitor EOR Displacement Fronts in Heavy Oil Fields of Kern County, California," paper SPE 19855 presented at the 1989 SPE Annual Technical Conference and Exhibition, San Antonio, TX, October 8-11.

13. Harris, J.M.: "Cross-Well Seismic Measurements in Sedimentary Rocks," paper SPE 19871 presented at the 1989 SPE Annual Technical Conference and Exhibition, San Antonio, TX, October 8-11.

14. Baker, L.J. and Harris, J.M.: "Cross-Borehole Seismic Imaging," presented at the 1984 Annual Meeting of the SEG, Atlanta, GA, December 2-6.

15. Bregman, N.D., Hurley, P.A., and West., G.F.: "Seismic Tomography at a Fire-Flood Site," Geophysics, (1989) 54, 1082-1090.

16. Chon, Yu-Taik: "Crosswell Bed Connectivity Analysis," presented at the 1993 SEG International Exposition, Washington, D.C., September 26-30.

17. Doublet, L.E., et al:: "Decline Curve Analysis Using Type Curves--Analysis of Oil Well Production Data Using Material Balance Time: Application to Field Cases," paper SPE 28688 presented at the 1994 Petroleum Conference and Exhibition of Mexico, Veracruz, Mexico, October $10-13$.

18. Fetkovich, M.J.: "Decline Curve Analysis Using Type Curves," JPT (June 1980) 1065-1077.

19. McCray, T.L.: Reservoir Analysis Using Production Decline Data and Adjusted Time, M.S. Thesis, Texas A\&M University, College Station, TX (1990).

20. Palacio, J.C. and Blasingame, T.A.: "Decline Curve Analysis Using Type Curves: Analysis of Gas Well Production Data ," paper SPE 25909 presented at the 1993 SPE Rocky Mountain Regional/Low Permeability Reservoirs Symposium, Denver, CO, April 12-14.

21. Jordan, J.K.: "Reliable Interpretation of Waterflood Production Data," JPT (August 1958) 18-24.

22. Hall, H.N.: "How to analyze waterflood injection well performance," World Oil (October 1963) 
128-130.

23. Thakur, G.C.: "Waterflood Surveillance Techniques - A Reservoir Management Approach," JPT (October 1991) 1180-1188.

24. Robertson, D.C. and Kelm, C.H.: "Injection-Well Testing to Optimize Waterflood Performance," $J P T$ (November 1975) 1337-1342.

25. Nevans, J.W., Pande, P.K., and Clark, M.B.: "Improved Reservoir Management With Water Quality Enhancement at the North Robertson Unit," paper SPE 27668 presented at the 1994 SPE Permian Basin Oil and Gas Recovery Conference, Midland, TX, March 16-18.

26. Banthia, B.S., Meyer, B.J., and Blasingame, T.A.: "Use of Surface-Derived Pressure Measurements for Cost-Effective Reservoir Surveillance of Waterflood Operations in the Permian Basin," paper SPE 27685 presented at the 1994 SPE Permian Basin Oil and Gas Recovery Conference, Midland, TX, March 16-18.

27. Hazebroek, P., Rainbow, H., and Matthews, C.S.: "Pressure Fall-Off in Water Injection Wells," Trans., AIME (1958), 213, 250-260.

28. Matheron, G.: The Theory of Regionalised Variables and its Applications, Cahier No. 5, Centre de Morphologie Mathematique de Fountainbleau (1971).

29. Kelkar, M.: "Introduction to Geostatistics," Tutorial Paper presented at the 1991 International Reservoir Characterization Conference, Tulsa, OK.

30. Kelkar, M.: Applied Geostatistics For Reservoir Characterization, draft, University of Tulsa, Tulsa, OK, (1993).

31. Igor-Graphing and Data Analysis Program (Version 2.7), WaveMetrics, Lake Oswego, OR, USA, 1992.

32. The Production Analyst Program (Version 2.3), OGCI Software, Inc., Tulsa, OK, USA, 1993.

33. PanSystemTM-Well Test Analysis Program (Version 1.8), Edinburgh Petroleum Services, Ltd., Edinburgh, Scotland, UK, April 1991.

34. Terrasciences Reservoir Analysis Package (Version 5.4), Terrasciences, Inc., Littleton, CO, USA, 1994.

35. SAS (Version 6.08), SAS Institute, Inc., Cary, NC, USA, 1993. 


\section{TABLE 1 - Reservoir and Fluid Property Data for the North Robertson (Clearfork) Unit.}

Reservoir Properties

Wellbore radius, $r_{w}$

Estimated average gross pay interval

Average net pay thickness, $h$

Average porosity (limestone matrix), $\phi$

Average irreducible water saturation, $S_{\text {wirr }}$

Formation permeability, $k$

Reservoir temperature

Original nominal well spacing

Current nominal well Spacing

$$
\begin{gathered}
0.31 \text { feet } \\
1200-1500 \text { feet } \\
\text { variable } \\
0.075 \\
0.30 \\
0.1-10 \mathrm{md} \\
110^{\circ} \mathrm{F} \\
40 \text { acres } \\
20 \text { acres }
\end{gathered}
$$

\section{Fluid Properties}

Initial saturation pressure

$1700 \mathrm{psia}(\mathrm{UCF})$

1540 psia (LCF)

Initial formation volume factor, $B$ $1.285 \mathrm{RB} / \mathrm{STB}$ (UCF)

$1.382 \mathrm{RB} / \mathrm{STB}$ (LCF)

Initial oil viscosity, $\mu$

$1.05 \mathrm{cp}$ (UCF)

$0.81 \mathrm{cp}$ (LCF)

Initial total compressibility, $c_{t i}$

$12.0 \times 10^{-6} \mathrm{psi}^{-1}$

Initial API oil gravity at $60^{\circ} \mathrm{F} / 60^{\circ} \mathrm{F}$

Average formation volume factor, $B$

Average oil viscosity, $\mu$

$34.4^{\circ}$ (UCF)

$39.6^{\circ}(\mathrm{LCF})$

$1.30 \mathrm{RB} / \mathrm{STB}$

Average total compressibility, $c_{t}$

$1.30 \mathrm{cp}$

$25.0 \times 10^{-6} \mathrm{psi}^{-1}$

Production Parameters

Initial reservoir pressure, $p_{i}$

$2625 \mathrm{psia}$ (UCF) 2950 psia (LCF)

Flowing bottomhole pressure, $p_{w f}$ 
TABLE 2 - Pore Types Identified From Core Thin-sections, XRD, and SEM Analysis, after Davies (Ref. 7).

\begin{tabular}{|c|c|c|c|c|c|c|}
\hline $\begin{array}{c}\text { Pore } \\
\text { Type }\end{array}$ & $\begin{array}{c}\text { Size } \\
(\boldsymbol{\mu} \text { m) }\end{array}$ & Shape & $\begin{array}{c}\text { Coordination } \\
\text { Number }\end{array}$ & Aspect Ratio & Arrangement & $\begin{array}{c}\text { Geologic } \\
\text { Description }\end{array}$ \\
\hline A & 30 to 100 & $\begin{array}{c}\text { Triangular } \\
\text { (Interparticle) }\end{array}$ & $\begin{array}{c}3 \text { to } 6 \\
\text { (Moderate) }\end{array}$ & $\begin{array}{c}>50-100: 1 \\
\text { (Moderate) }\end{array}$ & Interconnected & $\begin{array}{c}\text { Primary } \\
\text { Interparticle }\end{array}$ \\
\hline $\mathrm{B}$ & 60 to 120 & $\begin{array}{c}\text { Irregular } \\
\text { (Generally } \\
\text { elongate) }\end{array}$ & $\begin{array}{c}<3 \\
\text { (Low) }\end{array}$ & $\begin{array}{c}\text { up to } 200: 1 \\
\text { (High) }\end{array}$ & Isolated Molds - \\
Dissolution Vugs \\
C
\end{tabular}


TABLE 3 - Rock Types Defined for the Clearfork and Glorieta Formations, after Davies (Ref. 7).

\begin{tabular}{|c|c|c|c|c|c|c|c|c|}
\hline $\begin{array}{l}\text { Rock } \\
\text { Type }\end{array}$ & "Lithology & $\begin{array}{l}\text { Dominant } \\
\text { Pore Type }\end{array}$ & $\begin{array}{l}\text { Secondary } \\
\text { Pore Types }\end{array}$ & $\begin{array}{c}\text { Average Core } \\
\text { Porosity } \\
\text { (\%) }\end{array}$ & $\begin{array}{c}\begin{array}{c}\text { Average Core } \\
\text { Permeability } \\
\text { (md) }\end{array}\end{array}$ & $\begin{array}{c}\text { Recovery } \\
\text { Efficiency } \\
\text { (\%) }\end{array}$ & $\begin{array}{c}\text { Reservoir } \\
\text { Quality }\end{array}$ & $\begin{array}{c}\text { Crossflow } \\
\text { Barrier } \\
\text { Quality }\end{array}$ \\
\hline 1 & Dolostone & A & B,C,D & 5.41 & 5.52 & $35-45$ & Excellent & Poor \\
\hline 2 & Dolostone & $\mathrm{B}, \mathrm{C}$ & $\mathrm{D}, \mathrm{E}$ & 6.10 & 1.73 & $30-35$ & Good & Poor \\
\hline 3 & Dolostone & $\mathrm{C}$ & $\mathrm{D}, \mathrm{E}$ & 4.19 & 0.20 & $20-30$ & Poor & Moderate \\
\hline 4 & Dolostone & B & $F$ & 6.09 & 0.02 & 35 & Poor & Moderate \\
\hline 5 & Limestone & $\mathrm{C}$ & $\mathrm{A}, \mathrm{D}, \mathrm{E}, \mathrm{F}$ & 7.52 & 0.14 & $\begin{array}{c}30-35 \\
\text { (Water } \\
\text { Bearing) }\end{array}$ & $\begin{array}{c}\text { Good } \\
\text { (Water } \\
\text { Bearing) }\end{array}$ & Poor \\
\hline 6 & $\begin{array}{l}\text { Anhydritic } \\
\text { Dolostone }\end{array}$ & C,D & $F$ & 1.89 & 0.03 & 0 & None & Good \\
\hline 7 & $\begin{array}{c}\text { Silty } \\
\text { Dolostone }\end{array}$ & $\mathrm{E}, \mathrm{F}$ & -- & 3.61 & 0.01 & 0 & None & Good \\
\hline 8 & Shale & G & -- & 3.73 & 0.01 & 0 & None & Good \\
\hline
\end{tabular}


TABLE 4 - Quantitative Analysis of Mercury-Air Capillary Pressure Data, after Davies (Ref. 7).

\begin{tabular}{|c|c|c|c|}
\hline $\begin{array}{c}\text { Rock } \\
\text { Type }\end{array}$ & $\begin{array}{c}\text { Throat Radius } \\
(\mu \mathrm{m})\end{array}$ & $\begin{array}{c}\text { Displacement } \\
\text { Pressure } \\
\text { (psia) }\end{array}$ & $\begin{array}{c}\text { Ineffective Porosity } \\
\text { at 500 psia } \\
\text { Injection Pressure } \\
(\%)\end{array}$ \\
\hline \hline 1 & $7.61-53.30$ & $2-10$ & $8.2-29.6$ \\
\hline 2 & $2.67-3.55$ & $30-40$ & $23.1-49.5$ \\
\hline 3 & $0.36-1.33$ & $80-300$ & $61.6-72.3$ \\
\hline 4 & 1.77 & 60 & 88.0 \\
\hline 5 & $1.07-1.78$ & $60-150$ & $21.7-57.2$ \\
\hline 6 & 0.133 & 800 & 100 \\
\hline 7 & -- & -- & - \\
\hline 8 & -- & -- & \\
\hline
\end{tabular}




\section{TABLE 5 - Material Balance Decline Type Curve Results}

\section{NRU - All Unit Wells}

OOIP, MMSTB

280.0

Total Primary EUR, MSTB

20.0

Primary Recovery Factor, \%

7.1

Total Secondary EUR, MSTB

18.0

Secondary Recovery Factor, \%

6.4

NRU - Individual 40-acre Primary Wells

OOIP, MMSTB

261.8

Total Primary EUR, MSTB

19.6

Average Primary EUR, MSTB

Average Primary Recovery Factor, \%

Average Primary $k h, \mathrm{md}-\mathrm{ft}$

Average Primary Drainage Area, acres

NRU - Individual 20-acre Secondary Wells

Total Secondary EUR, MSTB

Average Secondary EUR, MSTB

91.3

Average Secondary Recovery Factor, \%

Average Secondary $k h, \mathrm{md}-\mathrm{ft}$ 
TABLE 6 - Bottomhole Pressure Data For Reservoir Simulation History Matching.

\begin{tabular}{|c|c|c|c|c|c|c|}
\hline \multirow[b]{2}{*}{ SECTION NO. } & \multicolumn{2}{|c|}{$\begin{array}{c}\text { Prior to Unitization } \\
(3 / 87)\end{array}$} & \multicolumn{2}{|c|}{$\begin{array}{c}\text { During Fillup Period } \\
(10 / 88-11 / 88)\end{array}$} & \multicolumn{2}{|c|}{$\begin{array}{c}\text { End of Reservoir Fillup } \\
\qquad(7 / 90-5 / 91)\end{array}$} \\
\hline & WELL NO. & $\begin{array}{l}\text { SIBHP } \\
\text { (psia) }\end{array}$ & WELL NO. & $\begin{array}{l}\text { SIBHP } \\
\text { (psia) }\end{array}$ & WELL NO. & $\begin{array}{l}\text { SIBHP } \\
\text { (psia) }\end{array}$ \\
\hline 5 & $\begin{array}{l}101 \\
204 \\
304\end{array}$ & $\begin{array}{l}202 \\
653 \\
452\end{array}$ & $\begin{array}{c}201 \\
208 \\
307 \\
1008 \\
\end{array}$ & $\begin{array}{c}1033 \\
719 \\
1157 \\
985\end{array}$ & 307 & 2200 \\
\hline 7 & & & & & 4104 & 1320 \\
\hline 8 & 2901 & 584 & 4202 & 507 & 4202 & 1280 \\
\hline 9 & 1601 & 564 & & & & \\
\hline 292 & $\begin{array}{l}2102 \\
2105\end{array}$ & $\begin{array}{c}268 \\
1247\end{array}$ & 2108 & 706 & 2108 & 1200 \\
\hline 325 & $\begin{array}{l}2203 \\
2209 \\
2211 \\
2216\end{array}$ & $\begin{array}{c}536 \\
1007 \\
776 \\
719 \\
\end{array}$ & $\begin{array}{l}2217 \\
2224 \\
2225\end{array}$ & $\begin{array}{l}1350 \\
1074 \\
1228\end{array}$ & $\begin{array}{l}2217 \\
2224 \\
2225\end{array}$ & $\begin{array}{l}1010 \\
2400 \\
1550\end{array}$ \\
\hline 326 & $\begin{array}{c}602 \\
2802\end{array}$ & $\begin{array}{l}375 \\
953\end{array}$ & $\begin{array}{c}804 \\
2704 \\
2804\end{array}$ & $\begin{array}{l}985 \\
1431 \\
1296\end{array}$ & $\begin{array}{c}804 \\
2704 \\
2804\end{array}$ & $\begin{array}{l}2100 \\
1130 \\
1410\end{array}$ \\
\hline 327 & $\begin{array}{l}1504 \\
3001 \\
3003 \\
3006 \\
3008 \\
3104 \\
\end{array}$ & $\begin{array}{c}804 \\
372 \\
1001 \\
1159 \\
257 \\
776 \\
\end{array}$ & $\begin{array}{l}1506 \\
3011\end{array}$ & $\begin{array}{l}840 \\
992\end{array}$ & $\begin{array}{l}1506 \\
3013\end{array}$ & $\begin{array}{l}1900 \\
1550\end{array}$ \\
\hline 328 & $\begin{array}{l}1403 \\
3206 \\
\end{array}$ & $\begin{array}{l}320 \\
473 \\
\end{array}$ & & & & \\
\hline 329 & $\begin{array}{l}3501 \\
3506 \\
3516\end{array}$ & $\begin{array}{l}1958 \\
1077 \\
867\end{array}$ & $\begin{array}{l}3510 \\
3517 \\
3523\end{array}$ & $\begin{array}{c}394 \\
939 \\
1199\end{array}$ & 3517 & 2100 \\
\hline
\end{tabular}


TABLE 7 - North Robertson Unit Deepenings - Producer Wells

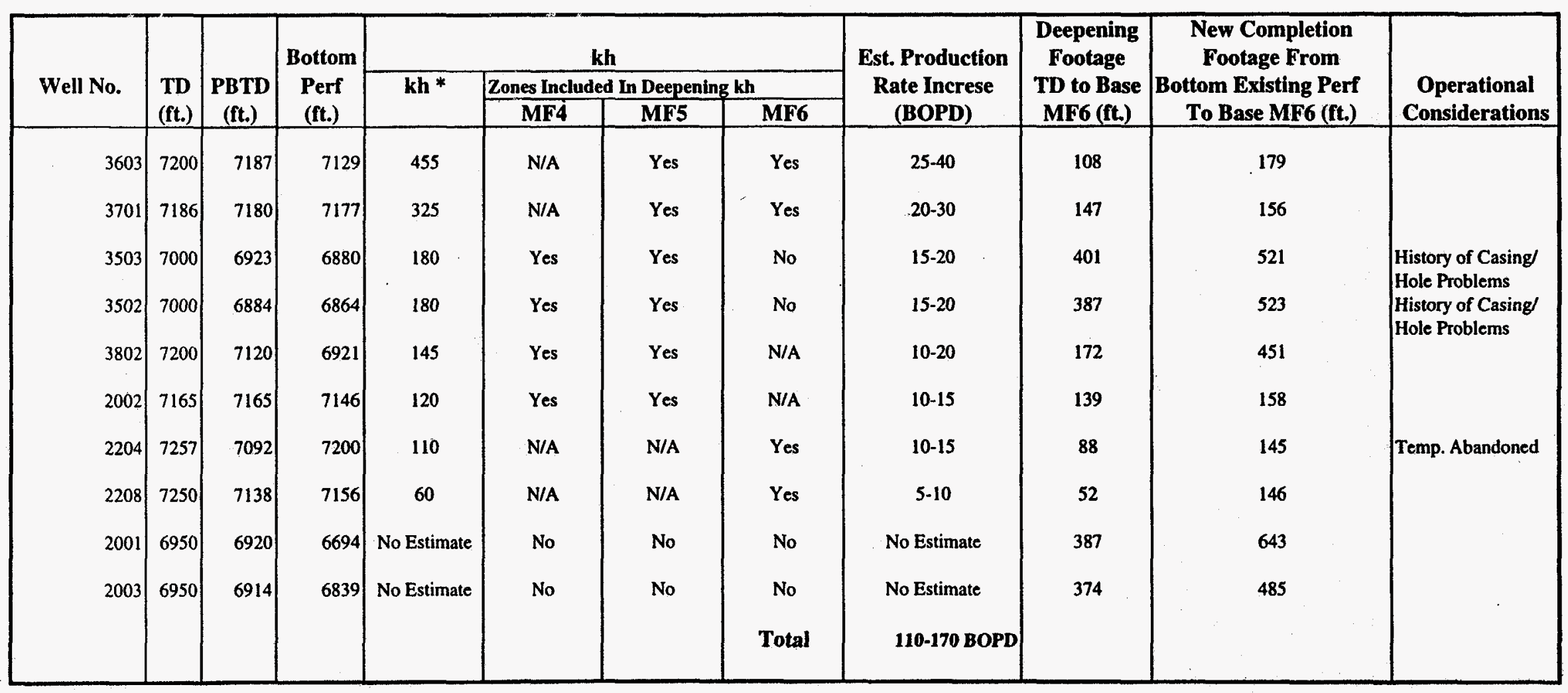

Notes on kh :

* : kh Reflects air permeability $\mathrm{k}$; Liquid permeabilities will be factor of 5-10 less

N/A : Not Applicable; Well has penetrated this marker

No Estimate : No estimate of kh made since wells are outside reasonable confidence interval for quantitative estimate 
TABLE 8 - North Robertson Unit Deepenings - Injector Wells

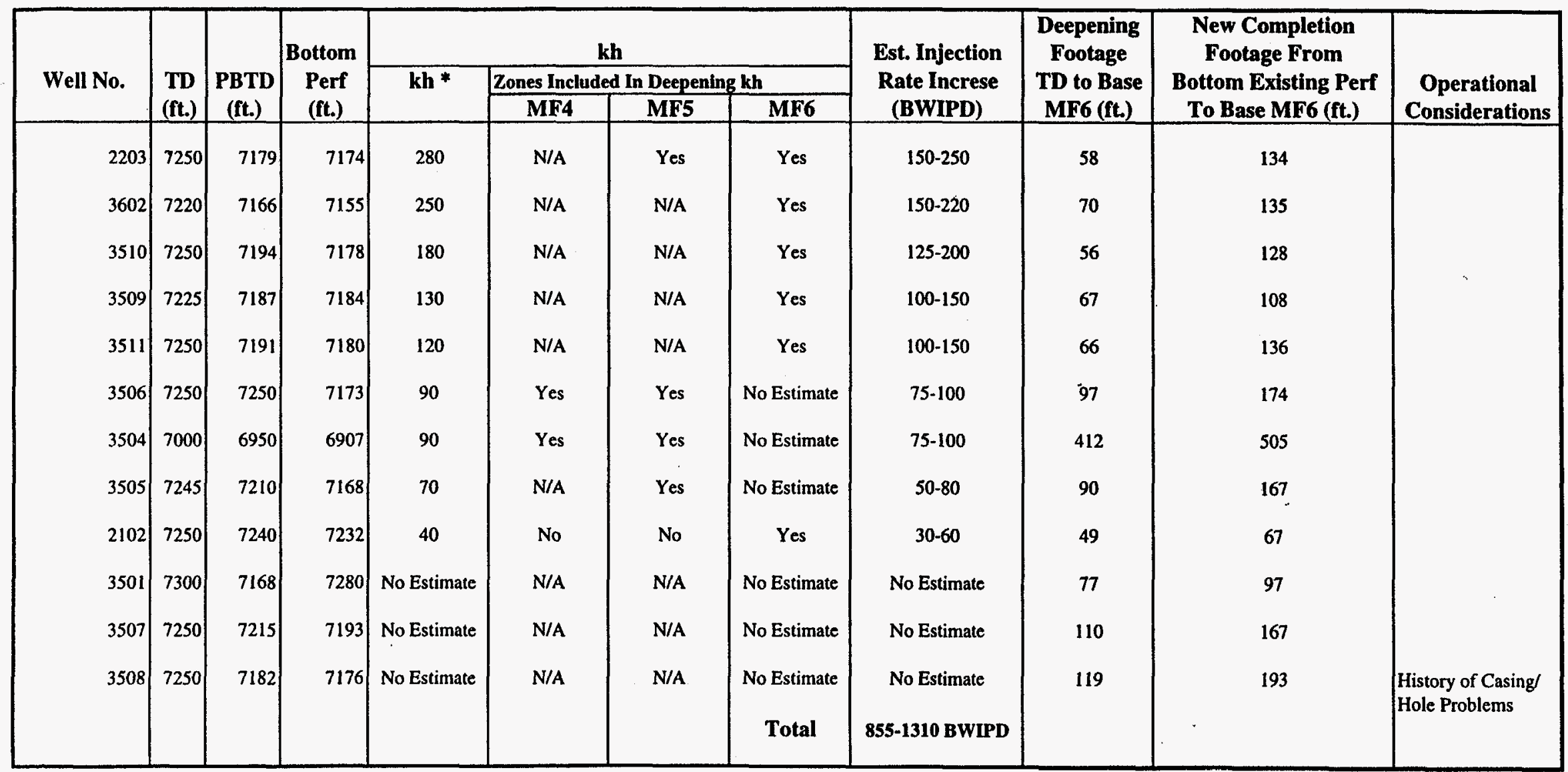

Notes on kh :

* : : kh Reflects air permeability $k$; Liquid permeabilities will be factor of 5-10 less

N/A : Not Applicable; Well has penetrated this marker

No Estimate : No estimate of kh made since wells are outside reasonable confidence interval for quantitative estimate 
TABLE 9 - Results of PVT Analysis on 1991 Surface Fluid Samples (Upper \& Lower Clearfork)

\begin{tabular}{|c|c|c|}
\hline Fluid Properties & $\begin{array}{c}\text { NRU 3522 } \\
\text { (Section 329) }\end{array}$ & $\begin{array}{c}\text { NRU 3013 } \\
\text { (Section 327) }\end{array}$ \\
\hline \hline Zone & Upper Clearfork & Lower Clearfork \\
\hline Sampling Date & February 7, 1991 & February 11, 1991 \\
\hline $\begin{array}{c}\text { Recombination Bubble } \\
\text { Point }\end{array}$ & $1,330 \mathrm{psia}$ & $1,305 \mathrm{psia}$ \\
\hline $\begin{array}{c}\text { Oil Viscosity at Bubble } \\
\text { Point }\end{array}$ & $2.67 \mathrm{cp}$ & $1.32 \mathrm{cp}$ \\
\hline $\begin{array}{c}\text { Oil Formation Volume } \\
\text { Factor at Bubble Point }\end{array}$ & $1.132 \mathrm{RB} / \mathrm{STB}$ & $1.280 \mathrm{RB} / \mathrm{STB}$ \\
\hline $\begin{array}{c}\text { Oil Density at Bubble } \\
\text { Point }\end{array}$ & $0.848 \mathrm{gm} / \mathrm{cc}$ & $0.762 \mathrm{gm} / \mathrm{cc}$ \\
\hline $\begin{array}{c}\text { Stock Tank Oil API } \\
\text { Gravity at 60\% }\end{array}$ & $30.5^{\circ}$ & $33.5^{\circ}$ \\
\hline
\end{tabular}


TABLE 10 - Results of PVT Analysis on Original Bottomhole Fluid Samples (Upper \& Lower Clearfork)

\begin{tabular}{|c|c|c|}
\hline Fluid Properties & Well Fee B-2L & Well Fee E-4U \\
\hline Zone & Upper Clearfork & Lower Clearfork \\
\hline Sampling Date & July 16,1958 & January 17, 1947 \\
\hline $\begin{array}{c}\text { "Original" Bubble Point } \\
\text { Pressure }\end{array}$ & 1,700 psia & $1,540 \mathrm{psia}$ \\
\hline $\begin{array}{c}\text { Initial Reservoir } \\
\text { Pressure }\end{array}$ & $2,625 \mathrm{psia}$ & $2950 \mathrm{psia}$ \\
\hline $\begin{array}{c}\text { Oil Viscosity at Bubble } \\
\text { Point }\end{array}$ & $1.05 \mathrm{cp}$ & $0.81 \mathrm{cp}$ \\
\hline $\begin{array}{c}\text { Oil Formation Volume } \\
\text { Factor at Bubble Point }\end{array}$ & $1.285 \mathrm{RB} / \mathrm{STB}$ & $1.382 \mathrm{RB} / \mathrm{STB}$ \\
\hline $\begin{array}{c}\text { Stock Tank Oil API } \\
\text { Gravity at 60\% }\end{array}$ & $34.4^{\circ}$ & $39.6^{\circ}$ \\
\hline
\end{tabular}




\begin{tabular}{|c|c|c|}
\hline SYSTEM & SERIES & $\begin{array}{c}\text { CENTRAL BASIN } \\
\text { PLATFORM }\end{array}$ \\
\hline QUATERNARY & Holocene & Holocene Sand \\
\hline TERTIARY & Pliocene & Ogallala \\
\hline CRETACEOUS & $\begin{array}{c}\text { Gulfian } \\
\text { Comanchean }\end{array}$ & Limestone \\
\hline JURASSIC & Absent & $x_{0}$ \\
\hline TRIASSIC & & Dockum \\
\hline \multirow{5}{*}{ PERMIAN } & Ochoa & $\begin{array}{c}\text { Dewey Lake } \\
\text { Rustler } \\
\text { Salado }\end{array}$ \\
\hline & Guadalupe & $\begin{array}{ccc} & \text { A } & \mathbf{G} \\
\text { Tansill } & \text { r } & \mathbf{r} \\
\text { Yates } & \text { t } & o \\
\text { Seven Rivers } & \text { e } & \mathbf{u} \\
\text { Queen } & \text { s } & \text { p } \\
\text { Grayburg } & \text { i } & \\
& \text { a }\end{array}$ \\
\hline & & $\begin{array}{l}\text { San Andres } \\
\text { Glorieta Ss. }\end{array}$ \\
\hline & Leonard & $\begin{array}{c}\text { Clear Fork } \\
\text { Wichita Albany }\end{array}$ \\
\hline & Wolfcamp & Wolfcamp \\
\hline \multirow{5}{*}{ PENNSYLVANIAN } & Virgil & \\
\hline & Missouri & \\
\hline & Des Moines & Strawn \\
\hline & Atoka & Atoka \\
\hline & Morrow & Morrow \\
\hline \multirow{4}{*}{ MISSISSIPPIAN } & Chester & \\
\hline & Meramec & Osage-Meramiec \\
\hline & Osage & \\
\hline & Kinderhook & Kinderhook \\
\hline \multirow[t]{2}{*}{ DEVONIAN } & \multirow{2}{*}{$\begin{array}{l}\text { Upper } \\
\text { Middle }\end{array}$} & Woodford \\
\hline & & Thirty one \\
\hline SILURIAN & Middle & $\begin{array}{c}\text { Wristen } \\
\text { Fusselman }\end{array}$ \\
\hline \multirow[t]{2}{*}{ ORDOVICIAN } & $\begin{array}{l}\text { Upper } \\
\text { Middle }\end{array}$ & $\begin{array}{l}\text { Montoya } \\
\text { Simpson }\end{array}$ \\
\hline & Lower & Ellenburger \\
\hline CAMBRIAN & Upper & Cambrian Ss. \\
\hline PRE CAMBRIAN & & Pre Cambrian \\
\hline
\end{tabular}

Figure 1 - Stratigraphic Units of the Central Basin Platform Area of the Permian Basin Region 


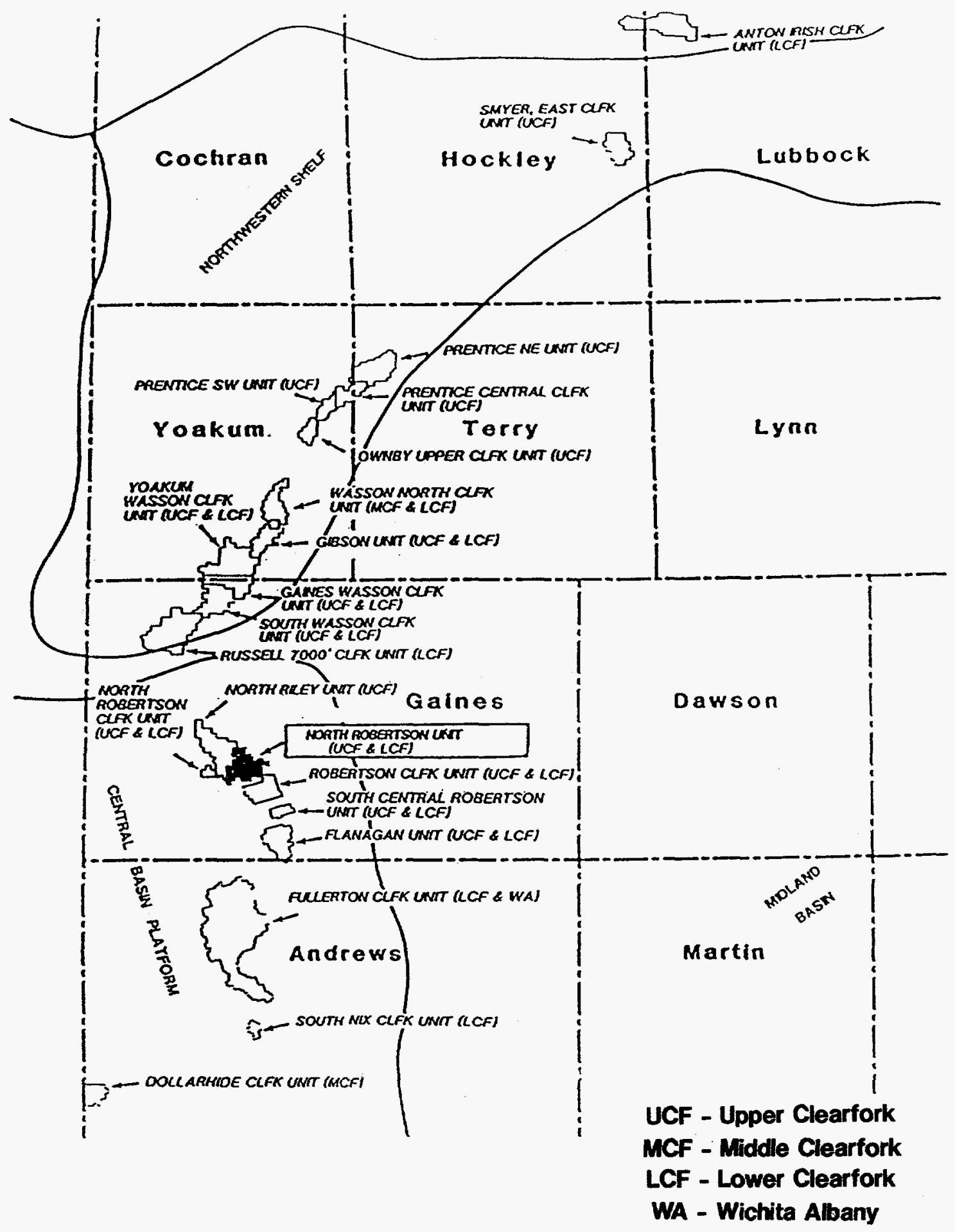

Figure 2 - Clearfork Waterflood Projects in the Permian Basin 


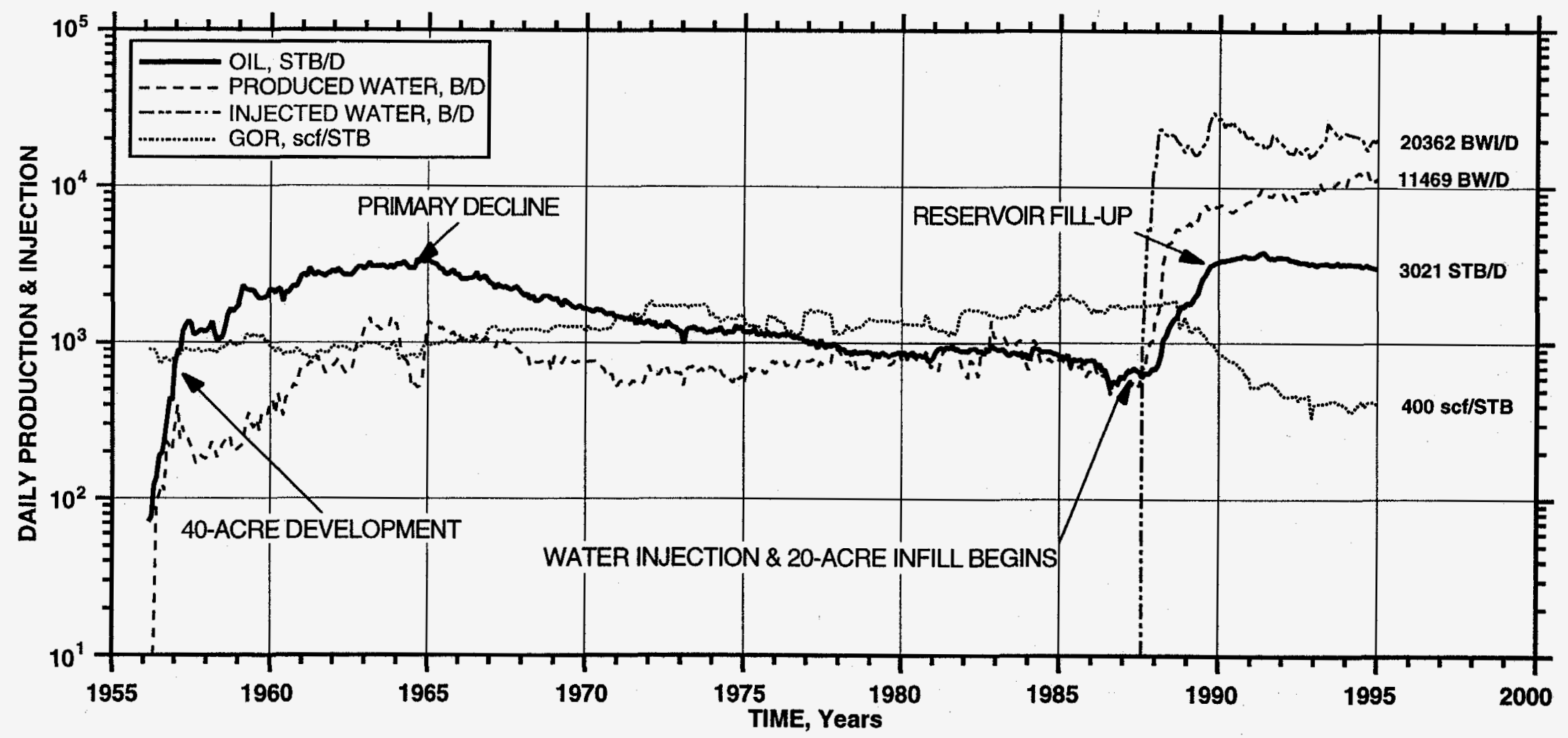

Figure 3 - Production and Injection History for the North Robertson (Clearfork) Unit. 







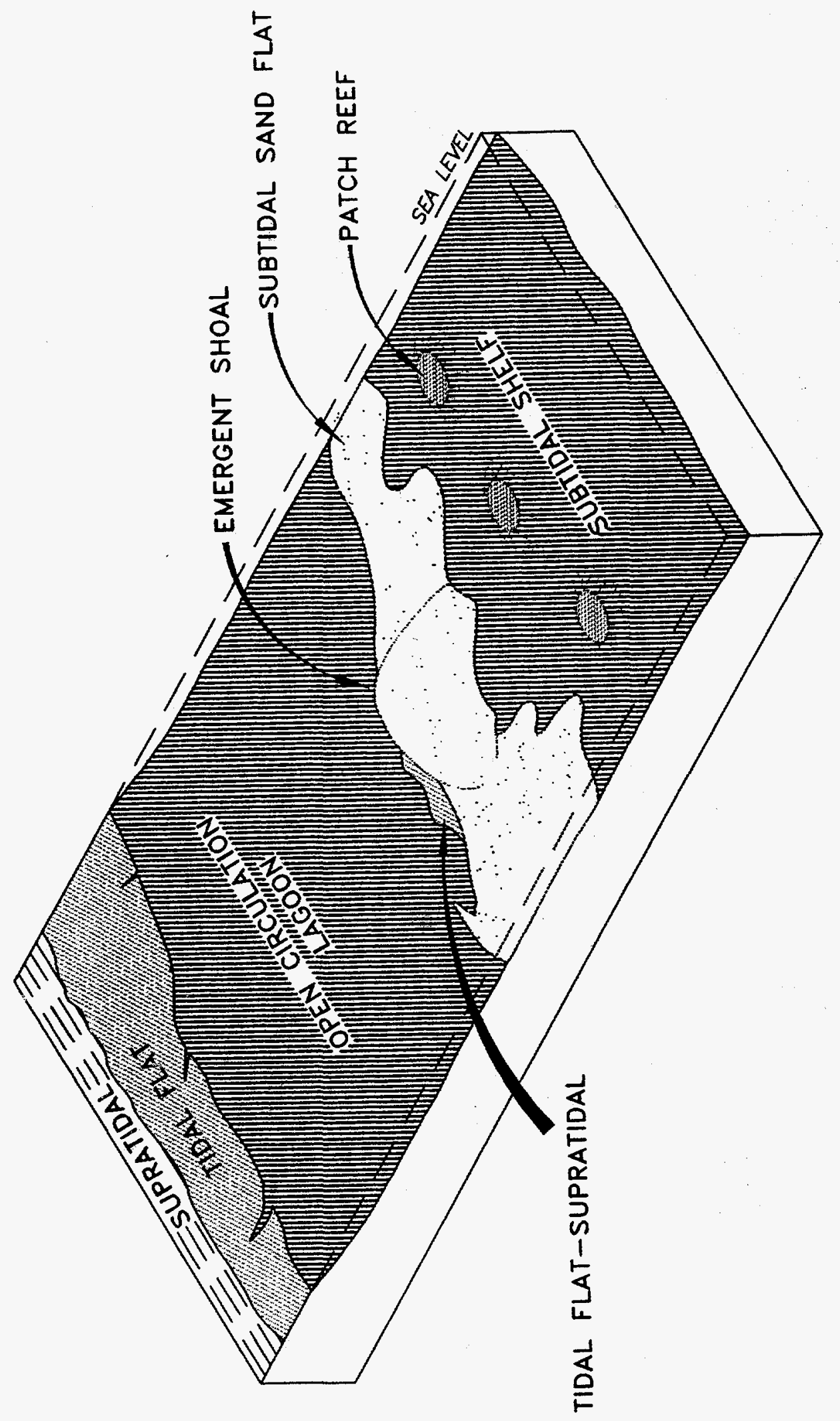




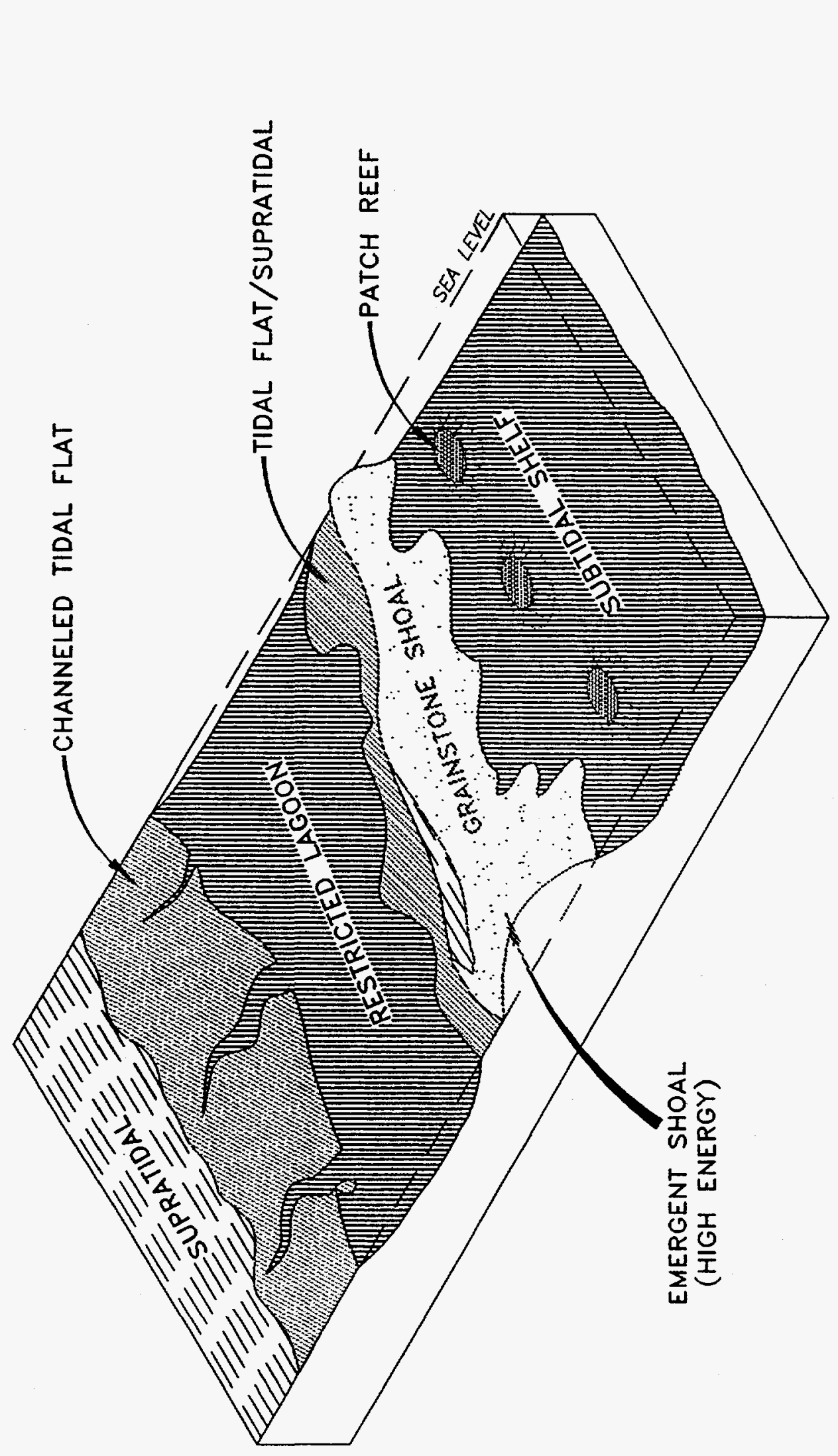

定

$\frac{9}{2}$

(5)

은

음

$\frac{x}{8}$

这

눙

응

응

올

क्ष

온

8

a

'

인 




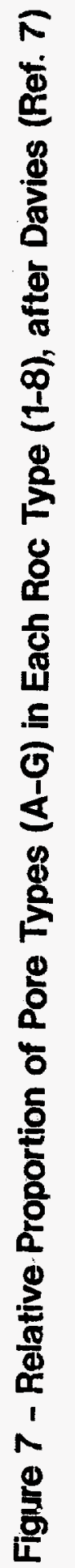




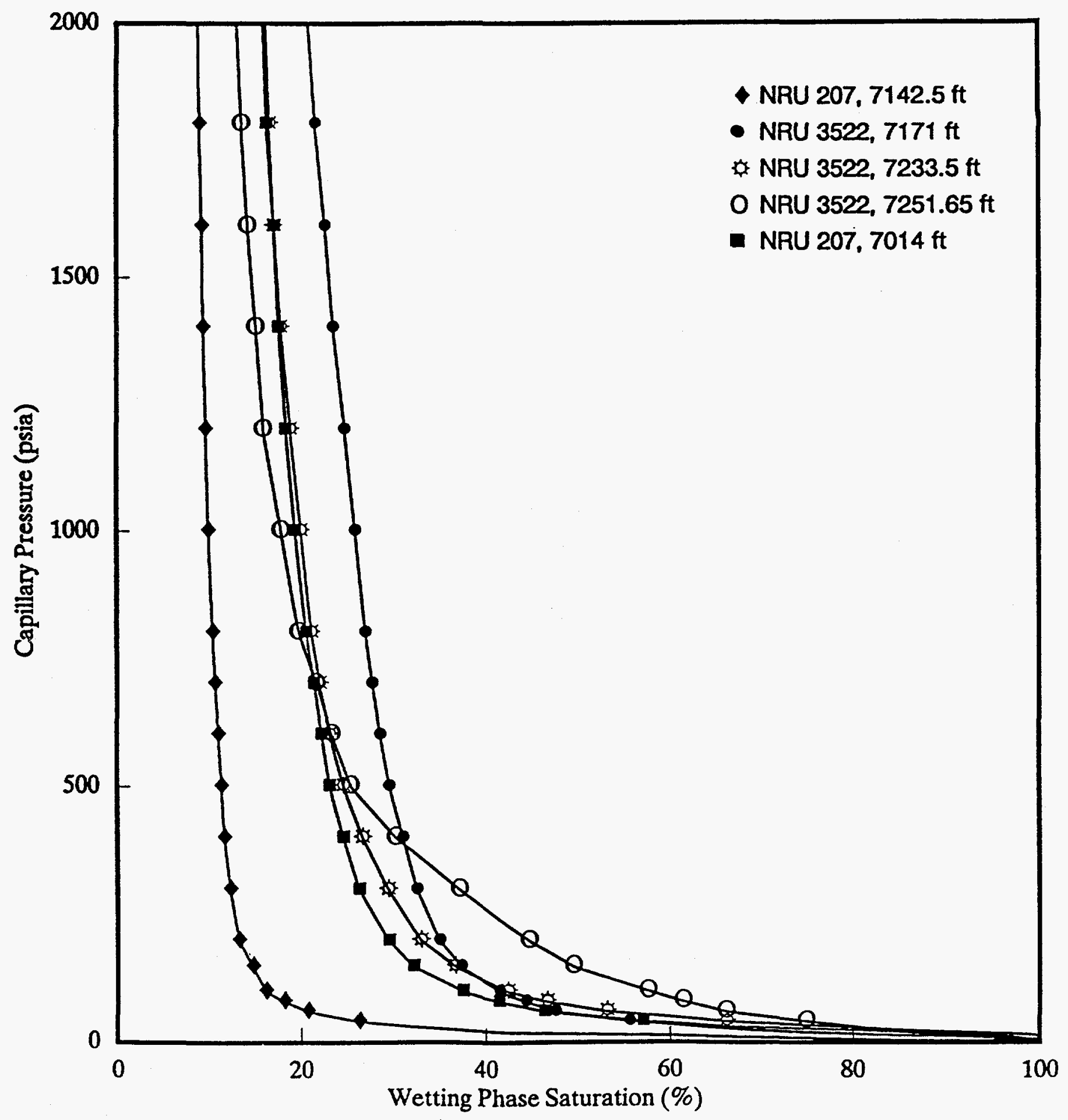

Figure 8 - Mercury/Air Capillary Pressure Curves - Rock Type 1, after Davies (Ref. 7) 


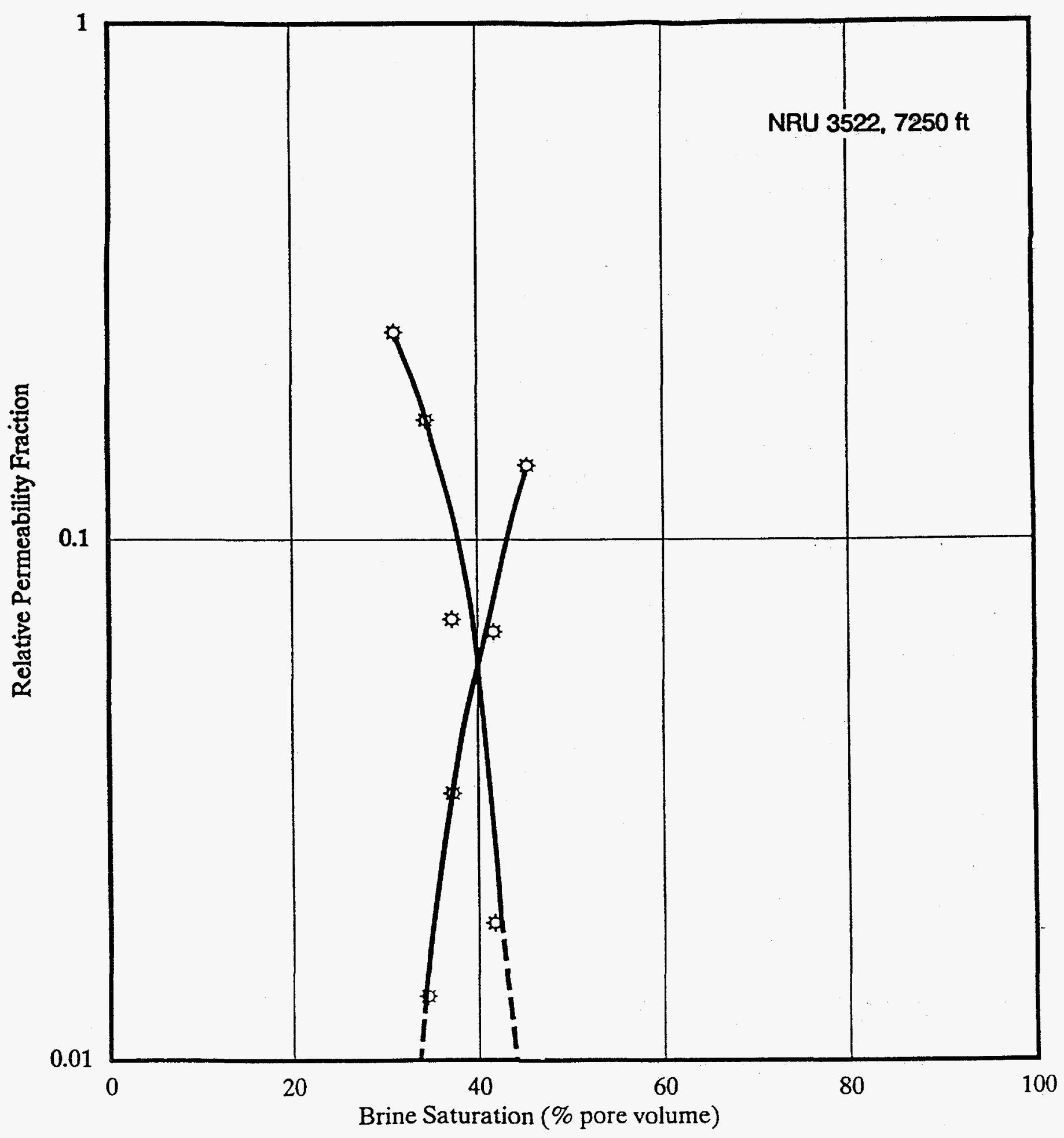

Figure 9 - Water/Oil Relative Permeability Curves - Rock Type 1, after Davies (Ref. 7) 


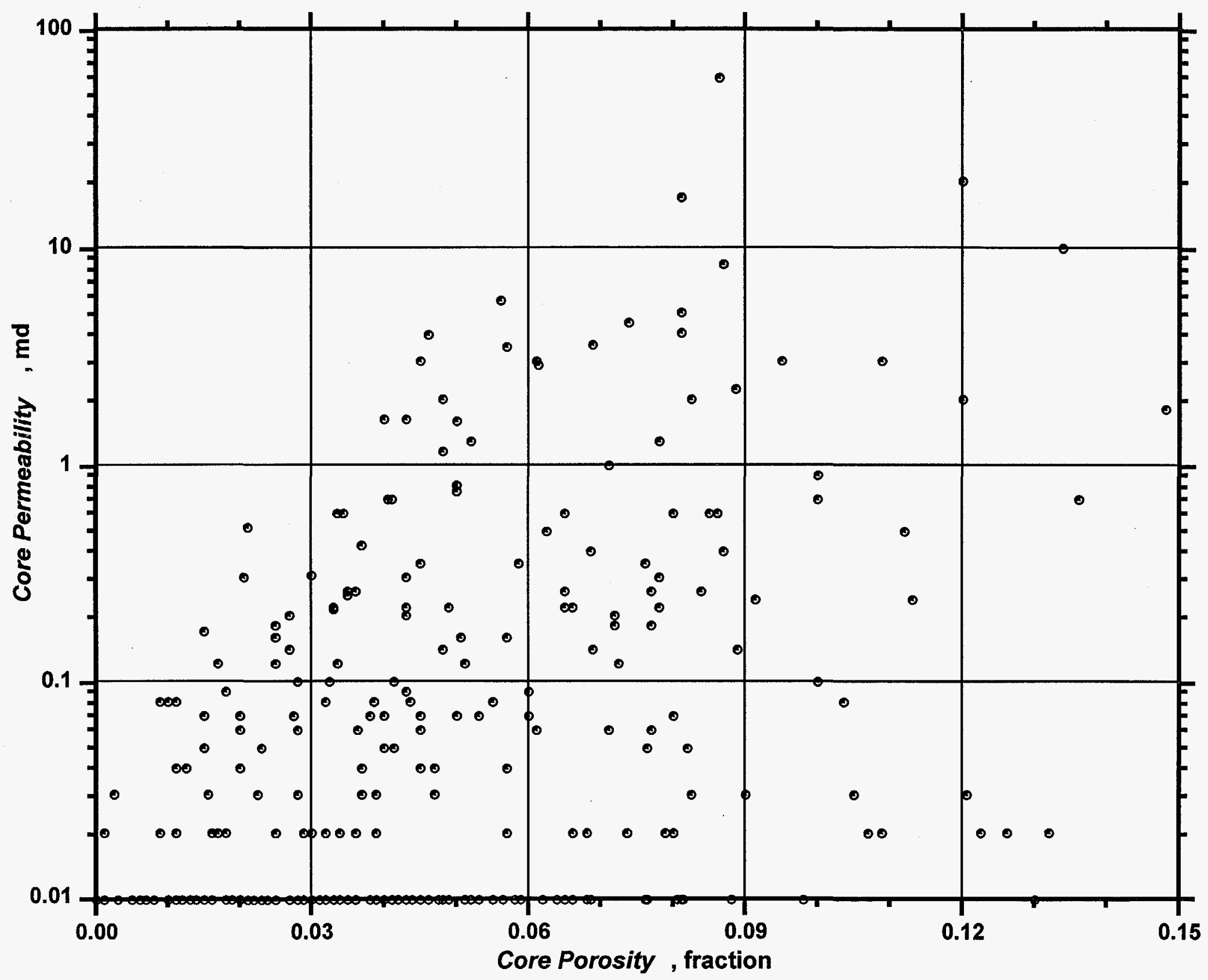

Figure 10 - Porosity-Permeability Crossplot for All Rock Types, after Davies (Ref. 7) 


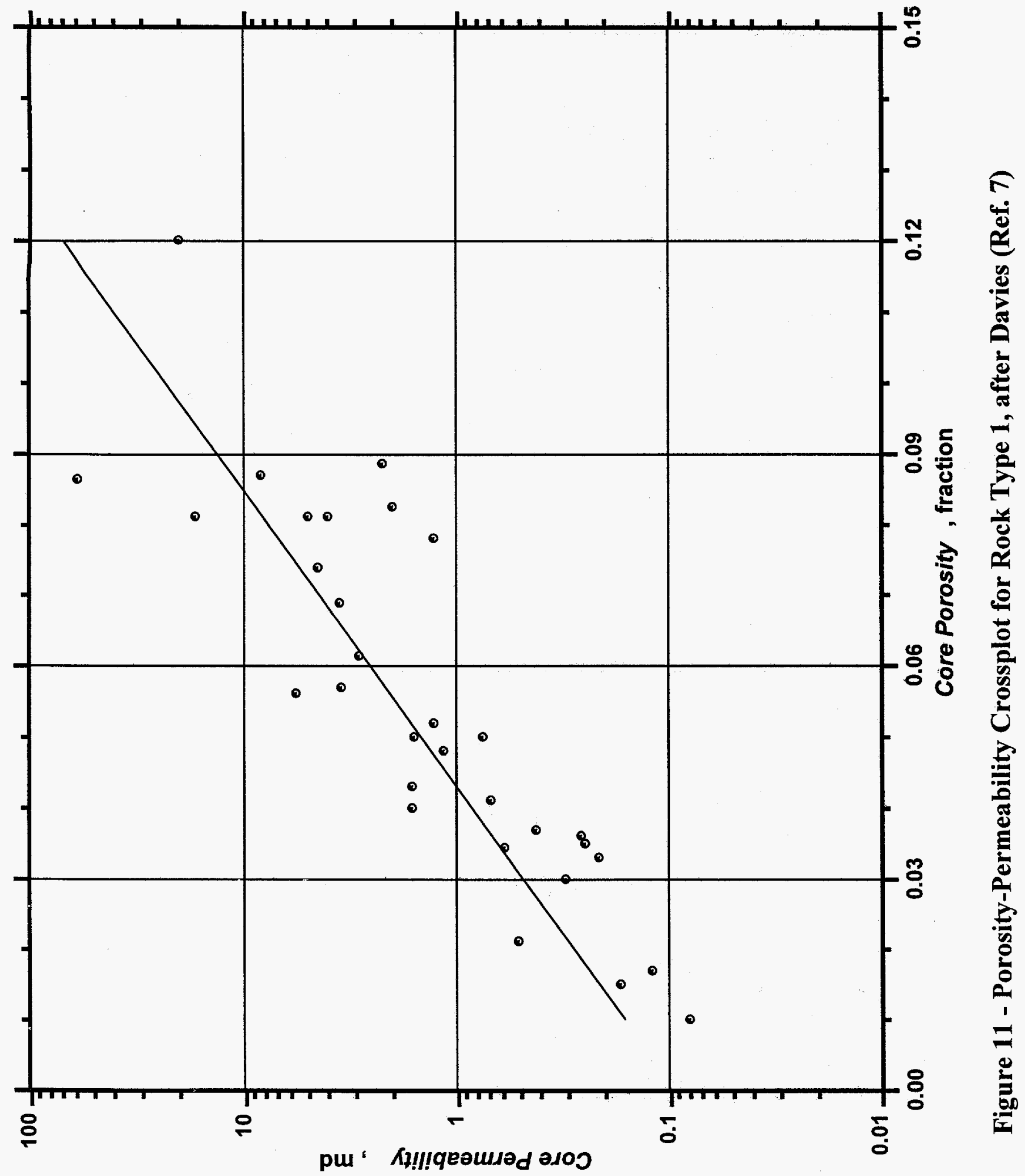




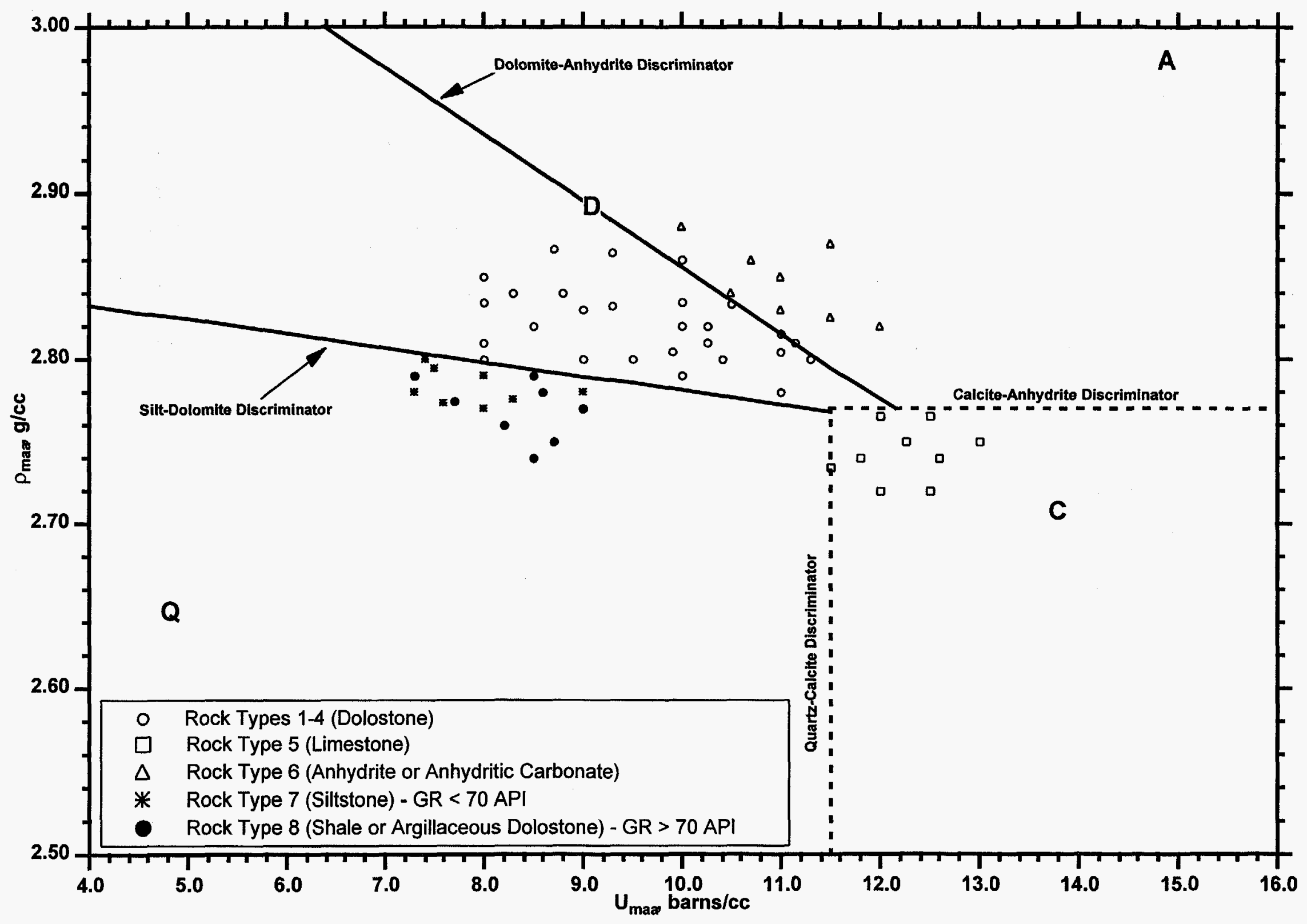

Figure 12 - Differentiating "Pay" from "Non-Pay" Reservoir Rock Types, after Davies (Ref. 7) 


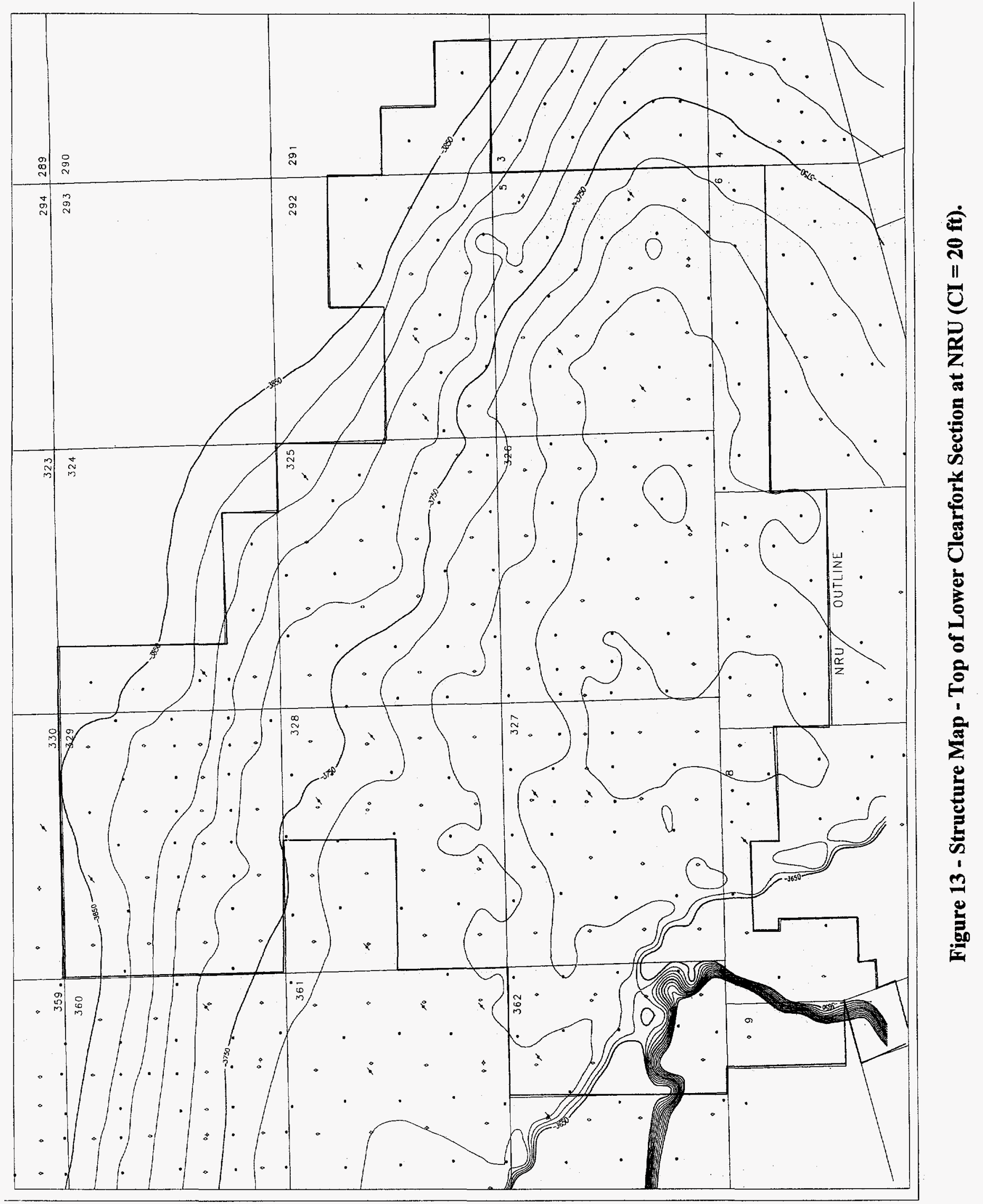




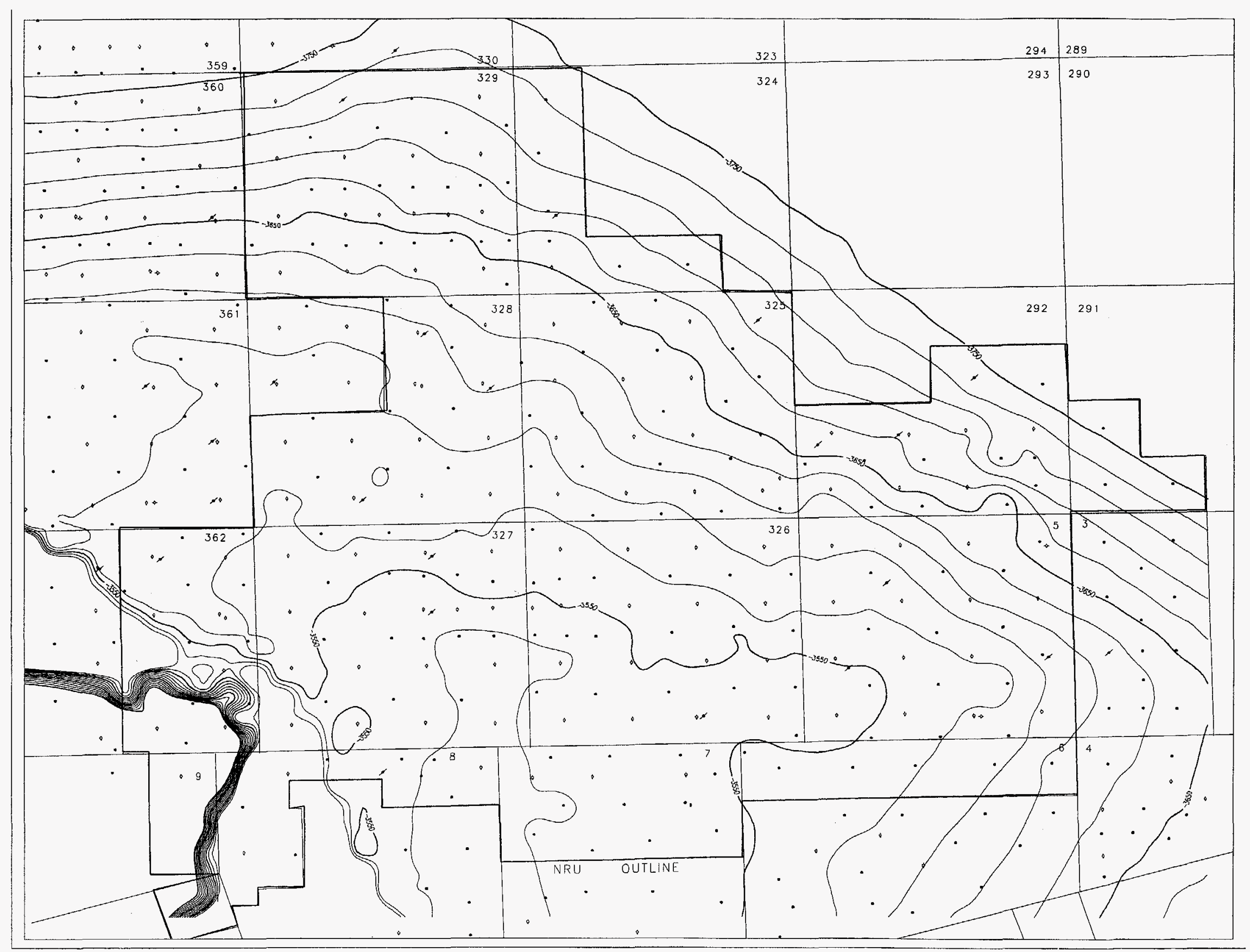

Figure 14 - Structure Map - Top of Tubb Section at NRU (CI = $20 \mathrm{ft})$. 







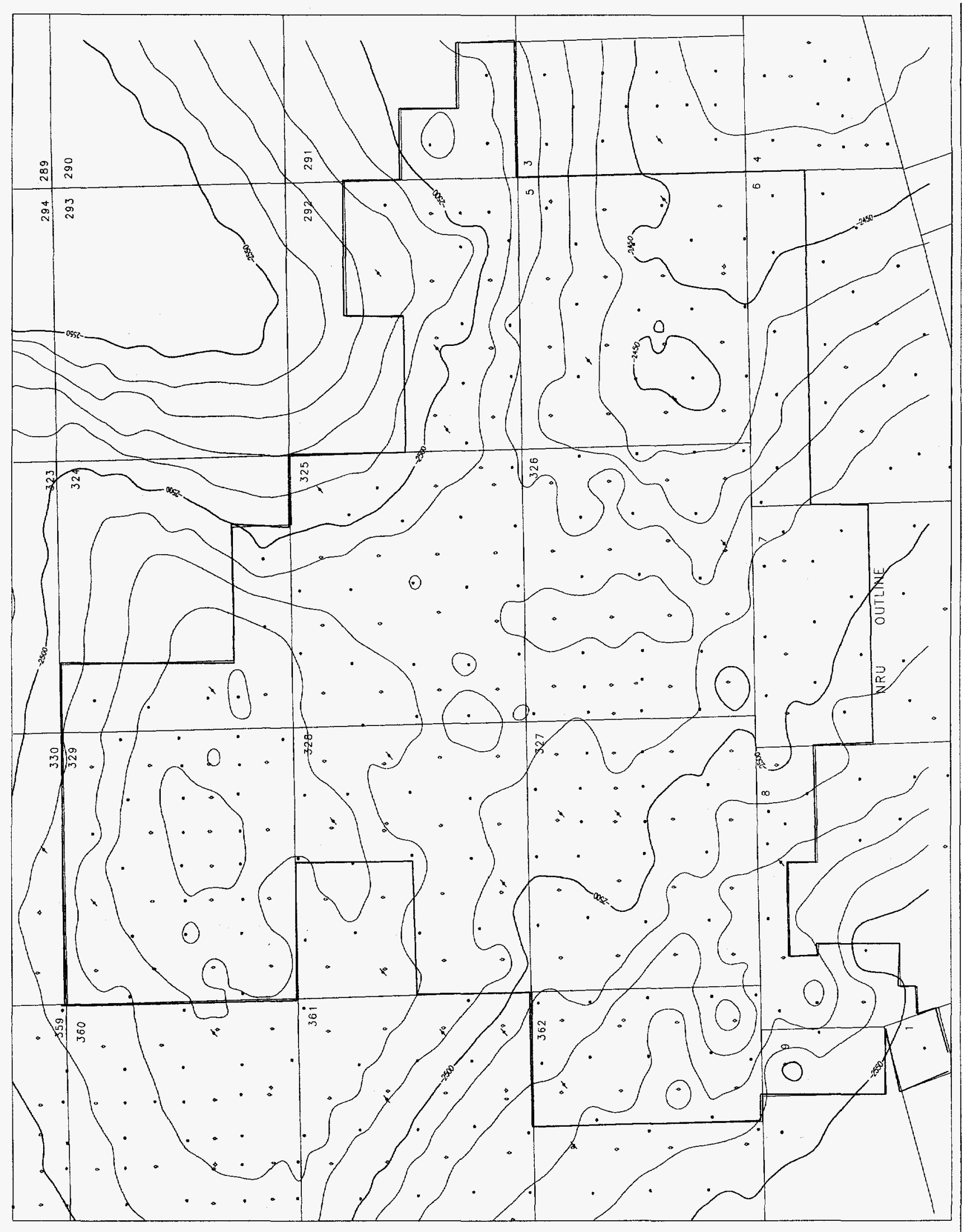

定 


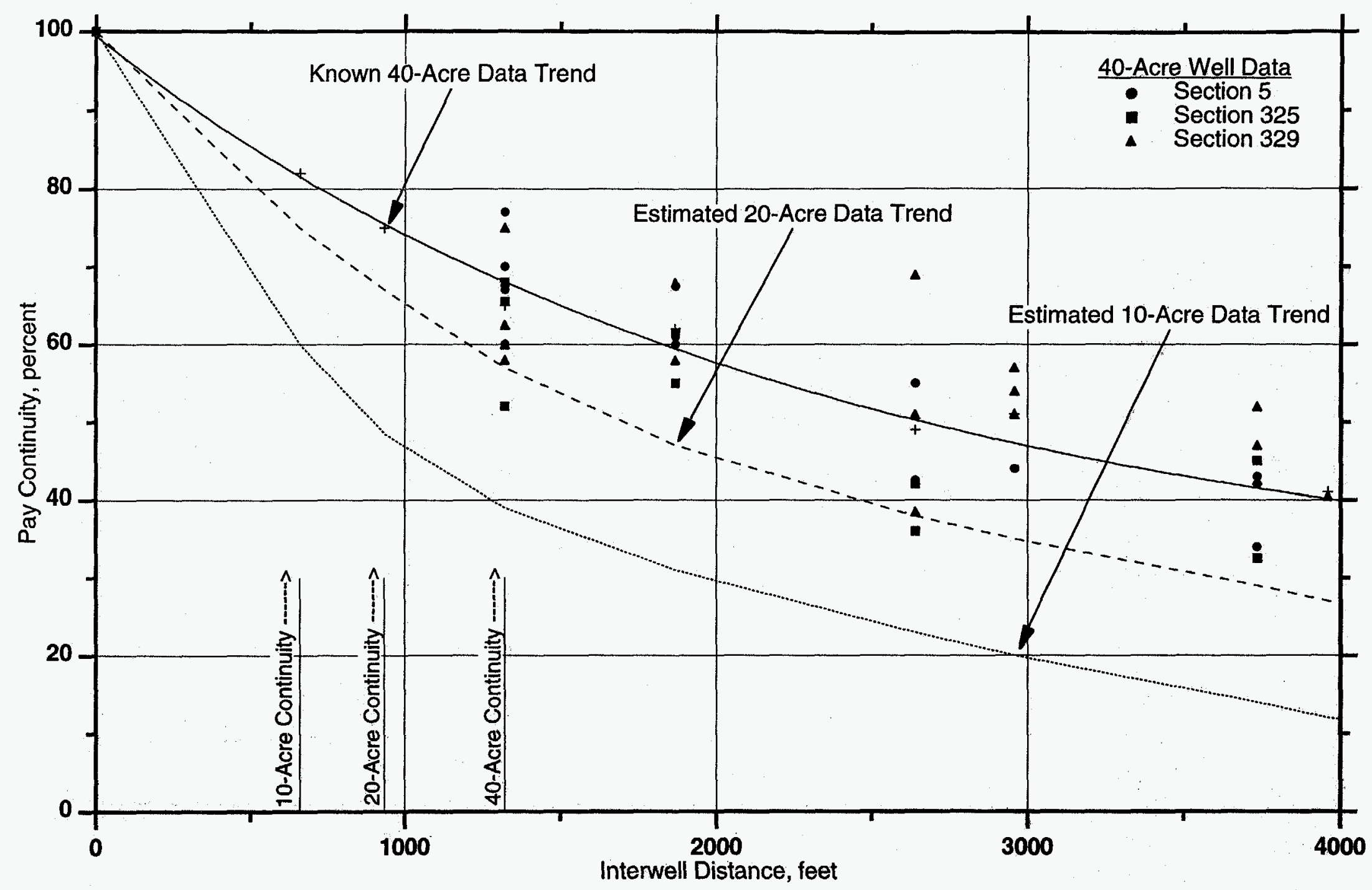

Figure 17 - Results of Pay Continuity Study From 40-Acre Well Data - NRU Sections 5, 325, and 329. 


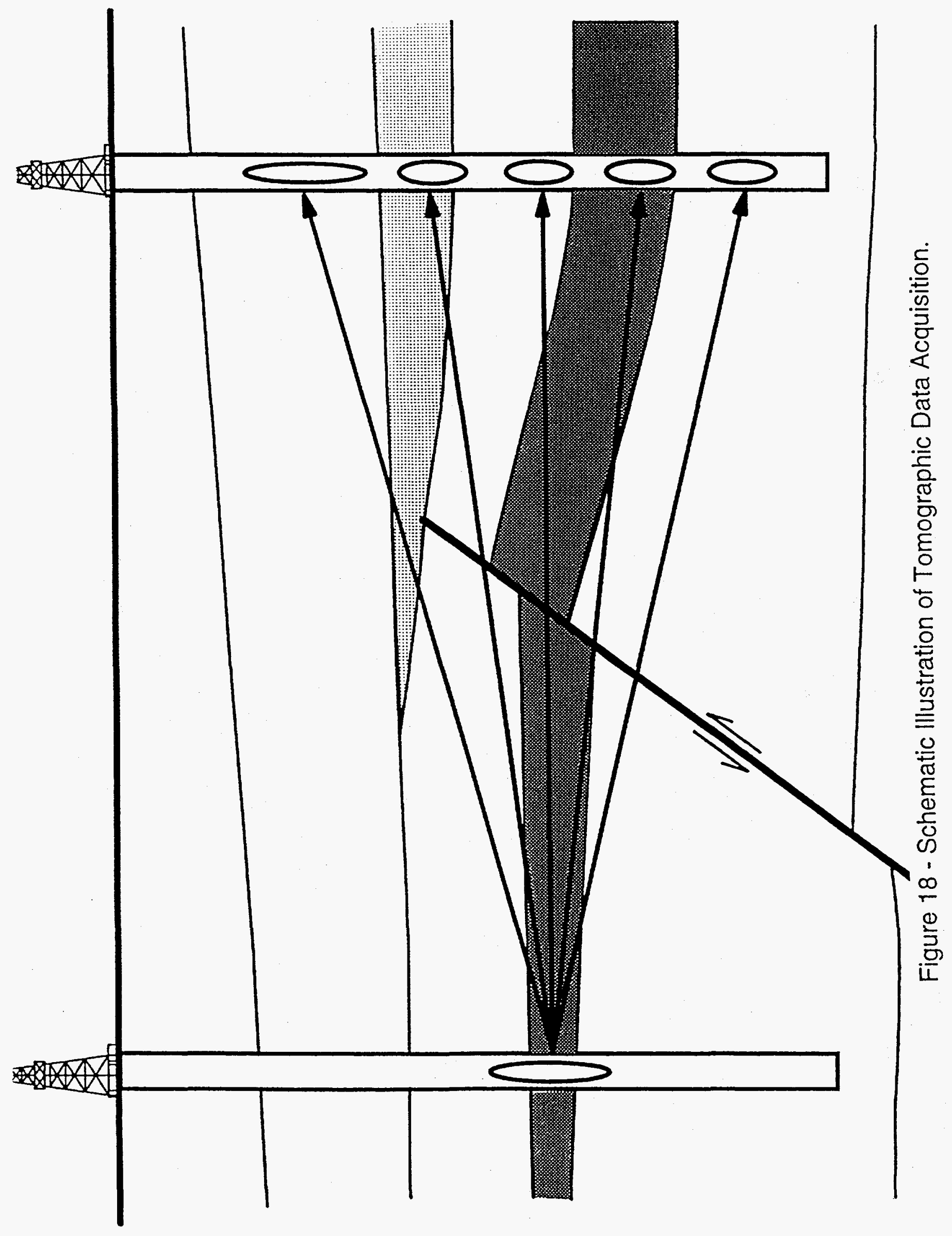


suompsod IOA!əoว 08

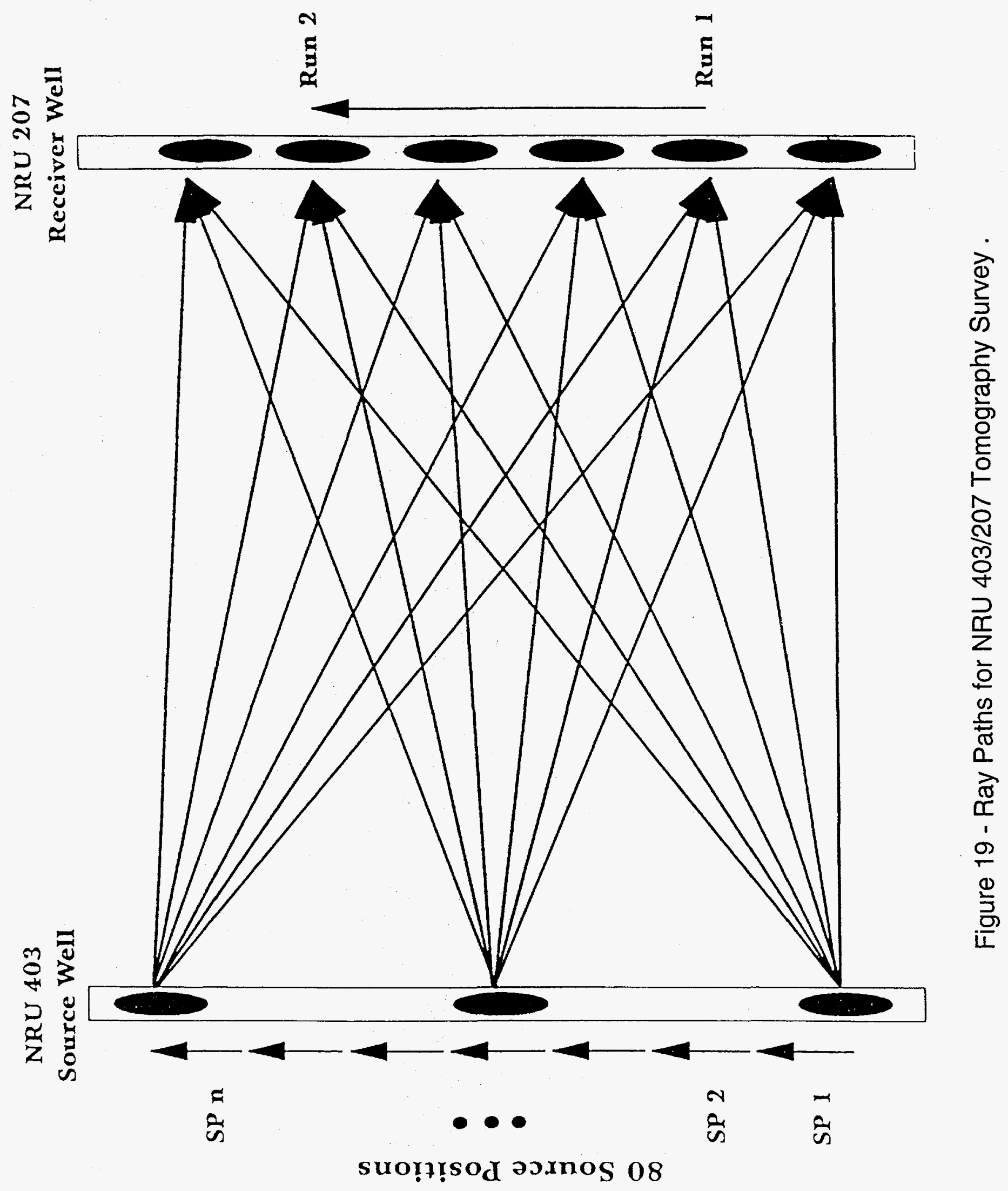




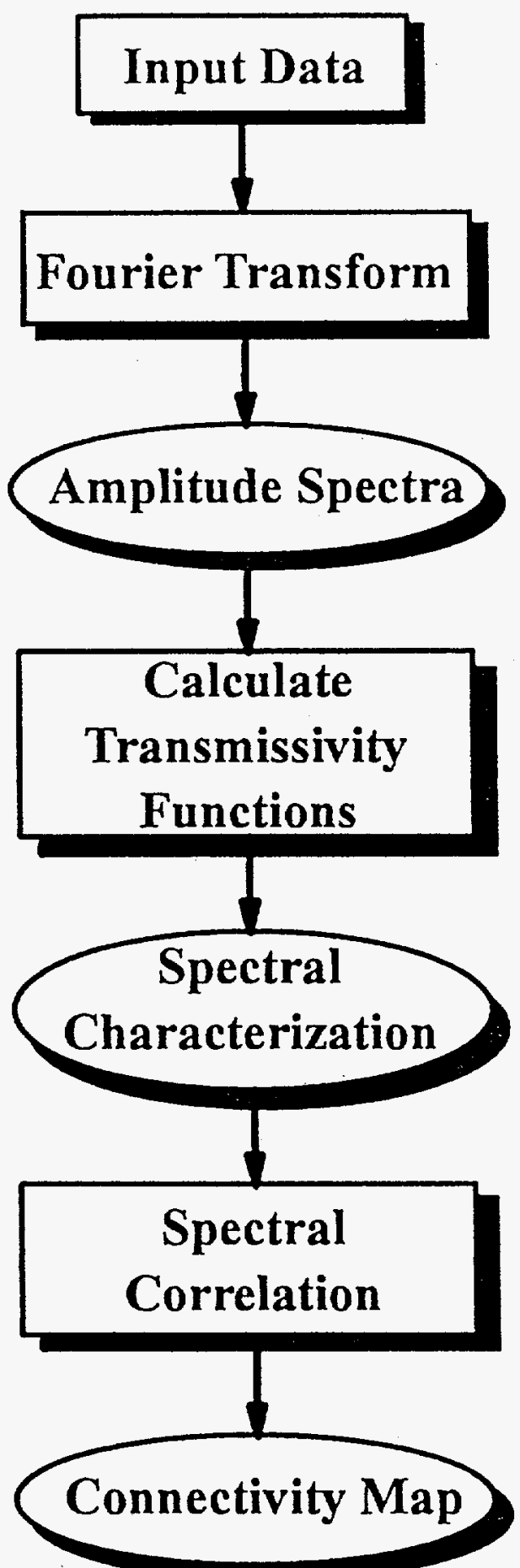

Figure 20 - Processing Flow Chart for Connectivity Mapping. 












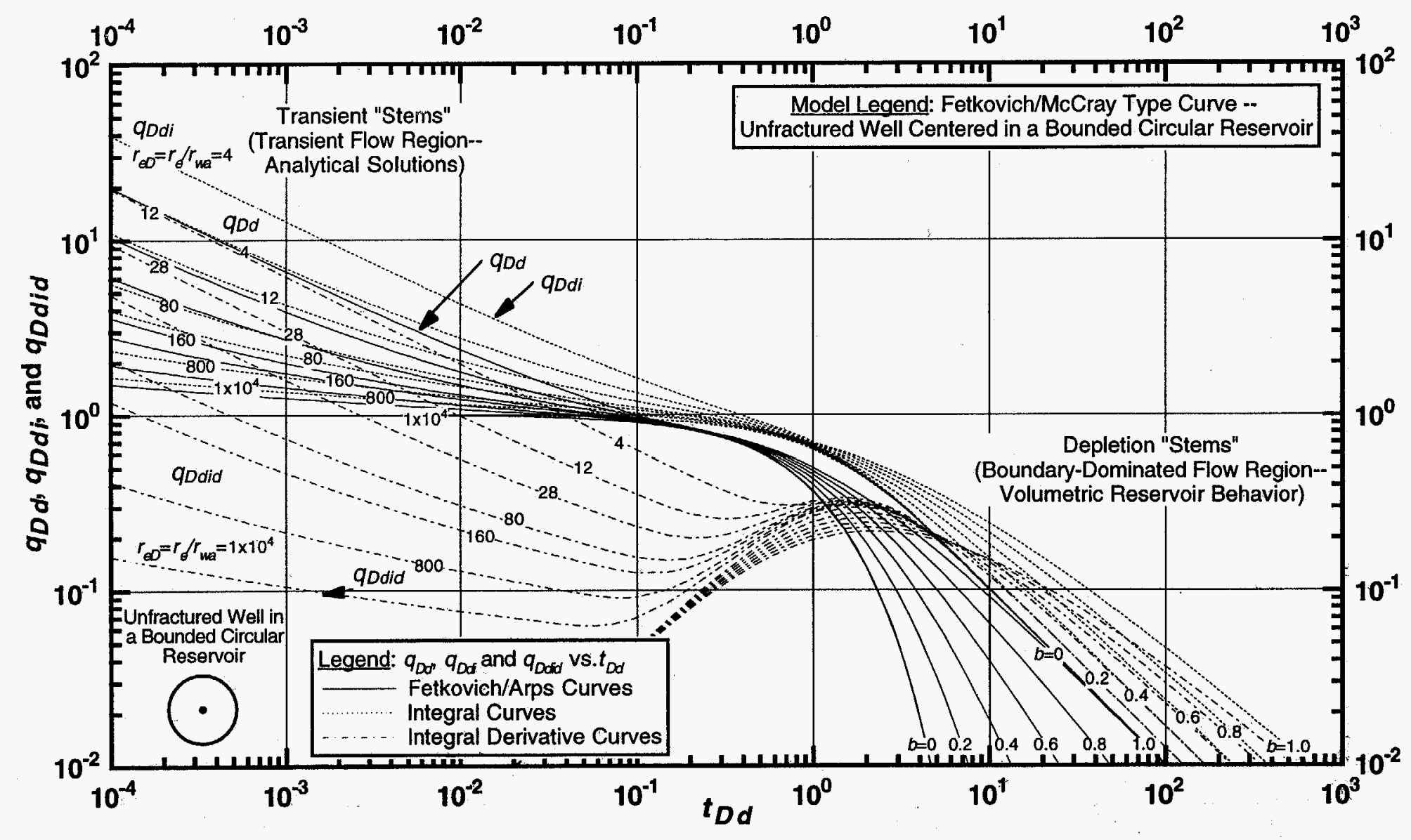

Figure 23 - Fetkovich/McCray Decline Type Curves for an Unfractured Well ${ }^{\left(q_{D d}, q_{D d i}\right.}{ }^{\text {and } q_{D d i d}}{ }^{\text {versus } t_{D d}}$ Solutions) 


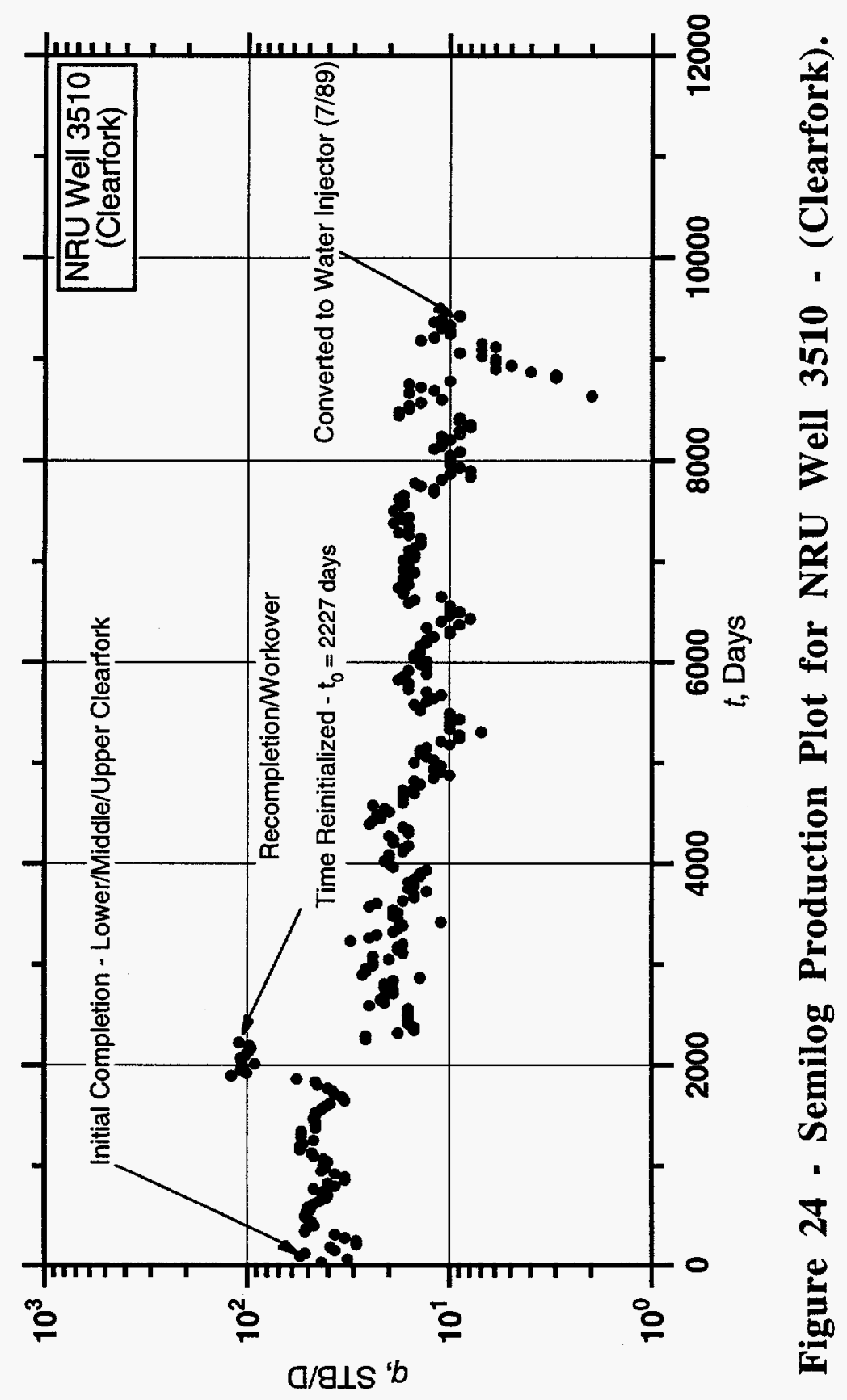




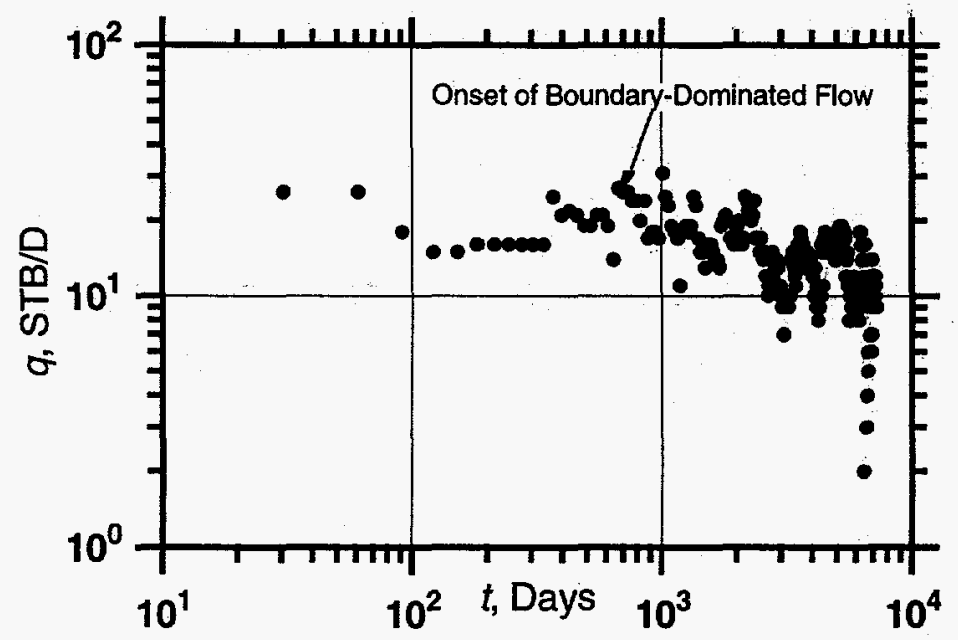

Figure 25 - Log-Log Production Plot for NRU Well 3510 - (Clearfork).

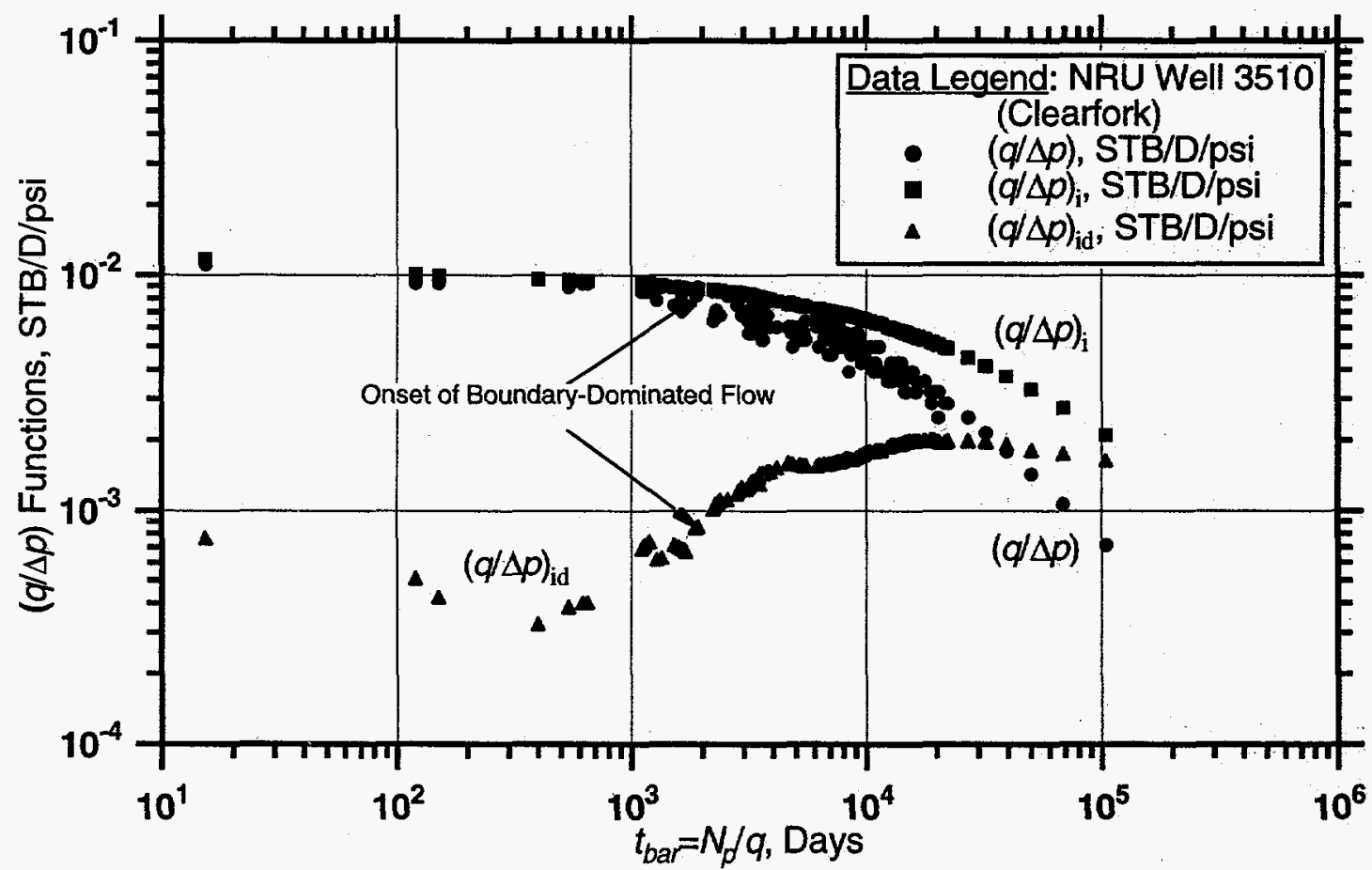

Figure 26 - Rate Functions for NRU Well 3510 - (Clearfork). 




Figure 27 - Match of Production Data for NRU Well 3510 - Clearfork (Radial Flow Type Curve). 


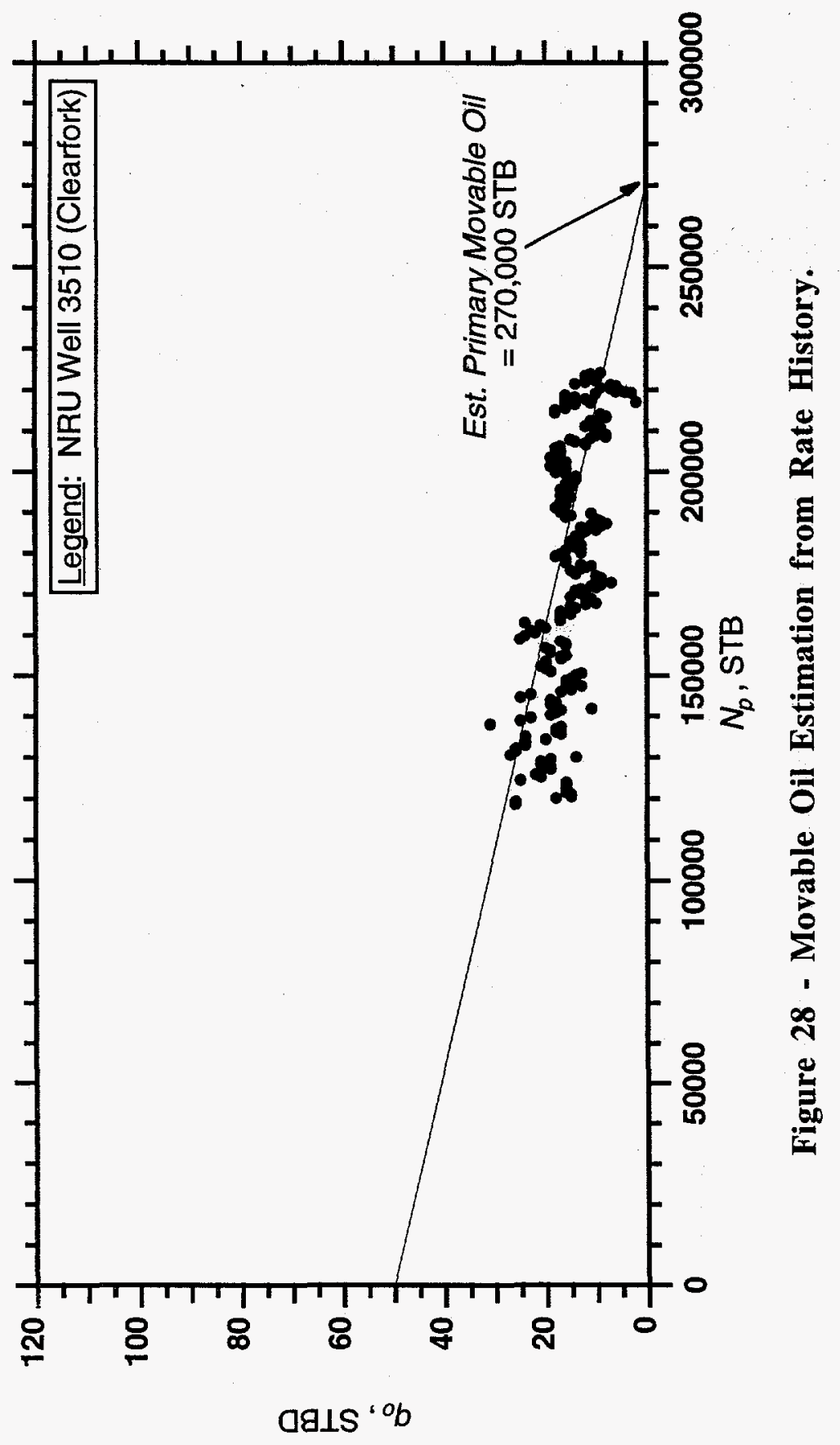









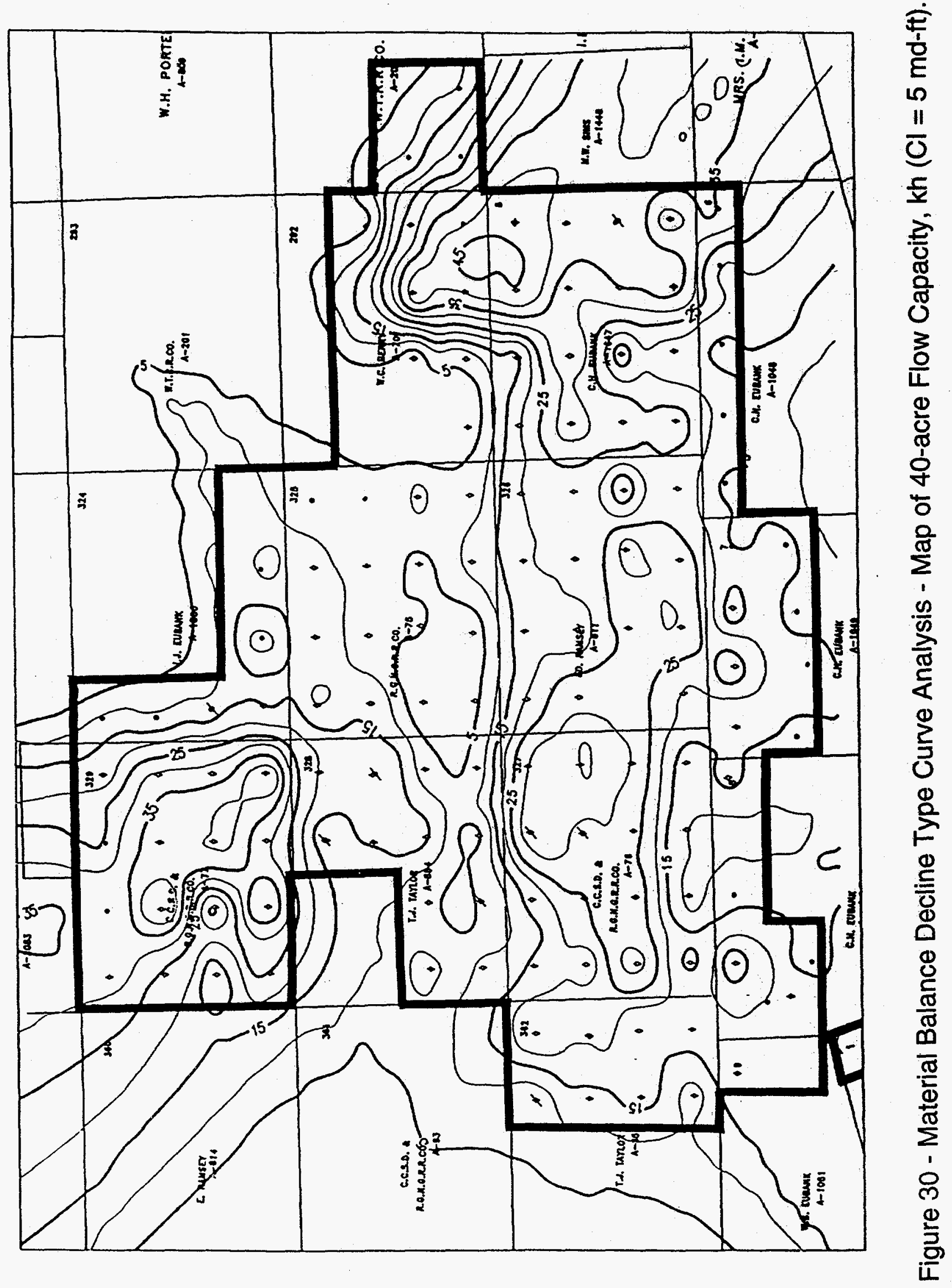




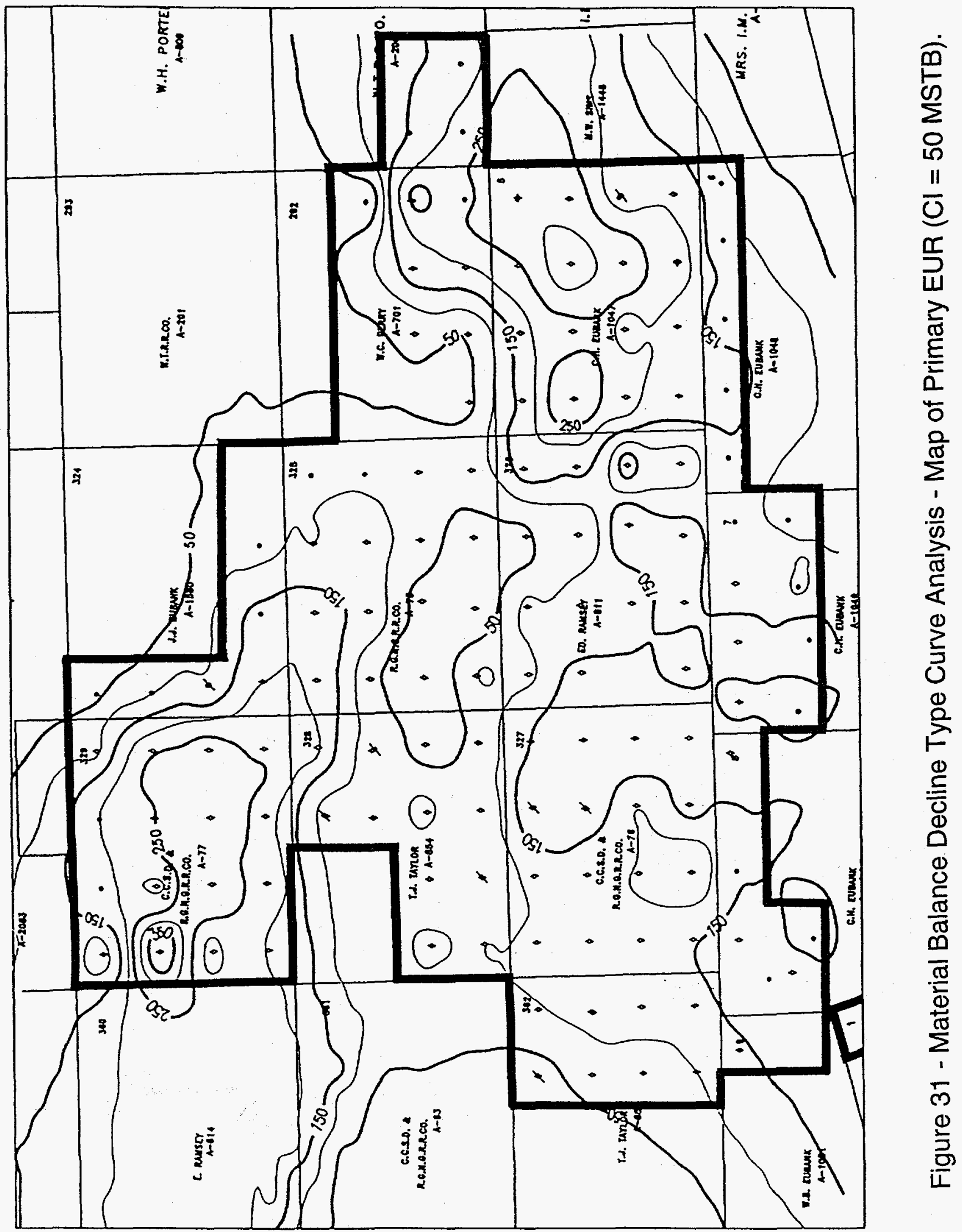




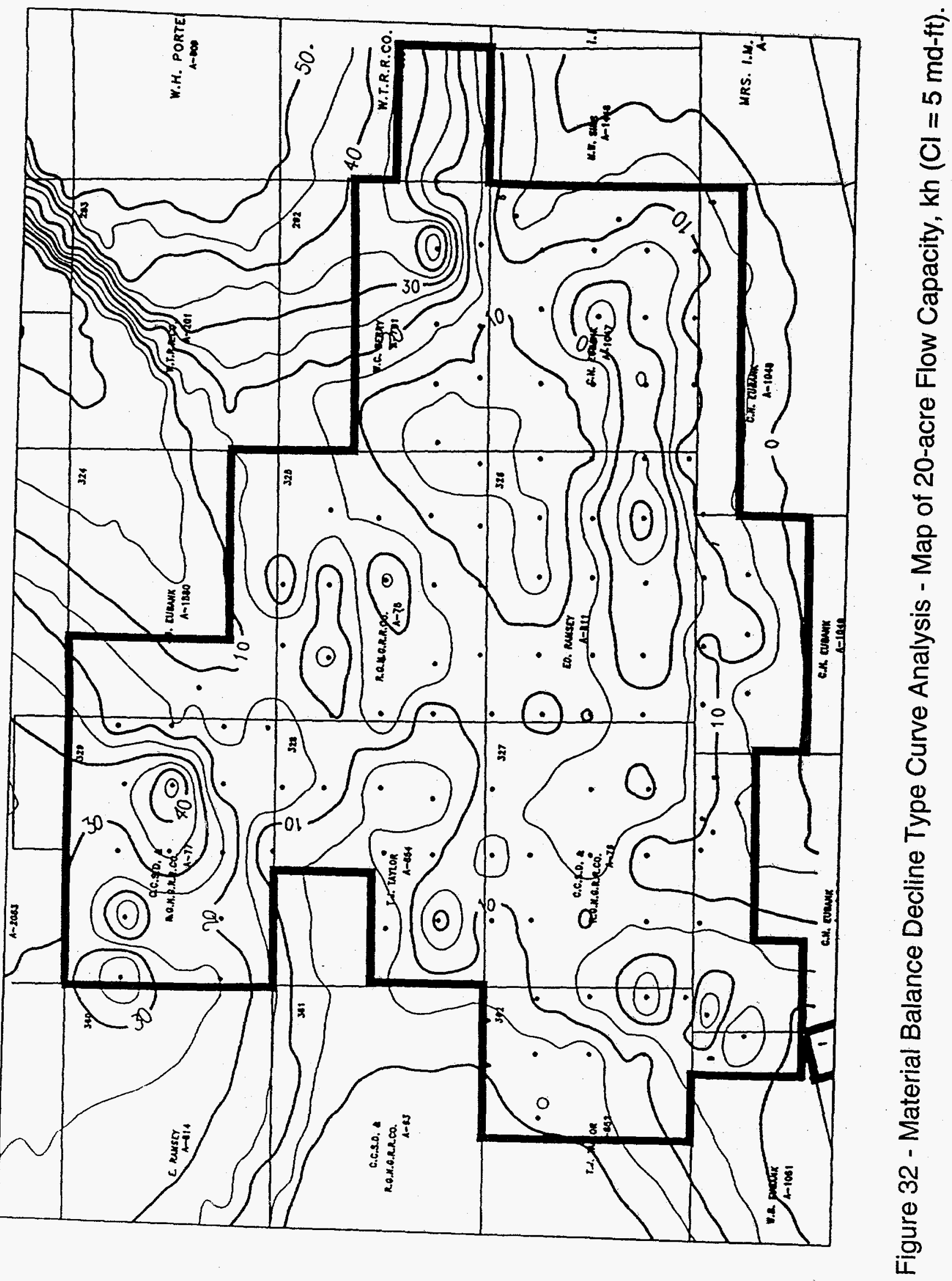




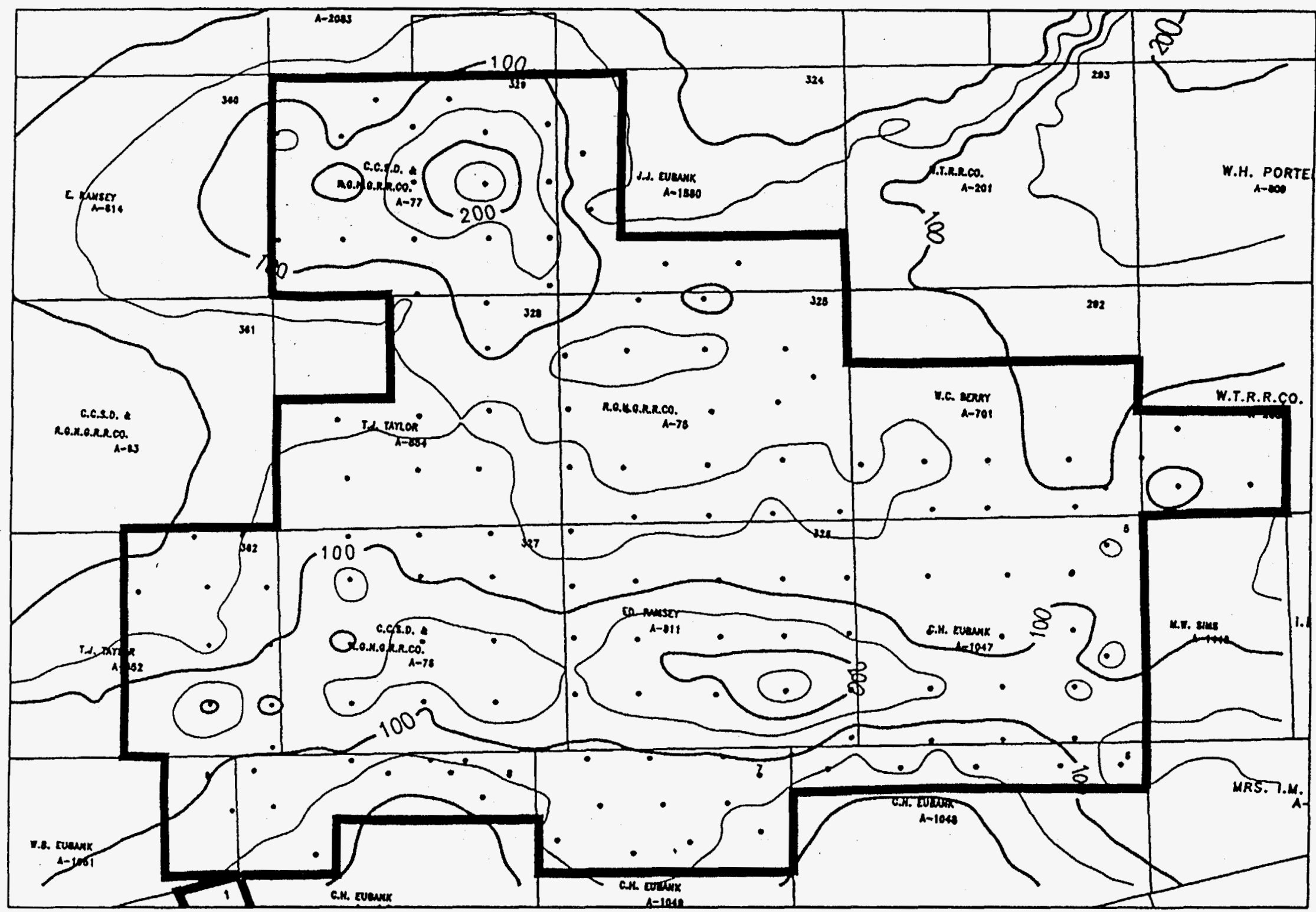

Figure 33 - Material Balance Decline Type Curve Analysis - Map of Secondary EUR (Cl = 50 MSTB). 


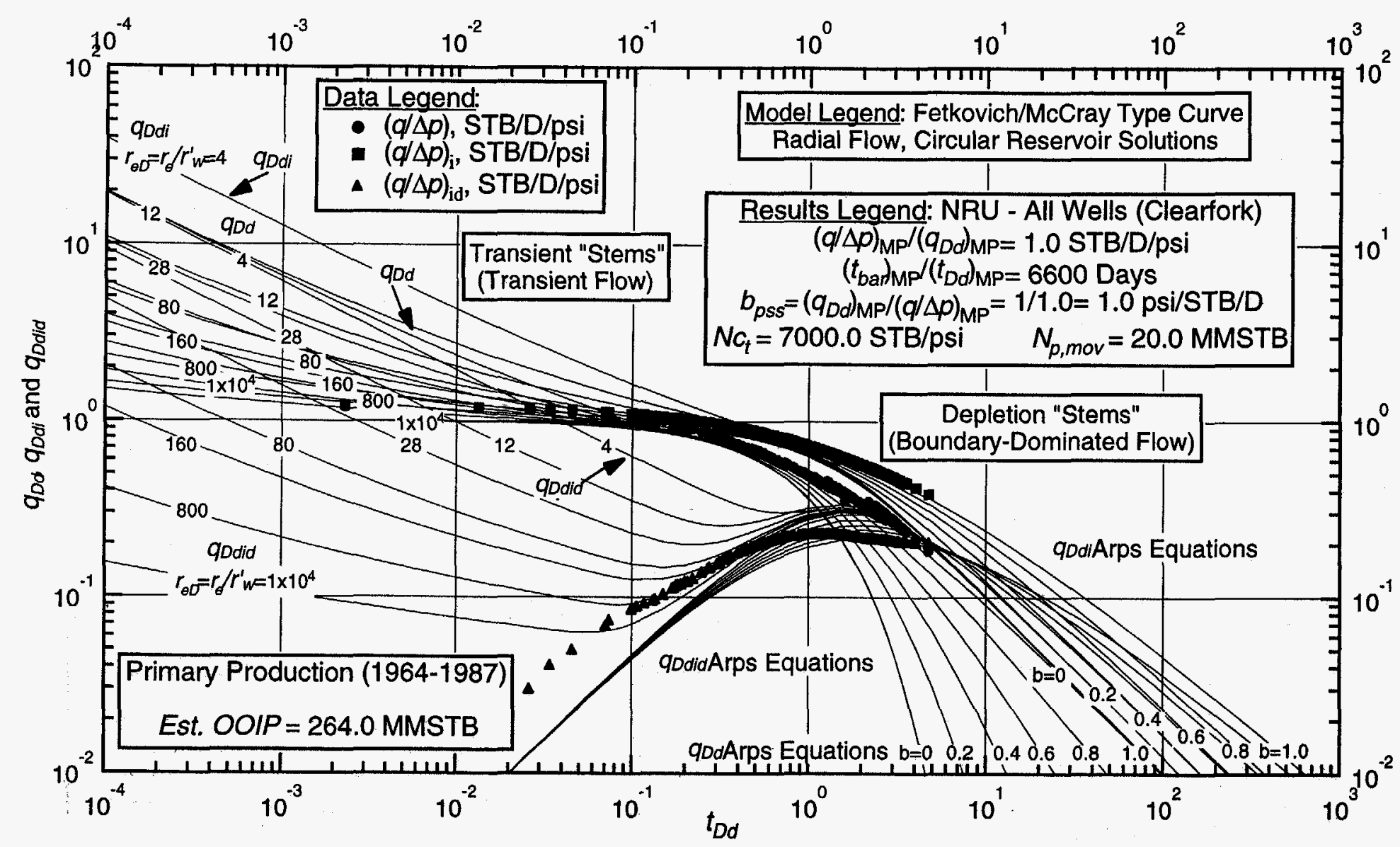

Figure 34 - Match of Primary Production Data for NRU (All Wells) - Clearfork (Radial Flow Type Curve). 


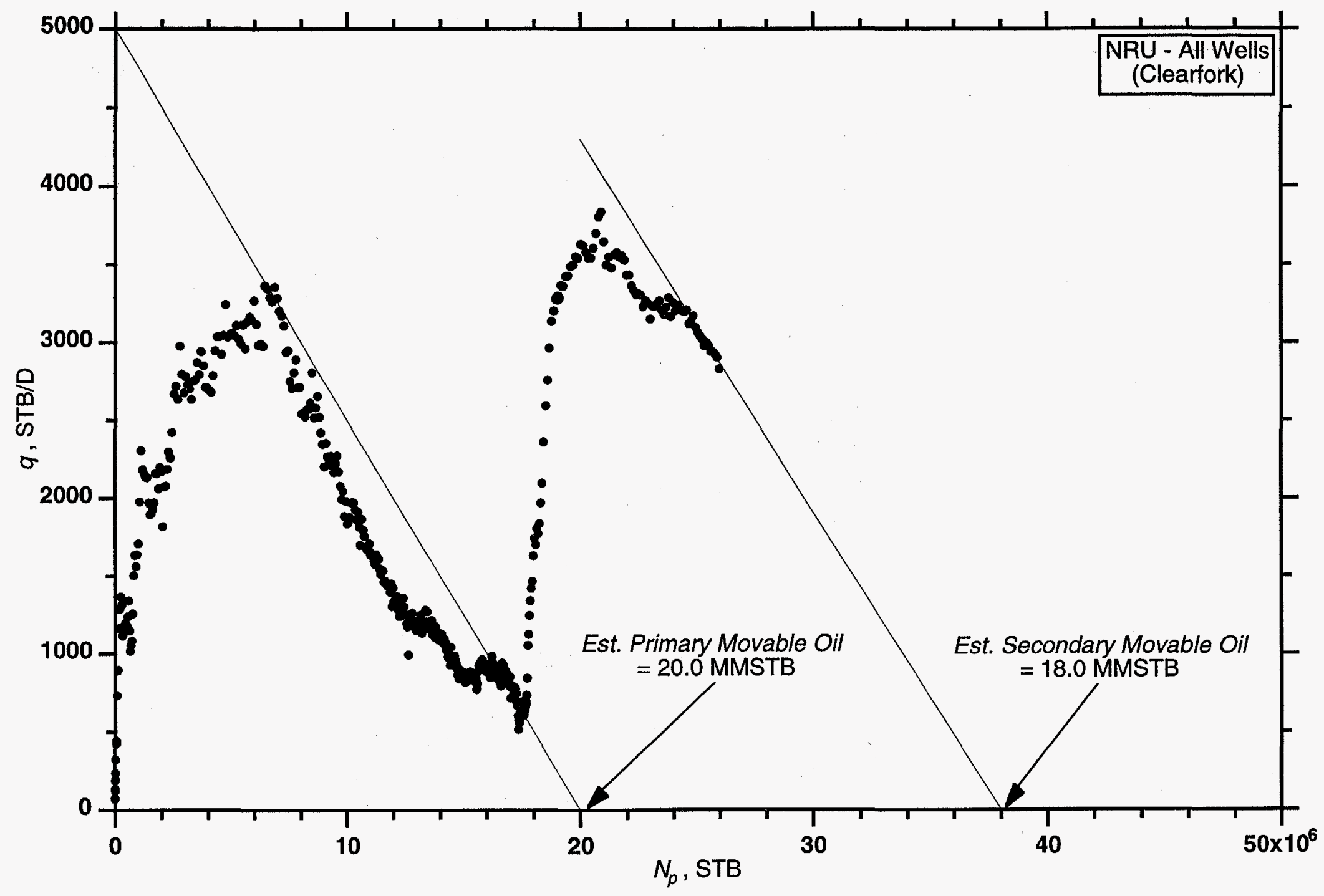

Figure 35 - NRU Estimated Total Movable Oil from Rate History. 


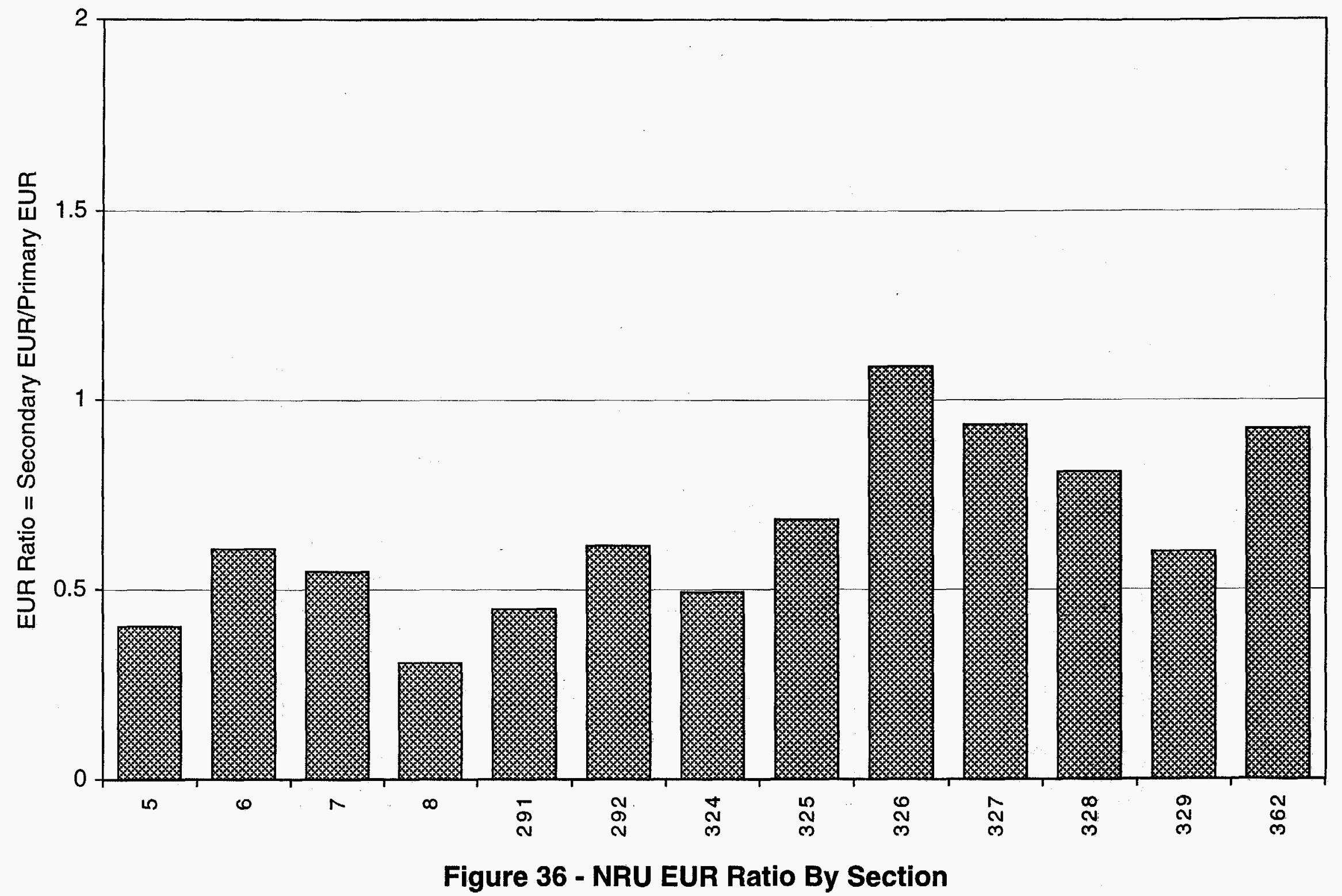




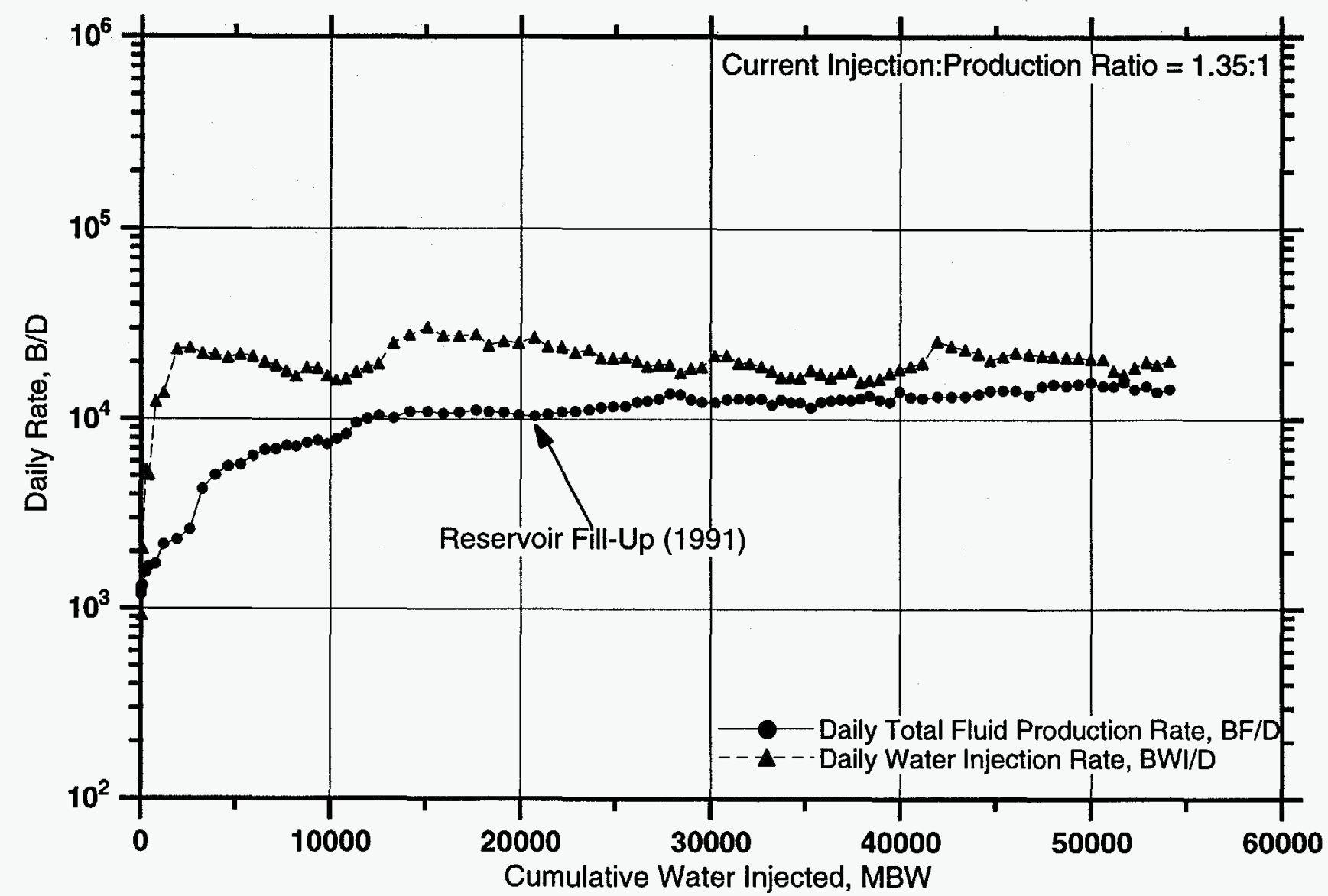

Figure 37 - NRU Daily Injection and Production as a Function of Cumulative Water Injected. 


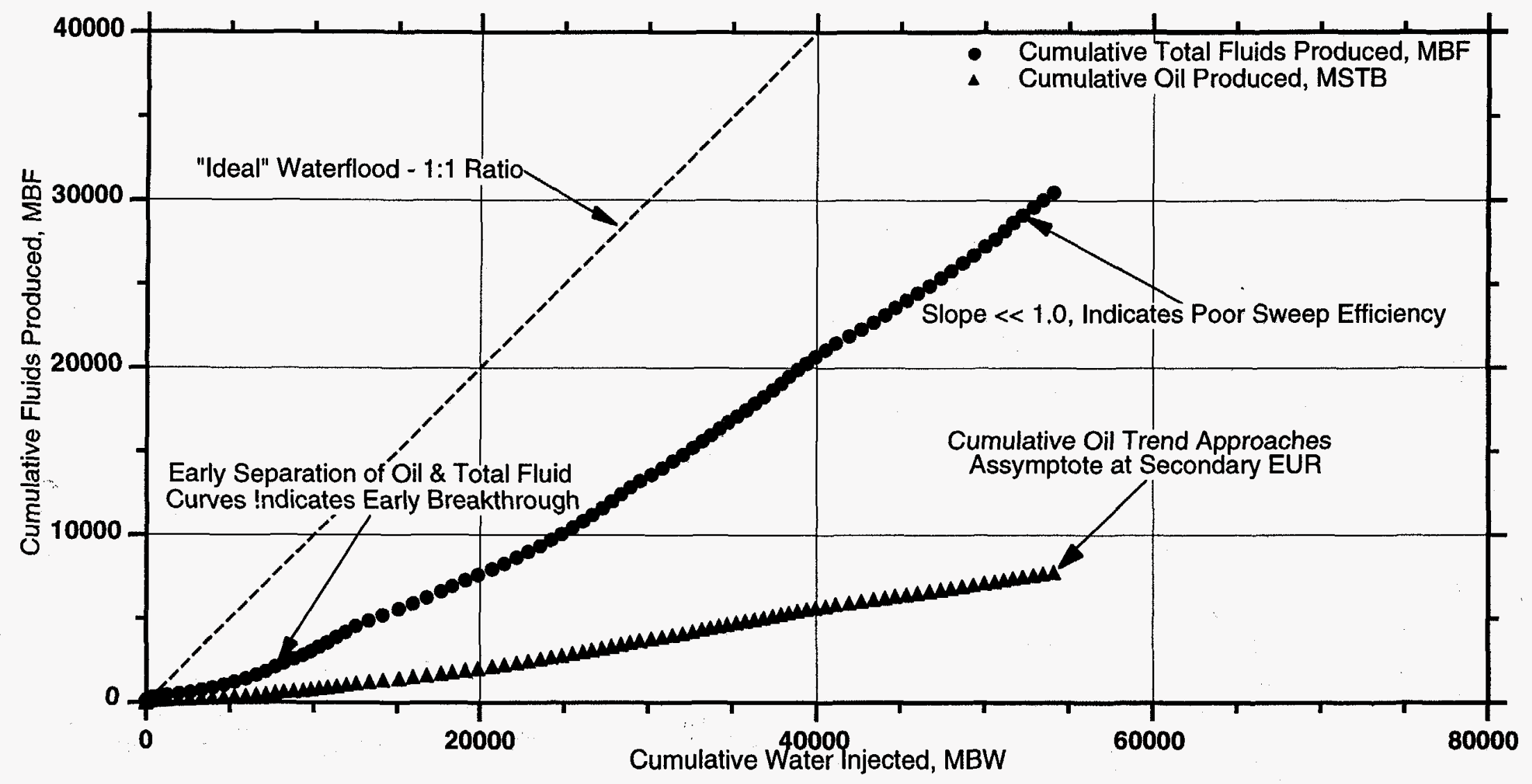

Figure 38 - Waterflood Performance Diagnostic Plot, after Jordan (Ref. 21). 


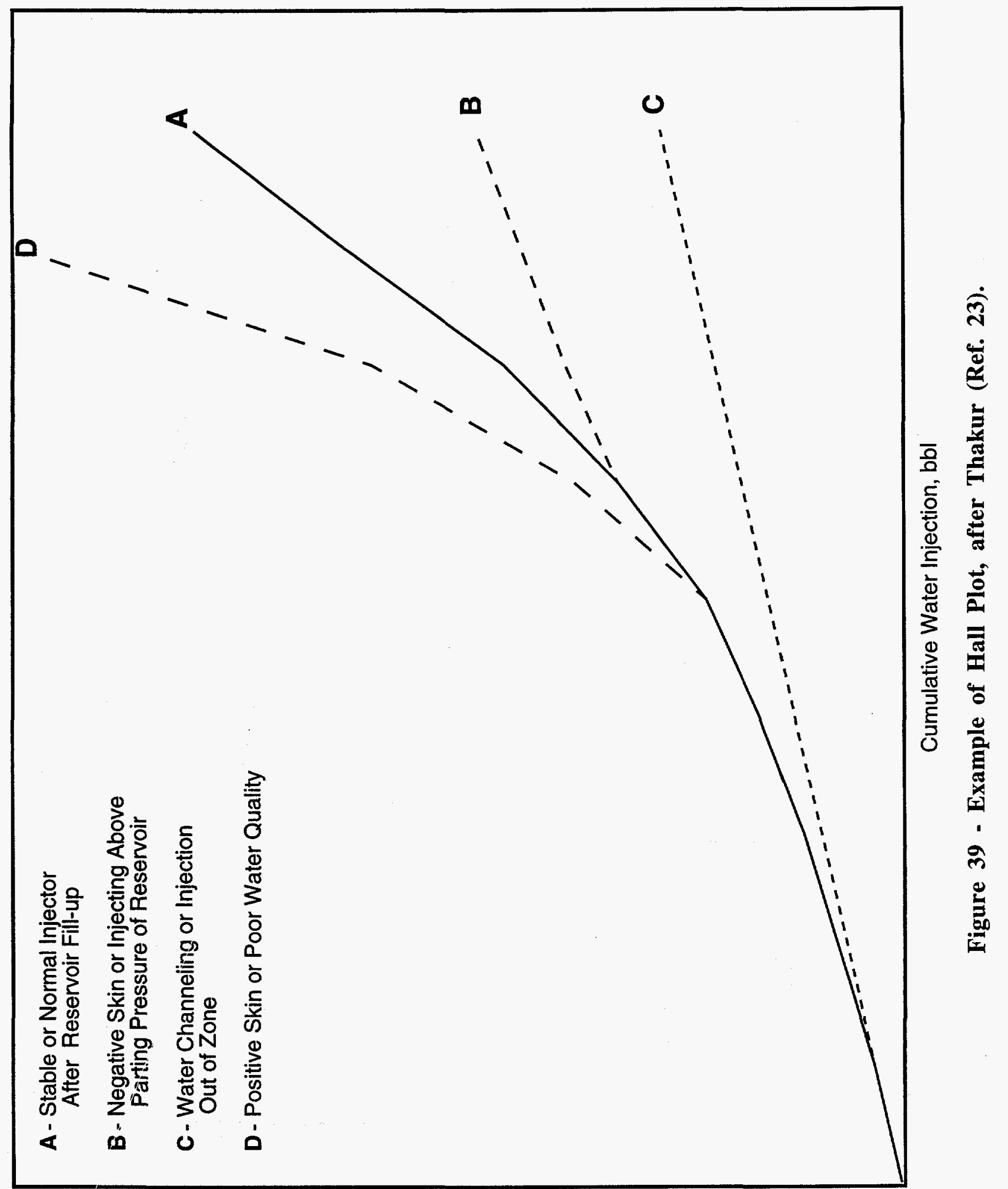

|qq/sאep-!̣d 'əגnssədd әм!̣e|nuno 





Hall Coefficient, Mpsi-days

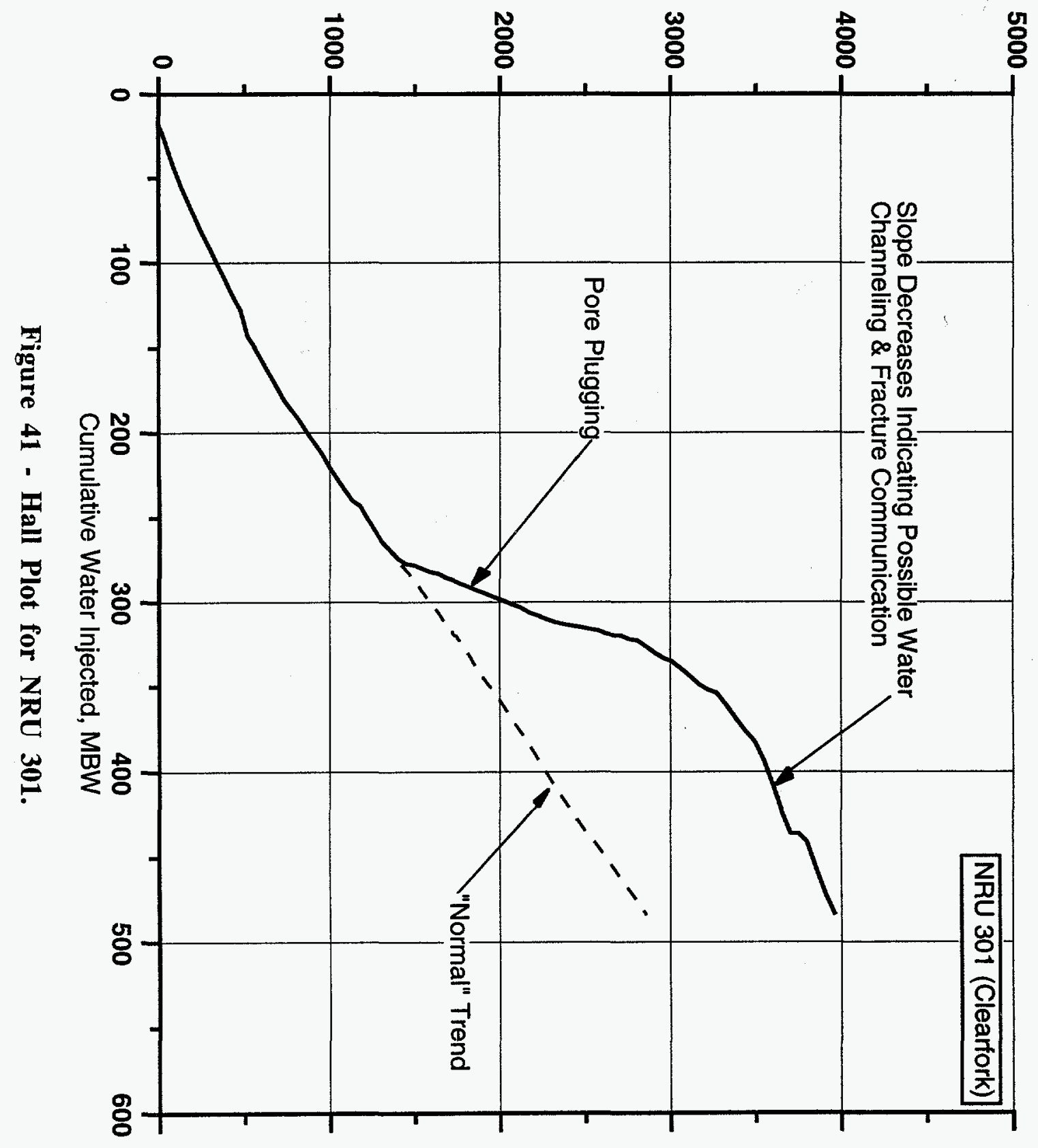




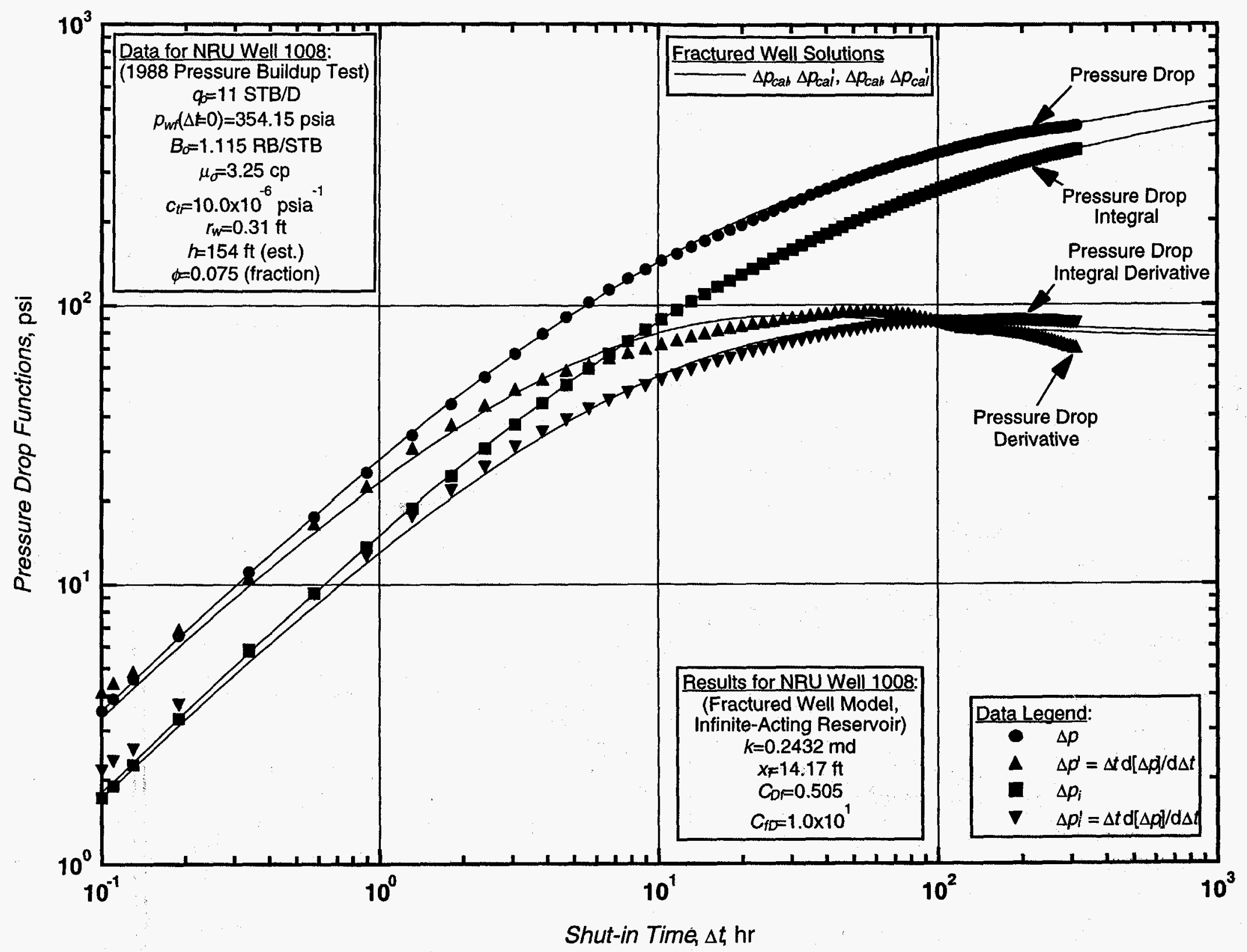

Figure 42 - NRU Well 1008 Pressure Buildup Analysis Using Pressure Derivative and Integral Derivative. 


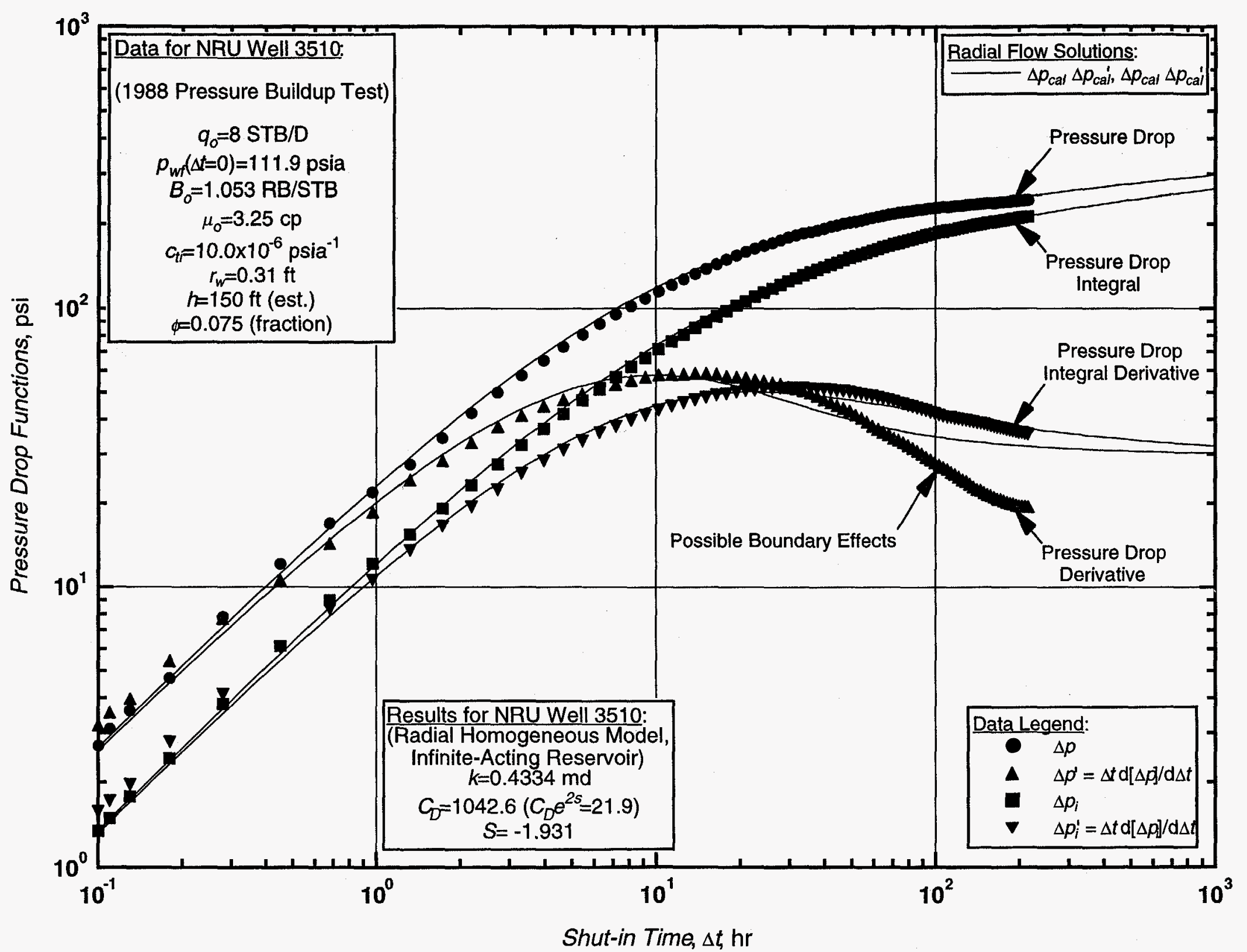

Figure 43 - NRU Well 3510 Pressure Buildup Analysis Using Pressure Derivative and Integral Derivative. 


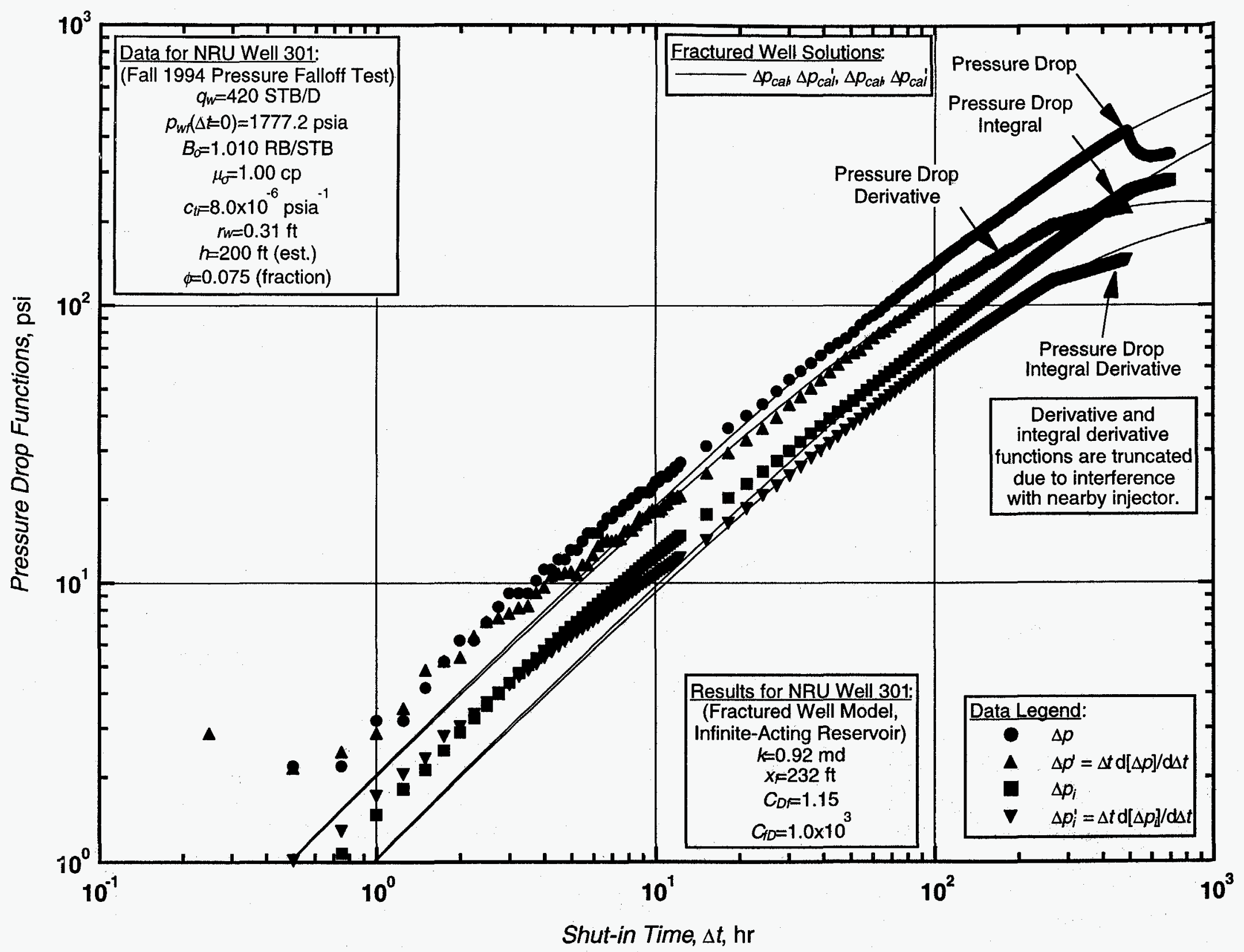

Figure 44 - NRU Well 301 Pressure Falloff Analysis Using Pressure Derivative and Integral Derivative. 


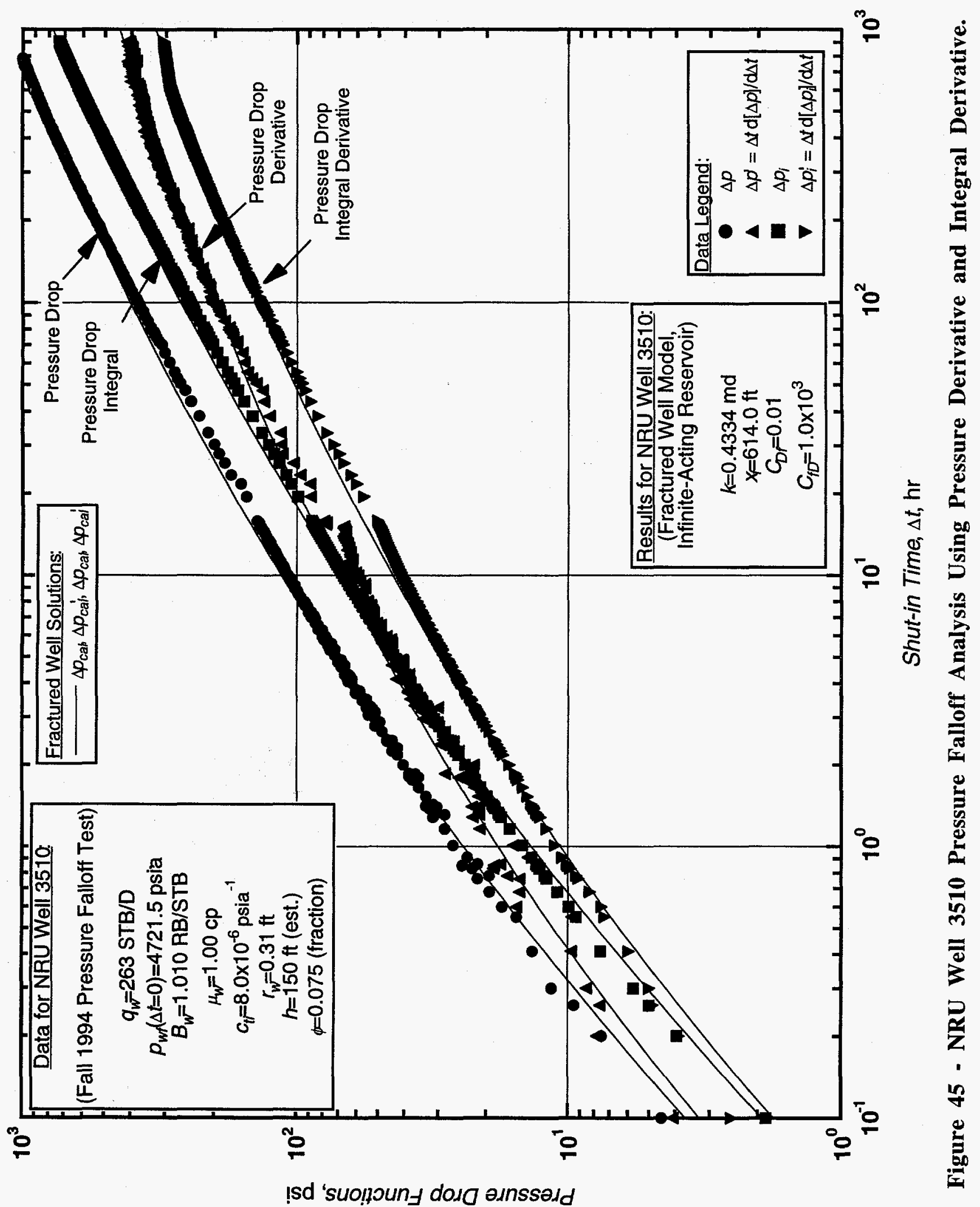




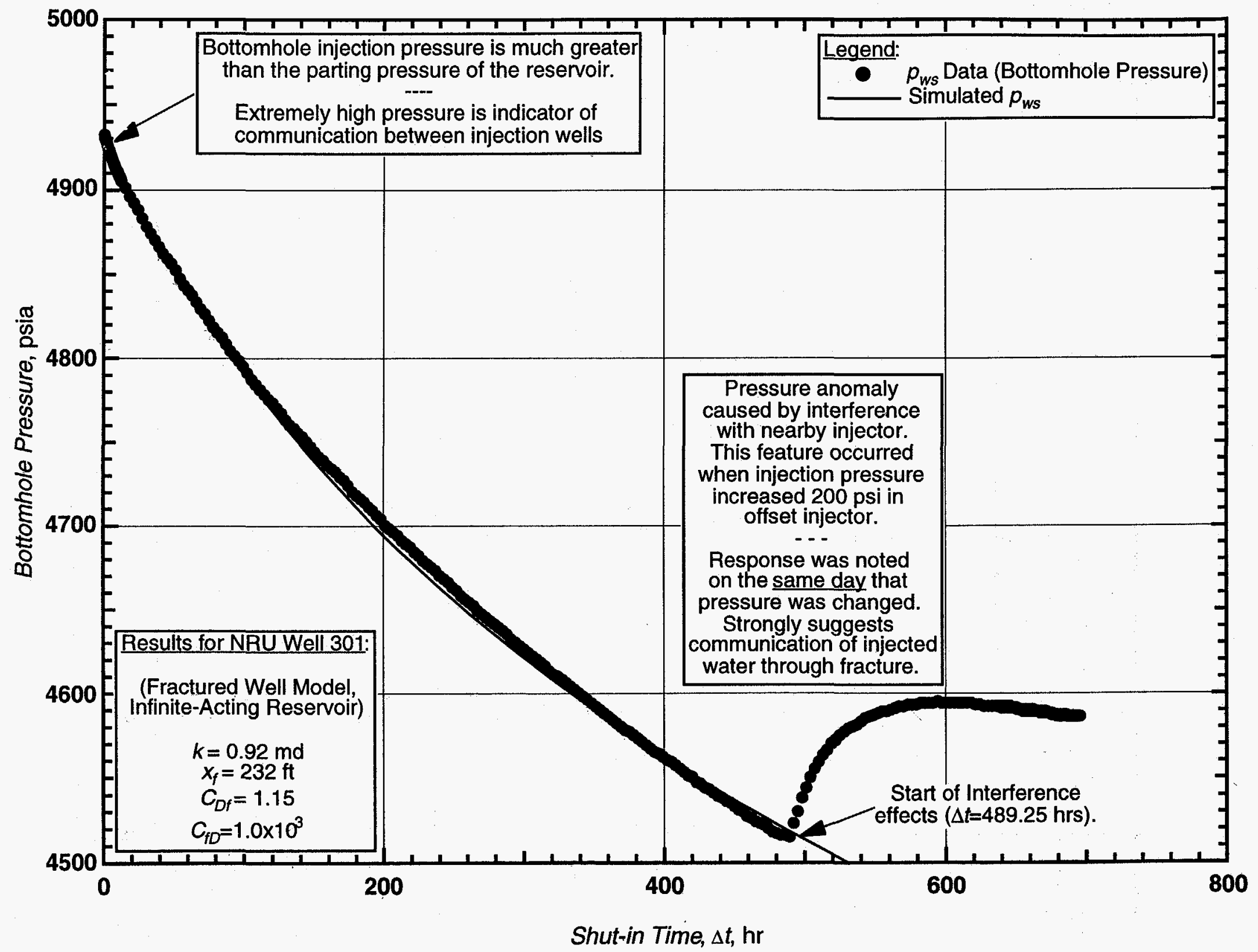

Figure 46 - Cartesian Plot of $p_{w s}$ versus Shut-In Time for NRU Well 301 Pressure Falloff Test. 


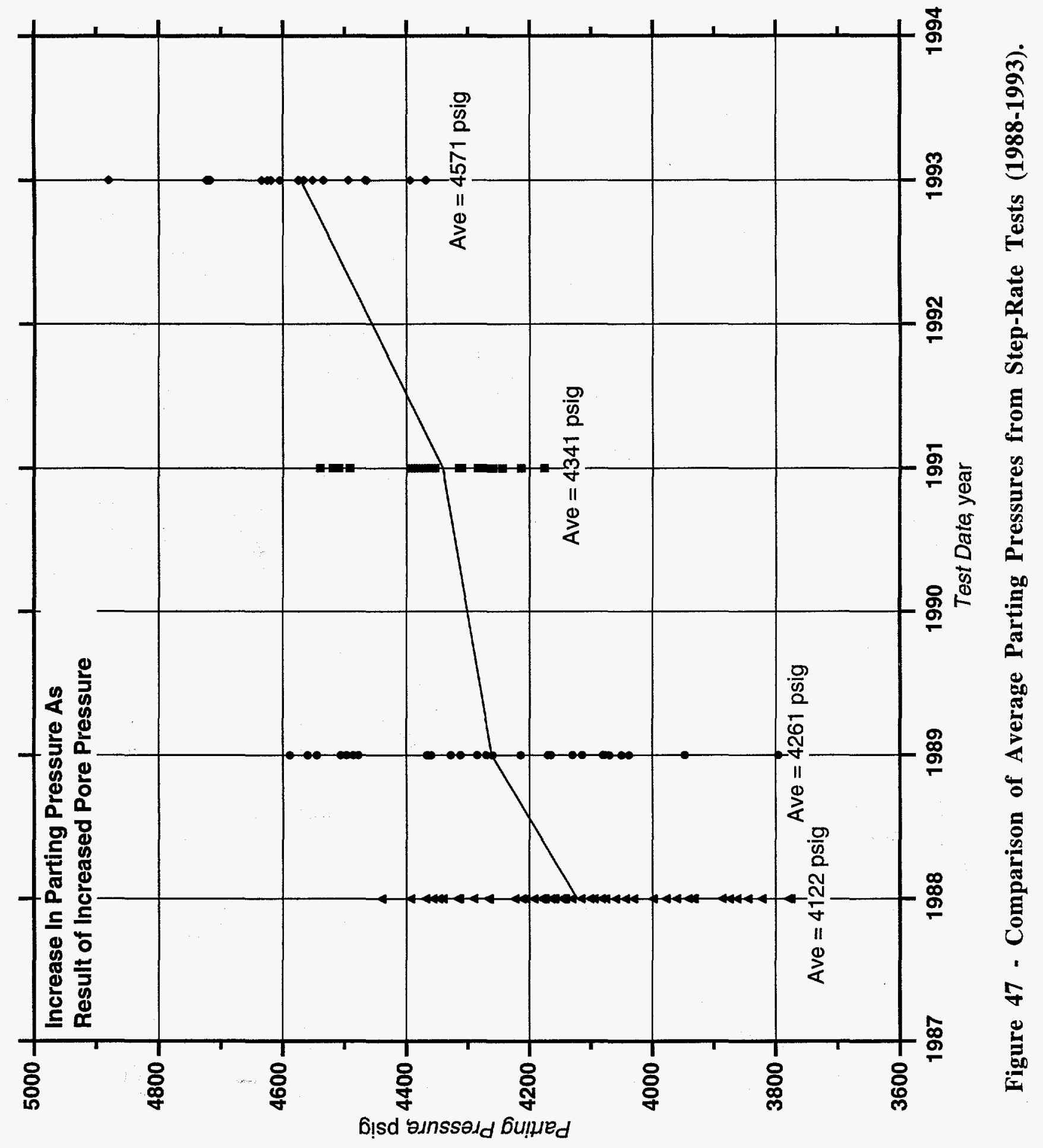




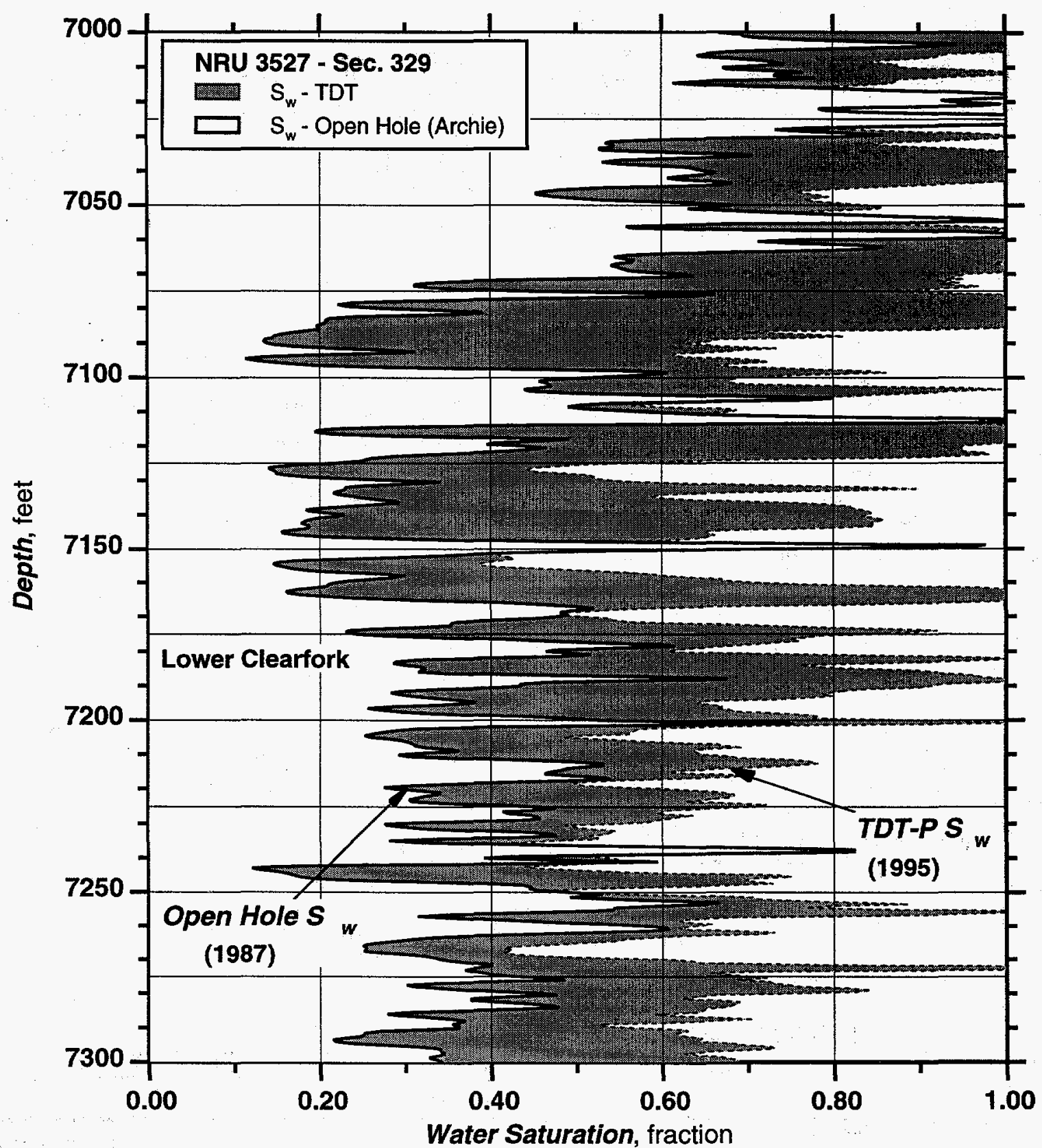

Figure $48-S_{w}$ Monitoring Using Thermal Decay Time Logs (Lower Clearfork). 


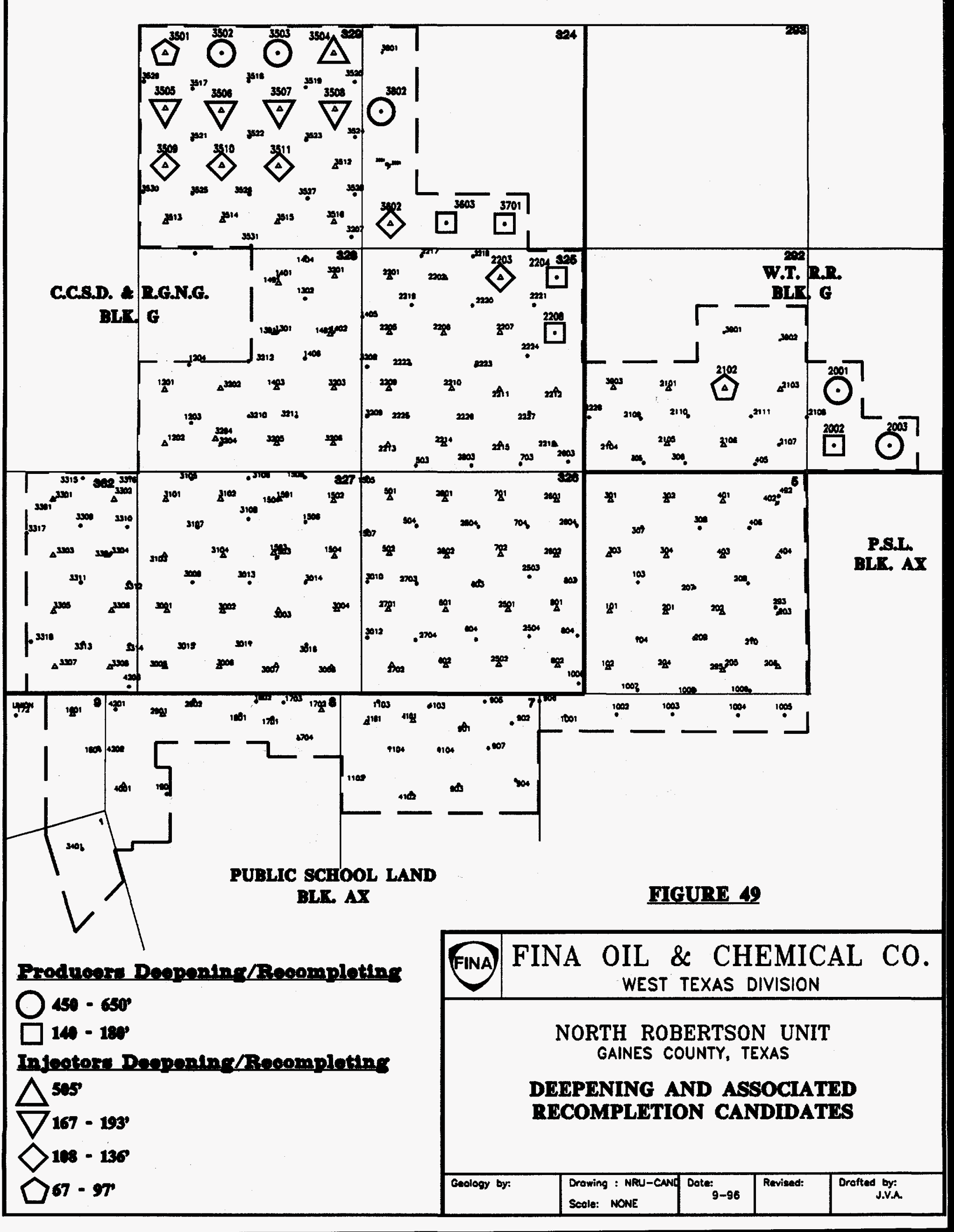




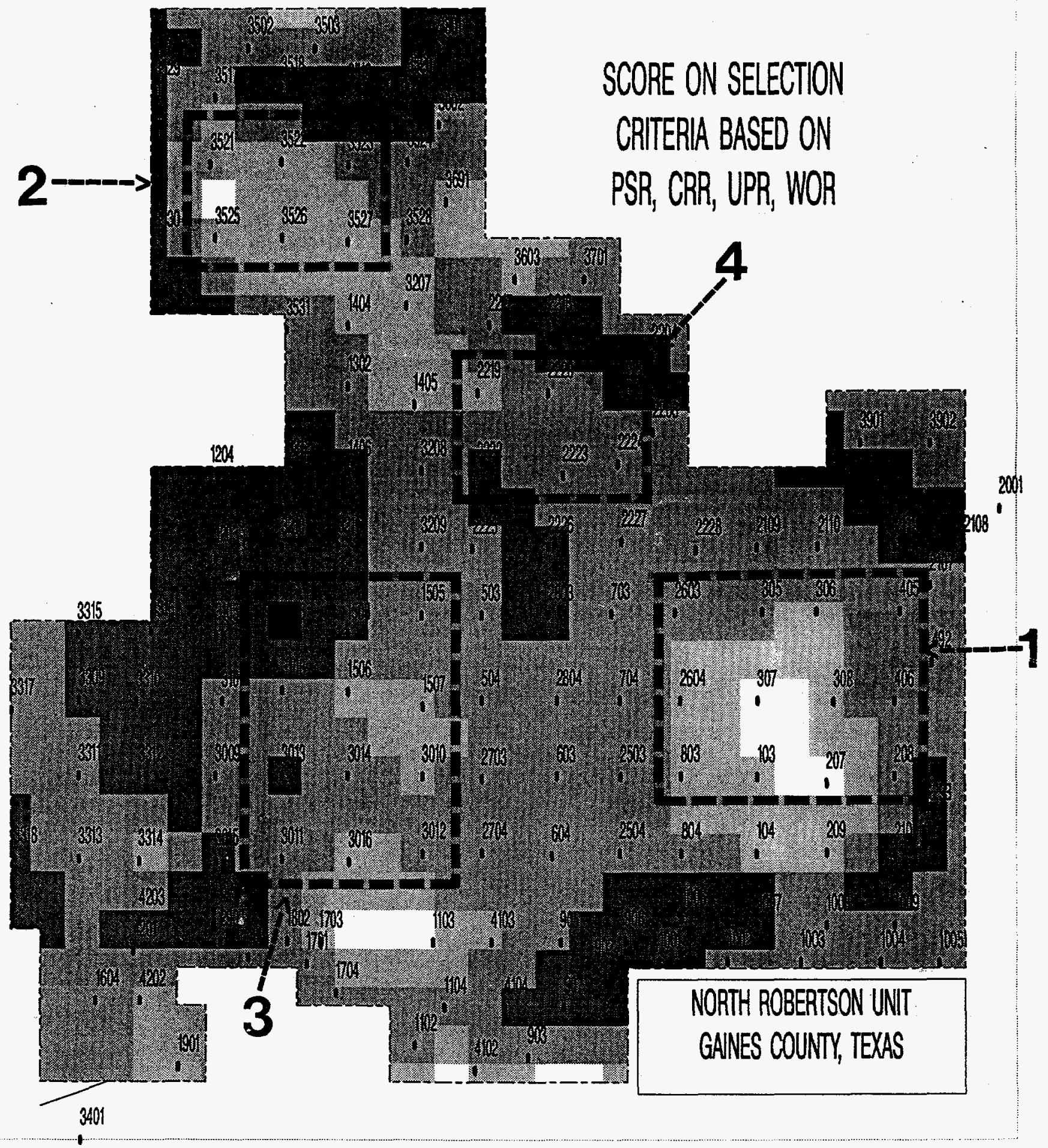

Figure 50 - Map of Tentative Partial-Unit Model Areas for Reservoir Simulation

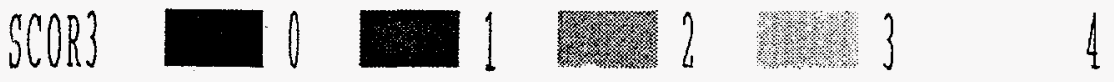

